\title{
Sustaining Attention to Simple Tasks: A Meta-Analytic Review of the Neural Mechanisms of Vigilant Attention
}

\author{
Robert Langner and Simon B. Eickhoff \\ Heinrich Heine University Düsseldorf and Research Centre Jülich, Jülich, Germany
}

\begin{abstract}
Maintaining attention for more than a few seconds is essential for mastering everyday life. Yet, our ability to stay focused on a particular task is limited, resulting in well-known performance decrements with increasing time on task. Intriguingly, such decrements are even more likely if the task is cognitively simple and repetitive. The attentional function that enables our prolonged engagement in intellectually unchallenging, uninteresting activities has been termed vigilant attention. Here we synthesized what we have learned from functional neuroimaging about the mechanisms of this essential mental faculty. To this end, a quantitative meta-analysis of pertinent neuroimaging studies was performed, including supplementary analyses of moderating factors. Furthermore, we reviewed the available evidence on neural time-on-task effects, additionally considering information obtained from patients with focal brain damage. Integrating the results of both meta-analysis and review, we identified a set of mainly right-lateralized brain regions that may form the core network subserving vigilant attention in humans, including dorsomedial, mid- and ventrolateral prefrontal cortex, anterior insula, parietal areas (intraparietal sulcus, temporoparietal junction), and subcortical structures (cerebellar vermis, thalamus, putamen, midbrain). We discuss the potential functional roles of different nodes of this network as well as implications of our findings for a theoretical account of vigilant attention. It is conjectured that sustaining attention is a multicomponent, nonunitary mental faculty, involving a mixture of (a) sustained/recurrent processes subserving task-set/arousal maintenance and (b) transient processes subserving the targetdriven reorienting of attention. Finally, limitations of previous studies are considered and suggestions for future research are provided.
\end{abstract}

Keywords: sustained attention, alertness, vigilance, meta-analysis, ALE

Supplemental materials: http://dx.doi.org/10.1037/a0030694.supp

Many everyday behaviors require continuous attention for more than a few seconds and, thus, rely on sustaining attention over time. Examples include scanning a supermarket shelf for a certain product, attending to a lecture, reading a book, or playing a demanding piece of music on an instrument. These examples may

This article was published Online First November 19, 2012.

Robert Langner and Simon B. Eickhoff, Institute of Clinical Neuroscience and Medical Psychology, Heinrich Heine University Düsseldorf, Düsseldorf, Germany, and Institute of Neuroscience and Medicine (INM1), Research Centre Jülich, Jülich, Germany.

This research was supported by National Institute of Mental Health Grant 1R01MH074457-01A1 and the Initiative and Networking Fund of the Helmholtz Association within the Helmholtz Alliance on Systems Biology (Human Brain Model). We thank all contacted authors who contributed results of relevant contrasts not explicitly reported in their original publications, and we apologize to all authors whose eligible articles we might have missed. We are grateful to Ian Robertson, Jonathan Smallwood, Deak Helton, Merim Bilalić, Danilo Bzdok, and Susanne Leiberg for their comments on earlier versions of the article. We are especially indebted to Thomas Fischer and Michael Steinborn for helpful discussions surrounding many issues touched upon in this work.

Correspondence concerning this article should be addressed to Robert Langner, Institut für Klinische Neurowissenschaften \& Medizinische Psychologie, Universitätsklinikum Düsseldorf, Universitätsstrasse 1, D-40225 Düsseldorf, Germany. E-mail: robert.langner@uni-duesseldorf.de differ greatly in duration and cognitive complexity, but they share the requirement for maintaining attention over time. This ability to keep one's mind continuously focused on a particular task is considered a fundamental dimension of attentional control, distinct from shifting or dividing the attentional focus or controlling its selectivity (Mirsky, Anthony, Duncan, Ahearn, \& Kellam, 1991; Posner \& Petersen, 1990; Raz \& Buhle, 2006; Robertson, Ward, Ridgeway, \& Nimmo-Smith, 1996; Sturm \& Willmes, 2001; Stuss, Shallice, Alexander, \& Picton, 1995; van Zomeren \& Brouwer, 1994).

Anecdotal as well as experimental evidence shows that it is usually harder to maintain attention in intellectually unchallenging, monotonous situations than in cognitively demanding but interesting ones (Kahneman, 1973; Manly et al., 2003; Parasuraman, 1984; Poffenberger, 1927; Robinson \& Bills, 1926; Wilkinson, 1964; see Robertson \& O'Connell, 2010, for a recent review). This seemingly paradoxical, inverse relationship between cognitive challenge and effort required to sustain attention has long been known to industrial psychologists: Simple, repetitive tasks requiring continuous attention were often found to be associated with increased stress responses and higher subjective effort expenditure, compared with more complex, variable tasks (Frankenhaeuser \& Gardell, 1976; Johansson, Aronsson, \& Lindström, 1978; Thackray, 1981; Ulich, 1960; see also Warm, Parasuraman, \& Matthews, 2008). 


\section{Vigilant Attention: Concept, Measurement, and Relevance}

\section{Concept}

Acknowledging the empirical differentiation between cognitively simple and more complex tasks, Robertson and Garavan (2004; see also Robertson \& O'Connell, 2010) introduced the term vigilant attention (VA) for sustaining attention to monotonous, intellectually unchallenging tasks. On the basis of their definition, we use this term to denote the process of sustaining efficient conscious stimulus processing over periods longer than about $10 \mathrm{~s}$ up to many minutes. By definition, this "stimulus processing" refers to the simple detection or discrimination of stimuli, including a simple cognitive or motor response but excluding "higher" attentional or executive functions such as spatial orienting, resolving interference, dividing attention, or selecting between several overt responses.

Our definition of VA deliberately includes instances of a rather short-term maintenance of attention, in line with models that assume VA to be implemented by "a short-cycle 'refresh' system ... [that] operates in situations (usually dull or repetitive) where attention is not exogenously triggered by novelty or other similar processes" (Robertson, Ridgeway, Greenfield, \& Parr, 1997, p. 291; see also Coull, 1998, p. 351). From experiments on temporal preparation processes, the cycle length of this endogenously controlled "refresh" system has been estimated to be much less than the minimum maintenance period (10 s) chosen here. In these experiments on preparatory attention, it was shown that peak levels of preparedness cannot be maintained for more than a few seconds, requiring repreparation processes for sustaining readiness (Alegria, 1974; Gottsdanker, 1975). This makes our 10-s cutoff a rather conservative choice and roughly agrees with what others have considered a sustained (vs. transient) allocation of attention (cf. Cabeza et al., 2003; Robertson, Ridgeway, et al., 1997; Thakral \& Slotnick, 2009).

On a conceptual level, this endogenous refresh system was previously described (Shallice, Stuss, Alexander, Picton, \& Derkzen, 2008; Stuss et al., 1995) as a set of control processes implemented by a supervisory attentional system (cf. Norman \& Shallice, 1986; Shallice \& Burgess, 1996). According to this framework, performing simple, repetitive, and therefore easily overlearned tasks such as simple stimulus detection or discrimination is based on activating and implementing a task schema (i.e., a memorized set of input-output rules). Theoretically, relevant schemata in routine tasks are triggered automatically by appropriate input, without the need for supervisory control. However, sustaining high performance levels over time is assumed to require top-down attentional control even in well-learned tasks as simple as speeded stimulus detection (cf. Henderson \& Dittrich, 1998). In particular, as proposed by Stuss et al. (1995),

If it is not continually used, a selected schema will gradually lose activation over several seconds, thereby decreasing its power to activate its lower level component schemata. This can occur by intrinsic decay of activation or by the selection of some irrelevant competing schema, which then inhibits the task-schema. (pp. 195-196).

On the other hand, fast-paced target presentation (i.e., continuous use of a given schema) is also no guarantee that automatic schema activation will persist over time, as overrapid use may result in the task schema becoming increasingly refractory (Stuss et al., 1995, p. 199; see also van Breukelen et al., 1995).

Stuss et al. (1995) considered four supervisory-system processes as essential for preventing such situations and maintaining performance in VA tasks over time (see also Shallice et al., 2008): (a) monitoring the activation level of the task schema, (b) (re)activating ("energizing") the task schema, (c) inhibiting conflicting schemata, and (d) monitoring performance (i.e., checking the appropriateness of behavioral outputs against the task goal). Thus, according to this framework, VA is supported by a combination of stimulus-triggered ("bottom-up") routine processing, in line with a fairly simple task schema, and supervisory-system ("top-down") modulations thereof, which facilitate the recurrent implementation of the relevant schema.

Given this framework, the question remains as to what changes in these processes underlie the frequently observed difficulties in VA maintenance. First of all, laboratory research corroborates the aforementioned anecdotal evidence and observations in the field by showing that sustaining attention to simple, monotonous tasks (i.e., VA) is perceived as effortful and highly demanding, inducing subjective strain or even fatigue over time (Grier et al., 2003; Szalma et al., 2004; Warm et al., 2008). These findings led several researchers to propose that such subjective experiences as well as concurrent objective difficulties in maintaining high (initial) performance levels directly result from a depletion of attentional resources that occurs with the continuous allocation of attention (Grier et al., 2003; Helton \& Warm, 2008; Smit, Eling, \& Coenen, 2004). This "resource depletion" (or "mental fatigue") account is strongly supported by several lines of research (Helton \& Russell, 2011a, 2011b; Helton et al., 2005; See, Howe, Warm, \& Dember, 1995; Temple et al., 2000; see Warm et al., 2008, for a review). In the supervisory-attention framework, resource depletion would correspond to an insufficiently energized task schema.

Others, however, have argued that cognitively more challenging, interesting tasks (e.g., prolonged computer gaming vs. radar screen monitoring) can pose similar or even higher demands on attention but still fail to elicit any subjective experiences of strain and fatigue or objective performance deterioration over time; in fact, such tasks can even induce positive "flow" experiences (cf. Csikszentmihalyi, 1975). On that basis, negative subjective experiences in prolonged simple, repetitive tasks have been interpreted as reflecting the experience of boredom (Pattyn, Neyt, Henderickx, \& Soetens, 2008; Scerbo, 1998), which has been found associated with increased absentmindedness and mind-wandering (Cheyne, Solman, Carriere, \& Smilek, 2009; Smallwood et al., 2004; see Smallwood \& Schooler, 2006, for a review). Mind-wandering here is considered a state in which cognitive processing is driven by internally oriented goals, such as recalling previous experiences or simulating future actions. Thus, this mental "absenteeism" reflects a reallocation of processing resources away from the VA task at hand toward some other goal and is, in turn, held responsible for the oft-observed performance decline over time (Manly, Robertson, Galloway, \& Hawkins, 1999; Pattyn et al., 2008; Robertson, Manly, Andrade, Baddeley, \& Yiend, 1997). In the supervisoryattention framework, this would correspond to an insufficient inhibition of competing schemata.

There is ample empirical evidence for both the fatigue/resourcedepletion and the boredom/absentmindedness accounts, but neither 
is consistent with all the available data. We, therefore, would like to promote a recent proposal that synthesizes both views (Langner, Willmes, Chatterjee, Eickhoff, \& Sturm, 2010). These authors argued that maintaining the attentional focus on an intrinsically nonrewarding (i.e., monotonous, "flow"-defying) but attentionally demanding task requires constant self-regulation (see Rueda, Posner, \& Rothbart, 2011, for a detailed review on the relationship between attention and self-regulation). Thus, the account implies an imbalance between subjective costs (i.e., effort exertion) and benefits (i.e., intrinsic rewards) of maintaining VA over time. Self-regulatory power, in turn, is considered a limited resource that gets depleted with prolonged continuous use (Hagger, Wood, Stiff, \& Chatzisarantis, 2010; Muraven \& Baumeister, 2000). Accordingly, self-control strength should decline over time while trying to maintain VA. This decline, then, is thought to result in (a) a diminished intensity of attention allocated to the task, leading to a weaker attentional modulation of task-relevant information processing (a state often labeled "mental fatigue" or "resource depletion"), and (b) diminished goal maintenance, leading to taskirrelevant processing and task-unrelated thoughts (a state often labeled "absentmindedness" or "mind-wandering"). Thus, Langner, Willmes, et al. (2010) considered sustained attentional demand a necessary condition (in line with resource theory) but not a sufficient one (in contrast to resource theory) for the typical time-related VA decrement to occur. In essence, Langner, Willmes et al.'s account introduced the mediator variable "self-regulatory power," which is assumed to remain unaffected during attentionally demanding but intrinsically rewarding tasks and thus can potentially explain the specific difficulty in upholding attention during intellectually simple, monotonous tasks. It should be noted, though, that the empirical evidence directly supporting this account is sparse as yet.

Notably, all three above-mentioned accounts of time-related VA decline do not consider motivational issues, at least not explicitly. Other work, however, emphasized the relevance of motivational changes with time on task, which may lead to strategic shifts in effort investment during sustained cognitive performance (Boksem \& Tops, 2008; Hockey, 1986, 1997). Broadly, these accounts assume an increasing imbalance between perceived costs and benefits of maintaining performance over time, resulting in a strategic reduction of effort invested into the VA task at hand. This switching of processing priorities can be incorporated into all three above accounts, leading either to diminished resource allocation to the VA task, interference from task-unrelated processing, or both.

Finally, we think it useful to touch briefly upon another concept that is relevant to VA: Although referring to nonidentical (albeit related) constructs, the terms arousal and sustained attention (comprising the less inclusive concept "vigilant attention") have sometimes been used interchangeably (see Parasuraman, 1984, for a related discussion). Since this indiscriminate use may have contributed to terminological confusion in research on attention, we would like to mention the conceptual differentiation: In our view, "arousal" is the net result from the joint action of several neuromodulatory brain systems; it drives the general excitability of cortical neurons and thus constitutes a basic precondition and modulator of (vigilant) attention (Fischer, Langner, Birbaumer, \& Brocke, 2008; Pfaff, 2006; Sarter, Givens, \& Bruno, 2001; see also Humphreys \& Revelle, 1984).
This is not to say that we consider arousal a unitary concept-on the contrary, we take arousal to be multidimensional, having specialized and generalized subcomponents (cf. Pfaff, 2006; Pfaff, Ribeiro, Matthews, \& Kow, 2008). As generalized arousal is thought to decrease with the predictability of the situation (Pfaff, 2006), one of the processes that contribute to the perceived high workload of simple, repetitive VA tasks might be the exertion of effort to compensate for the task-induced decrease in arousal (Fischer et al., 2008; O'Hanlon, 1981; Robertson \& Garavan, 2004; Thackray, 1981). As recent research has shown, however, such attempts at compensation might be in vain: By using self-report scales for measuring subjective arousal based on Thayer's (1978) two-dimensional arousal model, it was found that prolonged VA maintenance was related to increases in avoidancerelated "tense arousal" but decreases in approach-related "energetic arousal" (Helton \& Warm, 2008; Szalma et al., 2004). And it is the latter arousal component that is thought to reflect the availability of attentional resources for performing the task at hand (Helton \& Warm, 2008; Matthews \& Westerman, 1994).

\section{Measurement}

The basic experimental paradigm for assessing VA has participants monitor their environment for a (more or less frequently occurring) prespecified target. Mostly, one of the following paradigm subtypes has been used: (a) continuous stimulus detection (i.e., noncued simple reaction time [RT] tasks), (b) continuous stimulus discrimination (i.e., noncued go/no-go tasks), and (c) sustained covert (i.e., silent) target counting. Stimulus-detection tasks require no stimulus identification, since all presented stimuli are targets. There is only one invariable response, and the only uncertain aspect is the exact moment of stimulus occurrence. This kind of task is typically used to assess an aspect of VA that has been described as readiness for speeded responding to unwarned stimulation, variably labeled "intrinsic alertness" (e.g., Langner et al., 2012; Sturm et al., 1999) or "psychomotor vigilance" (Lim \& Dinges, 2008).

In the second type of paradigm (i.e., continuous stimulus discrimination), targets and nontargets are presented in an (usually unpredictably) intermixed fashion, with targets ("go" stimuli) requiring a response and nontargets ("no-go" stimuli) requiring withholding the response. Please note that forced-choice RT tasks, which require selecting between two or more overt responses, are, by definition, not considered to assess VA but rather more complex attentional abilities such as concentration (cf. Alexander, Stuss, Shallice, Picton, \& Gillingham, 2005; Steinborn, Flehmig, Westhoff, \& Langner, 2009). Classically, go/no-go tasks used in VA research contain many more nontarget ("no-go") than target ("go") events, including Mackworth's well-known Clock Task (Mackworth, 1948) or the classic Continuous Performance Task (CPT; Rosvold, Mirsky, Sarason, Bransome, \& Beck, 1956). Such tasks constitute the typical paradigm used in research on "vigilance" (cf. Davies \& Parasuraman, 1982), which refers to maintaining VA over prolonged periods (i.e., at least several minutes). Some well-established variants of this paradigm type, such as the AX-CPT or the rapid visual information processing task (Wesnes \& Warburton, 1983), additionally impose a modest working memory demand, since their target definition includes sequential dependencies (i.e., target status depends on the preceding stimulus). 
Moreover, "reverse" vigilance paradigms with many more go than no-go events, such as Conners's CPT (Conners, 1994) or the sustained-attention-to-response task (Robertson, Manly, et al., 1997), have recently garnered much interest.

\section{Relevance}

Apart from the introductory examples regarding the real-life importance of our ability to sustain attention, we would like to point out a few more domains in which the relevance of VA maintenance becomes evident. For instance, Robertson (2003) related two examples of catastrophic traffic accidents, which arose from single lapses of attention during the prolonged performance of routine behaviors. One involved a train driver missing a critical stop signal and causing a devastating train crash; the other involved a sleep-deprived, tired car driver who accidentally drove his car off the motorway down onto a railroad track, causing the derailment of a train and killing several people. Indeed, such failures in maintaining VA are the most common cause of railway accidents (Edkins \& Pollock, 1997). The second case implies that driver fatigue contributed to the fatal incident. A recent metaanalysis confirmed the special sensitivity of VA tasks to sleep deprivation (Lim \& Dinges, 2010), and according to Wickens, Gordon, and Liu (1998, p. 397), fatigue is estimated to be a causal factor in about 200,000 car accidents per year.

Besides such time-critical man-machine interactions in which remaining attentive is vital issue, VA maintenance is important in all occupational settings that require sustained monitoring such as quality inspection at assembly lines, luggage screening at airports, or radar observation (the task that triggered human-factors research on vigilance in the 1940s). Furthermore, VA is highly sensitive to psychiatric disorders and damage to the brain, substantially contributing to problems in everyday life in individuals suffering from, for example, schizophrenia (Green, 1996), attention-deficit/ hyperactivity disorder (Bellgrove, Hawi, Kirley, Gill, \& Robertson, 2005), traumatic brain injury (Robertson, Manly, et al., 1997), or various neurodegenerative diseases (O'Keeffe et al., 2007).

\section{Present Study}

We think that a better understanding of the system that mediates VA (and its failures) in healthy human beings as well as in patients involves an understanding of its neural basis. Neuropsychology and, more recently, neuroergonomics are two subdisciplines, among others, that have spearheaded this view, applying knowledge about neural mechanisms to improve clinical treatments and the design of occupational or educational settings, respectively. Therefore, our study aimed at providing a synthesis of what is known about the brain circuitry involved in maintaining VA by means of a coordinate-based meta-analysis of findings from neuroimaging studies using perfusion positron emission tomography (PET) or functional magnetic resonance imaging (fMRI). Coordinate-based meta-analysis localizes the above-chance convergence of task-related brain activity across multiple neuroimaging experiments in a common three-dimensional reference space. In contrast to qualitative reviews, it weighs the concordance between neuroimaging results by relying on location probabilities rather than neuroanatomical nomenclature, which is often used inconsistently. Thus, coordinate-based meta-analysis is a powerful tool for synthesizing distributed neuroimaging findings in a quantitative and impartial fashion (cf. Eickhoff \& Bzdok, in press).

Earlier qualitative reviews tended to converge on the conclusion that sustaining attention to simple detection or discrimination tasks was subserved by a predominantly right-lateralized network including various cortical and subcortical structures (Cabeza \& Nyberg, 2000; Husain \& Rorden, 2003; Parasuraman, Warm, \& See, 1998; Sturm \& Willmes, 2001). To our knowledge, however, our study is the first to examine quantitatively to what extent neuroimaging findings on VA converge into a core network. We also tested the neural effects of potentially important moderator variables that describe major differences between paradigms employed to assess VA. The first such variable was the duration VA needed to be maintained for without a break, as longer times of continuous attending increase the demand on the endogenous control of VA. Second, the task may or may not require overt motor responses to targets; if it does, it will involve sustained motor preparation (cf. Requin, Brener, \& Ring, 1991). Third, the task may require either stimulus detection (i.e., all stimuli are targets) or stimulus identification (i.e., targets need to be discriminated from nontargets). Fourth, temporal unpredictability of event occurrence, resulting from variable interstimulus intervals, obviates short-term "resting" breaks between the sustained monitoring for targets and should therefore enhance the burden on the monitoring subsystem. Finally, a supplementary analysis tested for the effects of stimulus modality on VA-related brain activity across experiments.

Since the duration of uninterrupted VA maintenance is a major factor determining sustained performance (Davies \& Parasuraman, 1982), the quest for neural correlates of time-related performance decrements is an important approach to discerning the relevance of particular brain areas for sustaining attention over time (cf. Parasuraman et al., 1998). For a quantitative integration, however, there have yet been too few neuroimaging studies testing such correlates. In addition to the meta-analysis, we therefore provide a qualitative review of the limited set of studies that investigated neural correlates of time on task in VA tasks. In this review, we also consider the few available studies on time-related VA changes in patients with focal brain damage. In our discussion, we integrate this evidence with the results of our meta-analysis toward a more comprehensive delineation of the neural mechanisms of VA. Finally, some implications of our synthesis for the concept of sustained attention are discussed, and open research questions as well as possible approaches to answer them are pointed out.

\section{Meta-Analysis of Neuroimaging Studies}

\section{Method}

Study selection. We used a stepwise procedure to identify the relevant experimental studies. First, studies were selected through a standard search in the PubMed (http://www.pubmed.gov) and ISI Web of Science (http://apps.isiknowledge.com) databases with the terms vigilant attention, sustained attention, continuous attention, vigilance, alertness, and continuous performance, in combination with fMRI, functional MRI, functional magnetic resonance, PET, and positron emission. Other term combinations, such as attention AND monitoring OR tracking, were included to identify relevant studies that had been labeled more specifically by their authors. 
To ameliorate the file-drawer problem arising from a potential publication bias toward significant results (Rosenthal, 1979), we extended the search to studies that included VA tasks that were not the focus of the respective publication but served as a "high-level baseline" or control condition. For example, from working memory studies that used the $n$-back paradigm and measured brain activity with PET or blocked fMRI designs, we included go/no-go 0-back control conditions. When the results of these control conditions were not reported in sufficient detail (but when further inclusion criteria were fulfilled; see below), corresponding authors were contacted and asked to provide the relevant data. Finally, further studies were found via the "related articles" function of the PubMed database and by tracing the references from review articles and the articles identified before.

Experiments were considered relevant if they met the following inclusion criteria:

1. The task required participants to continuously direct their attention to external stimuli for more than $10 \mathrm{~s}$.

2. The task posed only minimal cognitive demands, that is, did not require more than stimulus discrimination associated with a simple overt (e.g., manual) or covert (e.g., counting) response.

3. The task put only minimal demands on the selectivity and "executive" aspects of attention; that is, it did not require shifting the attentional focus, suppressing distractors, resolving conflict, dividing attention, or selecting between two or more overt responses.

In addition, the following selection criteria were applied:

- Only studies reporting results of whole-brain group analyses as coordinates in a standard reference space (Talairach/Tournoux or Montreal Neurological Institute [MNI]) were included, whereas single-subject reports, results of region-of-interest analyses (e.g., Kinomura, Larsson, Gulyas, \& Roland, 1996), and studies not reporting standardized stereotaxic coordinates (e.g., Lewin et al., 1996) were excluded.

- Only data from healthy adults were included; results obtained from patients and children were excluded. When studies with patients included a healthy control group, the data of these healthy controls were included if separately reported or if the authors provided us with the necessary information upon request.

- Data from conditions with pharmacological or other "state" manipulations (e.g., sleep deprivation) were excluded, whereas results from normal control conditions without manipulation were included if separately available.

- Only activation data resulting from subtractions between target conditions and sensorimotor control or resting-baseline conditions were included; thus, we did not consider deactivation data, correlations between brain activity and other predictors (such as performance or time on task; e.g., Coull, Frackowiak, \& Frith, 1998), or results from connectivity analyses (e.g., Mottaghy et al., 2006).

On the basis of these criteria, 55 studies were identified as eligible for inclusion into the meta-analysis. Together, these studies reported 962 activation foci obtained from 1,058 participants in 67 contrasts (see Appendix). Differences in coordinate spaces
(MNI vs. Talairach space) were accounted for by transforming coordinates reported in Talairach space into MNI coordinates with a linear transformation (Lancaster et al., 2007). Convergence of reported activation coordinates was analyzed for the main effect of VA-related activity as well as for the effects of potential moderator variables denoted above.

Activation likelihood estimation (ALE). All meta-analyses were performed with the revised ALE algorithm for coordinatebased meta-analysis of neuroimaging results (Eickhoff et al., 2009; Turkeltaub, Eden, Jones, \& Zeffiro, 2002). This algorithm seeks to identify brain areas whose activity converges across experiments more strongly than expected from a random spatial association. Reported coordinates are treated as centers of three-dimensional Gaussian probability distributions capturing the spatial uncertainty associated with each focus (Eickhoff et al., 2009). Hereby, the between-subjects variance is weighted by the number of participants per study, since larger sample sizes are deemed to provide more reliable approximations of the "true" activation effect and should therefore be modeled by "narrower" Gaussian distributions.

Subsequently, the probabilities of all foci reported of a given experiment were combined for each voxel, yielding a modeled activation map (Turkeltaub et al., 2012). Voxel-wise ALE scores (i.e., the union across modeled activation maps) then quantified the convergence across experiments at each location in the brain. To distinguish true from random convergence, ALE scores were compared to an empirical null distribution reflecting random spatial association among all modeled activation maps. The resulting random-effects inference focuses on the above-chance convergence across studies rather than the clustering within a particular study (Eickhoff et al., 2009). The null hypothesis was derived by computing the distribution that would be obtained when sampling a voxel at random from each of the modeled activation maps and taking the union of these values in the same manner as for the (spatially contingent) voxels in the original analysis (Eickhoff, Bzdok, Laird, Kurth, \& Fox, 2012). The $p$ value of a "true" ALE score was then given by the proportion of equal or higher values obtained under the null distribution. The resulting $p$ values were cut off at a threshold of $p<.05$ (family-wise error corrected at cluster level; cluster inclusion threshold at voxel level: $p<.001$ ) and transformed into $Z$ scores for display.

Testing for differences between task conditions. Differences between conditions were tested by first performing separate ALE meta-analyses for each condition and computing the voxel-wise difference between the ensuing ALE maps. The experiments contributing to either analysis were then pooled and randomly divided into two groups of the same size as the two sets of contrasted experiments (Eickhoff, Bzdok, et al., 2011). Voxel-wise ALE scores for these two randomly assembled groups were subtracted from each other. Repeating this process 10,000 times yielded an empirical null distribution of ALE score differences between the two conditions. This was used for testing the significance of the observed difference in each voxel's ALE scores by thresholding at a posterior probability of $p>.95$ for a true difference between the two samples. Surviving voxels were inclusively masked by the respective main effect, that is, the significant effect of the ALE analysis for the minuend (Eickhoff, Bzdok, et al., 2011; Rottschy et al., 2012). In addition, a cluster extent threshold of $k \geq 25$ voxels was applied. 
Anatomical labeling. Results were anatomically labeled by reference to probabilistic cytoarchitectonic maps of the human brain with the maximum probability maps included in the Anatomy Toolbox (Eickhoff et al., 2007, 2005) of the SPM5 software package (Wellcome Department of Imaging Neuroscience, London, England). Hereby, activations were assigned to the most probable histologically defined area at the respective location. This histology-based anatomical labeling is reported in each result table; references to details of the cytoarchitecture may be found in the respective table notes.

\section{Results}

Meta-analysis across all included experiments. The metaanalysis of all 67 VA experiments revealed significant convergence in 14 distinct clusters (see Table 1 and Figure 1): bilateral (though right-dominant) presupplementary motor area (pre-SMA) and midcingulate cortex, extending to more anterior medial prefrontal cortex (PFC); bilateral inferior PFC (inferior frontal junction [IFJ] and dorsal area 44), extending to ventral premotor cortex (vPMC) in the right hemisphere; bilateral (though right-dominant) anterior insula and, in the right hemisphere, adjacent frontal operculum; bilateral thalamus; right midlateral PFC; right temporoparietal junction (TPJ); right inferior parietal lobule and intraparietal sulcus (IPS); right middle occipital gyrus, reaching medially to area 17; left dorsal PMC (dPMC); left temporo-occipital junction extending to fusiform gyrus; and cerebellar vermis.

Using a more lenient threshold (uncorrected cluster-level $p<$ $.05)$, we observed additional loci of convergence in right occipital areas (homotopic to the above-reported left-sided focus at the temporo-occipital junction), right posterior IPS, left medial midbrain-brain stem junction (in the vicinity of the left pedunculopontine tegmental nucleus), and bilateral anterior putamen (see Table 1 and, in the supplemental materials, Figure S1).

Correlation of brain activity with duration of VA maintenance. The demand on the system subserving VA should increase with the time attention has to be maintained without a break. We, therefore, tested which nodes of the VA-related network identified in the main analysis (see above) were more likely to show activity with increasing time VA was maintained for without interruption. In the included experiments, these times ranged from 14 to $1,800 \mathrm{~s}(M=116.8, S D=267.1$; cf. Appendix). Significant positive correlations were found in a right-lateralized network comprising anterior insula, pre-SMA, midcingulate cortex, midlateral PFC, vPMC, posterior ventrolateral PFC, IPS and adjacent inferior parietal lobule, TPJ, thalamus, and cerebellar vermis (see Table 2 and Figure 2). We did not find any negative correlations; thus, no regions showed less consistent activation across studies with longer VA maintenance.

Meta-analyses of tasks with and without overt responding. To assess how VA-related brain activity is influenced by the requirement for overt motor responses to targets, we contrasted tasks that involved motor responses $(n=55)$ and those that did not $(n=12)$. Motor tasks (vs. nonmotor tasks) showed significantly stronger convergence of activity in bilateral pre-SMA, IFJ, occipital cortex, and cerebellar vermis as well as in left dPMC, putamen, ventrolateral thalamus, and brain stem (rostromedial pons; see Figure 3 and, in the supplemental materials, Table S1). The absence of convergence in the primary motor cortex most likely results from the inconsistent use of the right versus left hand across experiments as well as from the fact that a substantial number of experiments $(n=11)$ contrasted VA-related activity against motor control conditions that involved regular button presses. Conversely, contrasting nonmotor tasks with motor tasks yielded significantly stronger convergence of activity in a right-lateralized "triangle" consisting of vPMC, midlateral PFC, and ventrolateral PFC. Further foci were observed in bilateral anterior-medial occipital cortex, right postcentral gyrus, and left anterior insula (see Figure 3 and Table S2).

Meta-analyses of detection versus discrimination tasks. VA-related brain activity may also be affected by whether the task requires stimulus detection or discrimination. In discrimination tasks, compared with simple detection ones, stimuli need be processed more "deeply," as identification is required, and the stimulus-response ( $\mathrm{S}-\mathrm{R})$ mapping is more complex, as each trial can either require the predefined response (to the "go" stimulus) or require withholding this response (to the "no-go" stimulus; $\mathrm{cf}$. Cavina-Pratesi et al., 2006). The cognitive simplicity of detection tasks, on the other hand, may render them even more repetitive and de-arousing, increasing the demand for endogenous control of VA maintenance.

To examine differences in brain activity related to the type of paradigm, we thus contrasted detection $(n=25)$ and discrimination $(n=42)$ tasks included in our sample. This comparison yielded clusters of significantly stronger convergence for detection compared with discrimination tasks in right dorsolateral and medial PFC, right postcentral gyrus, and left posterior ventrolateral PFC (see Figure 4 and Table S3). Conversely, significantly stronger convergence for discrimination compared with detection tasks was observed in a bilateral pattern of foci comprising IFJ, IPS, and temporo-occipital junction, as well as left anterior insula and left putamen (see Figure 4 and Table S4).

Analysis of the effect of time uncertainty. A fixed temporal structure of stimulus occurrence can improve performance by directing attention to relevant moments in time according to implicit temporal expectations (Coull \& Nobre, 2008). This might lead to regular fluctuations in VA level without performance loss, since VA peaks can be well synchronized with stimulus occurrence. Conversely, temporal variation of stimulus presentations hampers implicit preparation for (early) moments of potential stimulus occurrence (Niemi \& Näätänen, 1981; Steinborn \& Langner, 2011, 2012), and therefore VA needs to be maintained at a more stable level over the entire time. Indeed, temporally irregular signal occurrence has been shown to negatively affect performance in VA tasks (Richter, Senter, \& Warm, 1981; Scerbo, Warm, \& Fisk, 1986-1987; Shaw, Finomore, Warm, \& Matthews, 2012).

To examine neural effects of such temporal uncertainty in tasks tapping VA, we contrasted the respective subsamples of experiments (tasks with temporally predictable stimulus occurrence: $n=37$; tasks with temporally unpredictable stimulus occurrence: $n=30$ ). Temporal predictability was associated with significantly stronger convergence in a bilateral network comprising IFJ, IPS, and temporooccipital junction. Unilaterally increased convergence related to temporal predictability was observed in left anterior insula, lateral occipital cortex, putamen, and cerebellum, as well as right ventrolateral PFC and cerebellar vermis (see Figure 5 and Table S5). Conversely, when contrasting tasks with temporally unpredictable against predictable stimulus occurrence, we observed significantly stronger 
Table 1

Brain Regions of Significant Convergence of Activity Related to Vigilant Attention Across All Experiments

\begin{tabular}{|c|c|c|c|}
\hline Macroanatomical structure & $x, y, z$ & Histological assignment ${ }^{\mathrm{a}}$ & $t$ score \\
\hline \multicolumn{4}{|l|}{ Cluster $1(k=1,201)$} \\
\hline \multirow[t]{2}{*}{ L/R anterior paracentral lobule (pre-SMA) } & -2850 & \multirow{4}{*}{$\begin{array}{l}\text { Area } 6 \\
\text { Area } 6\end{array}$} & 6.4 \\
\hline & -2660 & & 5.4 \\
\hline R medial posterior SFG (BA 8) & 83246 & & 3.7 \\
\hline L/R dorsal midcingulate cortex (BA 32) & 02634 & & 4.3 \\
\hline \multicolumn{4}{|l|}{ Cluster $2(k=748)$} \\
\hline $\mathrm{R}$ inferior frontal junction (BA 9) & 50832 & \multirow{4}{*}{ Area 44} & 6.2 \\
\hline $\mathrm{R}$ precentral sulcus (ventral PMC) & 50442 & & 5.2 \\
\hline R posterior IFG (pars opercularis) & 48622 & & 5.0 \\
\hline $\mathrm{R}$ posterior $\mathrm{MFG}$ (BA 9) & 54846 & & 4.4 \\
\hline \multicolumn{4}{|l|}{ Cluster $3(k=529)$} \\
\hline $\mathrm{R}$ anterior insula & $4022-4$ & & 6.9 \\
\hline $\mathrm{R}$ inferior frontal gyrus (pars triangularis) & 42244 & Area 45 & 4.4 \\
\hline \multicolumn{4}{|l|}{ Cluster $4(k=431)$} \\
\hline $\mathrm{R}$ inferior frontal sulcus (BA 46) & 463620 & & 6.3 \\
\hline R MFG (BA 46) & 424420 & & 5.0 \\
\hline \multicolumn{4}{|l|}{ Cluster $5(k=347)$} \\
\hline \multirow{2}{*}{ L precentral gyrus (dorsal PMC) } & $-40-1260$ & Area 6 & 6.0 \\
\hline & $-40-450$ & Area 6 & 4.9 \\
\hline \multicolumn{4}{|l|}{ Cluster $6(k=249)$} \\
\hline L inferior occipital gyrus & $-46-68-6$ & & 4.4 \\
\hline L fusiform gyrus & $-40-70-16$ & & 3.7 \\
\hline L middle occipital gyrus & $-46-764$ & hOc5 (V5) & 3.5 \\
\hline \multicolumn{4}{|l|}{ Cluster $7(k=231)$} \\
\hline $\mathrm{L}$ inferior frontal junction & -48830 & Area 44 & 5.1 \\
\hline $\mathrm{L}$ posterior IFG & -58620 & Area 44 & 3.4 \\
\hline \multicolumn{4}{|l|}{ Cluster $8(k=217)$} \\
\hline \multirow[t]{2}{*}{$\mathrm{R}$ temporoparietal junction } & $62-3817$ & & 4.5 \\
\hline & $62-3620$ & IPC (PF, PFcm) & 3.9 \\
\hline \multicolumn{4}{|l|}{ Cluster $9(k=192)$} \\
\hline $\mathrm{R}$ anterior and middle thalamus & $8-126$ & & 5.3 \\
\hline \multicolumn{4}{|l|}{ Cluster $10(k=183)$} \\
\hline $\mathrm{R}$ middle occipital gyrus & $32-904$ & & 5.7 \\
\hline $\mathrm{R}$ cuneus & $22-886$ & Area 17 & 3.8 \\
\hline $\mathrm{R}$ middle occipital gyrus & $34-962$ & hOc3v (V3v) & 3.5 \\
\hline \multicolumn{4}{|l|}{ Cluster $11(k=149)$} \\
\hline \multirow[t]{2}{*}{$\mathrm{L}$ anterior insula } & $-4212-2$ & & 4.2 \\
\hline & $-3422-4$ & & 4.1 \\
\hline \multicolumn{4}{|l|}{ Cluster $12(k=106)$} \\
\hline $\mathrm{L}$ anterior and middle thalamus & $-10-146$ & & 5.3 \\
\hline \multicolumn{4}{|l|}{ Cluster $13(k=104)$} \\
\hline $\mathrm{L} / \mathrm{R}$ cerebellum (vermis) & $6-58-18$ & Lobules V, VI (Vermis) & 4.4 \\
\hline \multicolumn{4}{|l|}{ Cluster $14(k=103)$} \\
\hline $\mathrm{R}$ inferior parietal lobule & $44-4446$ & IPC (PFm) & 3.9 \\
\hline $\mathrm{R}$ intraparietal sulcus & $40-4244$ & hIP2 & 3.8 \\
\hline \multicolumn{4}{|l|}{ Additional clusters $(40<k<80)^{\text {b }}$} \\
\hline $\mathrm{R}$ fusiform gyrus $(k=68)$ & $36-60-22$ & & 3.8 \\
\hline $\mathrm{R}$ posterior inferior temporal gyrus $(k=61)$ & $46-64-12$ & & 3.9 \\
\hline
\end{tabular}


Table 1 (continued)

\begin{tabular}{lcc}
\multicolumn{1}{c}{ Macroanatomical structure } & $x, y, z$ & Histological assignment $^{\mathrm{a}}$ \\
\hline $\mathrm{R}$ posterior intraparietal sulcus $(k=55)$ & $36-6048$ & $\mathrm{hIP3}$ \\
L pontomesencephalic tegmentum (possibly PPTg) $(k=53)$ & $-6-22-12$ & 4.3 \\
R putamen $(k=53)$ & 2660 & 4.9 \\
L putamen $(k=44)$ & -2486 & 4.1 \\
\hline
\end{tabular}

Note. Coordinates $x, y, z$ of local maxima refer to Montreal Neurological Institute space; $k=$ number of voxels in cluster; $\mathrm{L}=$ left; $\mathrm{R}=$ right; pre-SMA $=$ presupplementary motor area; $\mathrm{SFG}=$ superior frontal gyrus; $\mathrm{BA}=$ Brodmann area; $\mathrm{PMC}=$ premotor cortex $\mathrm{IFG}=$ inferior frontal gyrus; $\mathrm{MFG}=$ middle frontal gyrus; PPTg = pedunculopontine tegmental nucleus.

${ }^{a}$ References for histological assignments: Area 6: Geyer (2004); Area 17: Amunts et al. (2000); Areas 44, 45: Amunts et al. (1999); hIP2: Choi et al. (2006); hIP3: Scheperjans et al. (2008); hOc3v: Rottschy et al. (2007); hOc5: Malikovic et al. (2007); IPC (PF, PFm, PFcm): Caspers et al. (2006); Lobules V, VI (Vermis): Diedrichsen et al. (2009). ${ }^{\mathrm{b}}$ Significant at $p<.05$ (uncorrected at cluster level; cluster-forming threshold at voxel level: $p<.001$ ).

convergence in right superior medial and midlateral PFC, as well as bilateral postcentral gyrus (see Figure 5 and Table S6).

Supplementary analysis of modality-specific effects. We also tested for the effects of using auditory $(n=13)$ versus visual ( $n$ $=45$ ) stimuli. Experiments using (only) tactile stimuli were too few $(n=4)$ for separate analysis. Contrasting auditory with visual tasks revealed significantly stronger convergence in bilateral auditory belt regions (superior temporal and adjacent inferior parietal cortex), Broca's region, and right ventrolateral PFC (see Figure S2 and Table S7). Conversely, comparing visual against auditory tasks yielded a network comprising bilateral visual areas (lateral occipital cortex, temporo-occipital junction) and posterior parietal cortex, as well as left IFJ, left putamen, and bilateral pre-SMA extending to more anterior medial PFC and midcingulate cortex (see Figure S2 and Table S8).

\section{Review of Studies on Neural Correlates of Time-Related Effects in VA Tasks}

For the review of studies on neural correlates of time-on-task effects in VA tasks, the search was extended to studies in patients with circumscribed gray-matter lesions (excluding studies in populations with diffuse brain damage, such as traumatic brain injury, or interventions targeting white-matter tracts, such as commissur-

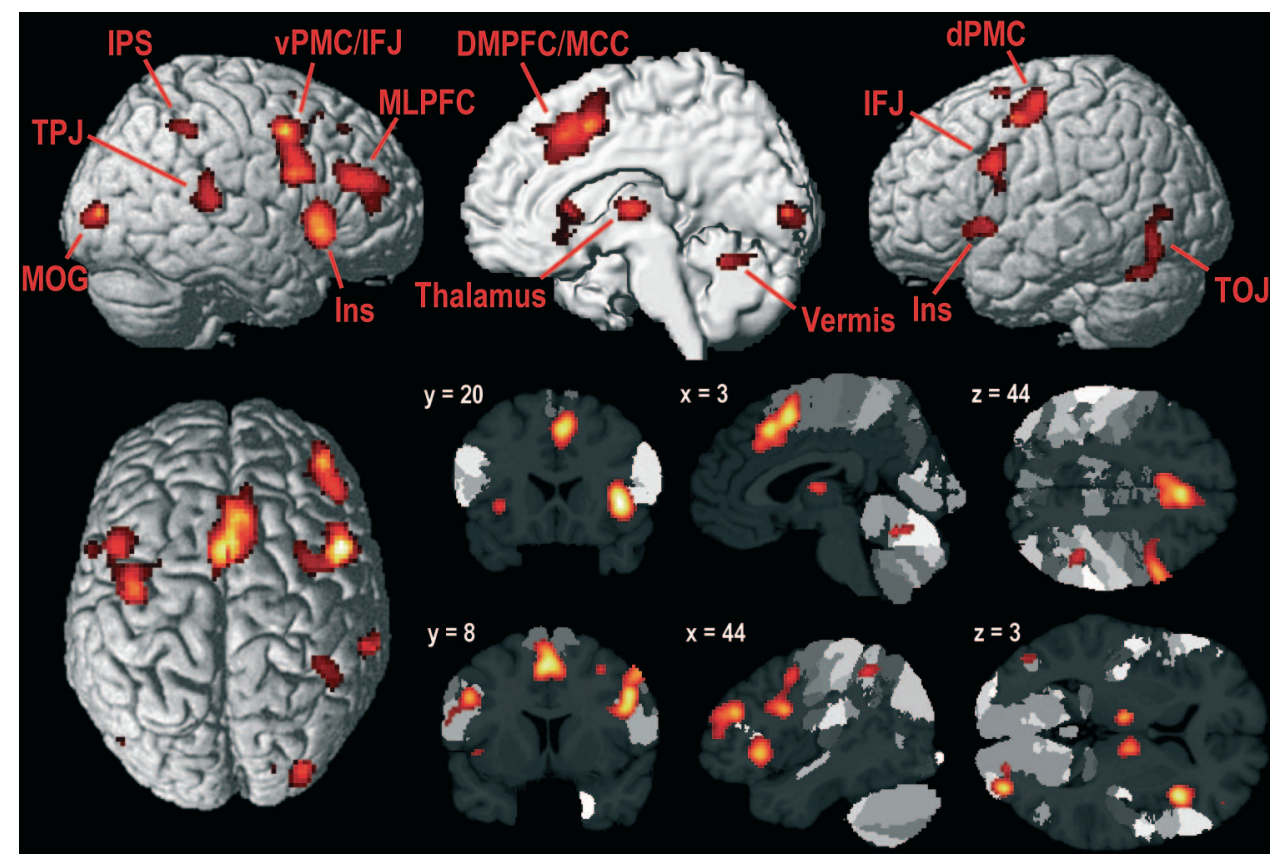

Figure 1. Foci of brain activity with significant convergence across all 67 experiments included in the meta-analysis (cluster-level $p<.05$, family-wise error corrected for multiple comparisons; cluster-forming threshold $p<.001$ at voxel level). Brain sections show foci of significant convergence overlaid on the template brain with maps of cytoarchitectonically defined areas as included in the SPM Anatomy Toolbox 1.7 (Eickhoff et al., 2005). Coordinates refer to Montreal Neurological Institute space and follow the neurological convention $($ left $=$ left $)$. DMPFC $=$ dorsomedial prefrontal cortex (including presupplementary motor area); $\mathrm{dPMC} / \mathrm{vPMC}=\mathrm{dorsal} / \mathrm{ventral}$ premotor cortex; IFJ $=$ inferior frontal junction; Ins $=$ anterior insula; IPS $=$ intraparietal sulcus (including adjacent inferior parietal lobule); MLPFC = midlateral prefrontal cortex; MOG = middle occipital gyrus; TOJ/TPJ = temporo-occipital/temporoparietal junction. 
Table 2

Brain Regions Showing Significantly Stronger Across-Experiment Convergence of Vigilant-Attention-Related Activity With Increasing Duration of Continuous Attending

\begin{tabular}{|c|c|c|c|}
\hline Macroanatomical structure & $x, y, z$ & Histological assignment ${ }^{\mathrm{a}}$ & $t$ score \\
\hline $\mathrm{R}$ anterior insula & 34140 & & 4.5 \\
\hline $\begin{array}{l}\mathrm{R} \text { anterior paracentral lobule (pre-SMA), extending to } \\
\text { dorsal midcingulate cortex }\end{array}$ & 22052 & Area 6 & 5.9 \\
\hline $\mathrm{R}$ inferior frontal sulcus, MFG (BA 46) & 384218 & & 4.5 \\
\hline $\mathrm{R}$ anterior and middle thalamus & $10-1210$ & & 5.0 \\
\hline $\mathrm{R}$ precentral sulcus (vPMC) & 46038 & Area 6 & 4.6 \\
\hline R IPS, inferior parietal lobule & $46-4446$ & hIP1-3, IPC (PFm) & 4.5 \\
\hline R posterior IFG (pars opercularis) & 50820 & Area 44 & 4.5 \\
\hline $\mathrm{R} / \mathrm{L}$ cerebellum (vermis) & $2-56-22$ & Lobule V & 5.7 \\
\hline $\mathrm{R}$ temporoparietal junction (STG) & $60-4010$ & & 1.9 \\
\hline
\end{tabular}

Note. Coordinates $x, y, z$ of the cluster's peak voxel refer to Montreal Neurological Institute space; histological assignments refer to (parts of) the cluster (and not necessarily the peak voxel). $\mathrm{R}=$ right; pre-SMA = presupplementary motor area; $\mathrm{MFG}=$ middle frontal gyrus; $\mathrm{BA}=\mathrm{Brodmann}$ area; $\mathrm{vPMC}=$ ventral premotor cortex; IPS: intraparietal sulcus; IFG = inferior frontal gyrus; L = left; STG = superior temporal gyrus.

${ }^{a}$ References for histological assignments: Area 6: Geyer (2004); Area 44: Amunts et al. (1999); hIP1, hIP2: Choi et al. (2006); hIP3: Scheperjans et al. (2008); IPC (PFm): Caspers et al. (2006); Lobule V: Diedrichsen et al. (2009).

otomy). Crucially, we included only those studies in the review that reported statistical associations between time-related performance decline and lesion location, or between time on task and regional changes in hemodynamic brain activity.

\section{Studies in Patients With Focal Brain Damage}

A study by Rueckert and Grafman (1996) reported that patients with right frontal lesions, compared to patients with left frontal lesions and healthy controls, not only showed slower overall responses and missed more targets in a detection as well as a discrimination task, but also showed a steeper performance decline over $10 \mathrm{~min}$ in the discrimination task. In a follow-up study (Rueckert \& Grafman, 1998), patients with lesions in posterior (parietal) cortex performed worse overall and showed a stronger time-related performance decline in the discrimination task. This time, however, no significant difference between right- and lefthemisphere lesions was found, although the authors themselves speculated that this null result may have been due to lack of statistical power.

A recent study (Malhotra, Coulthard, \& Husain, 2009) in patients with right posterior parietal lesions replicated the overall deficit of patients in sustained detection as well as discrimination tasks. A more severe performance decline over $8 \mathrm{~min}$, however, was only found in those right-hemisphere patients who had developed a neglect syndrome, and it was restricted to discrimination tasks that required maintaining attention to spatial locations. Another patient study (Koski \& Petrides, 2001) compared the effects of right or left frontal or temporal lesions on performance in a 30-min simple RT task with spatially cued lateralized targets. It was found that patients with right frontal damage showed a stronger time-on-task decrement than all other patient groups or healthy controls. Finally, comparing healthy participants and patients with focal PFC lesions (left or right lateral, inferior medial or dorsomedial PFC), Shallice et al. (2008) reported that only lesions in dorsomedial PFC (including anterior midcingulate cortex) were associated with stronger performance decline over time in a task requiring the silent counting of tones presented serially about every $3 \mathrm{~s}$.

\section{Studies Using Functional Neuroimaging}

As with patient studies, only a handful of imaging studies have so far investigated intraindividual changes in VA-related brain activity with time on task. A landmark PET study by Paus et al. (1997) employed a 60-min auditory discrimination task and found time-related decreases in a right-lateralized cortical network including ventro- and dorsolateral PFC, parietal and temporal cortex,

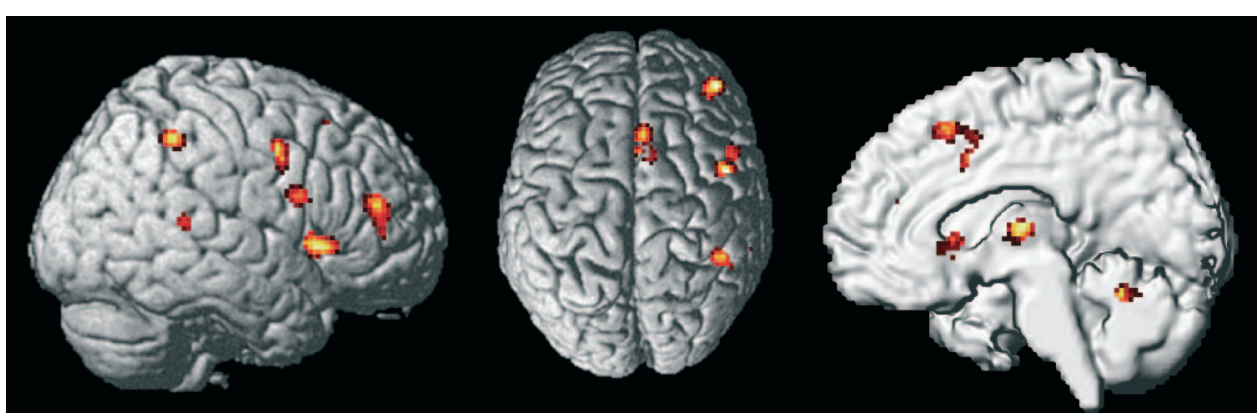

Figure 2. Foci of brain activity that show significantly stronger across-experiment convergence with increasing duration of uninterrupted maintenance of vigilant attention. 


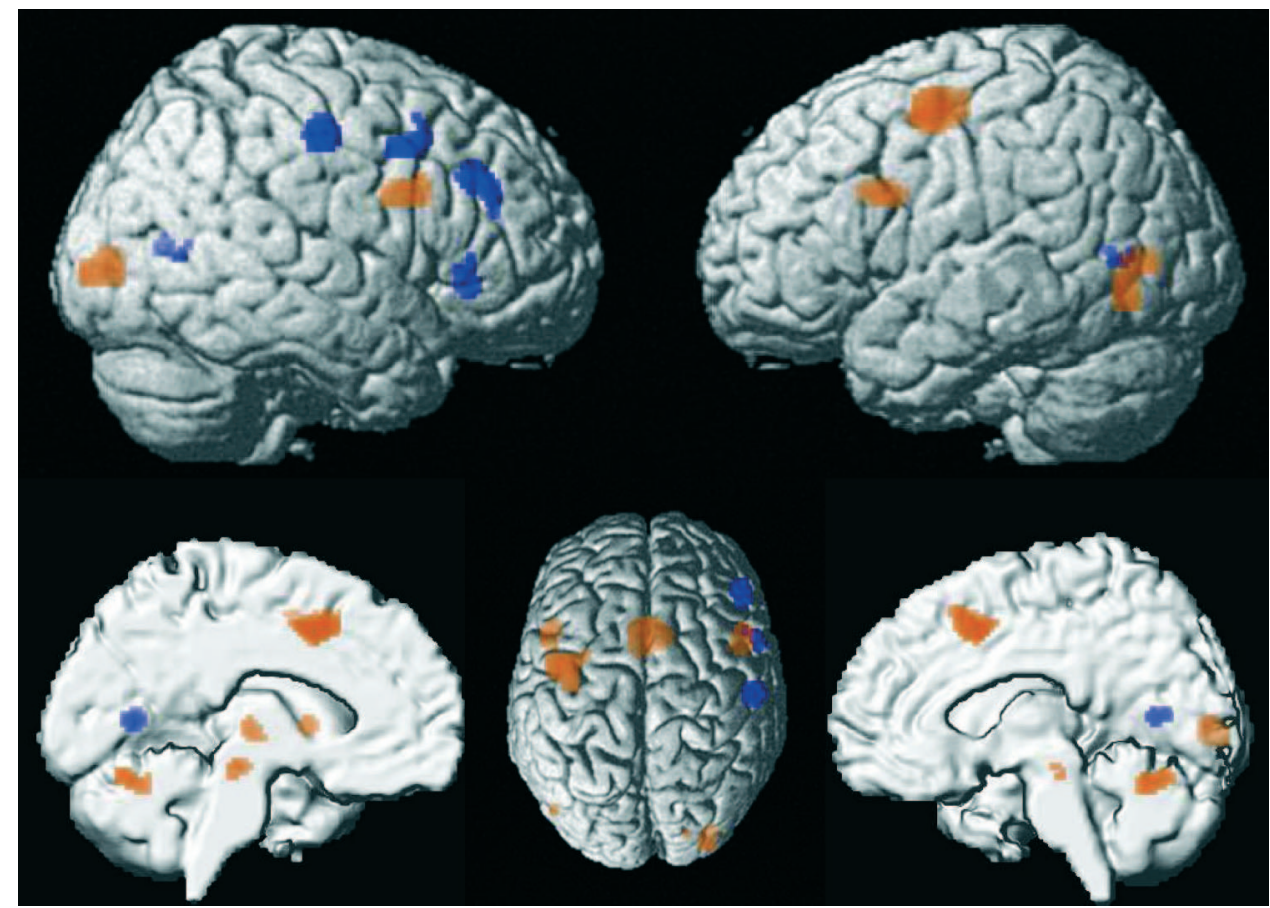

Figure 3. Foci of brain activity with significantly stronger convergence in experiments involving an overt (yellow) or no overt (blue) motor response to target stimuli.

as well as in mainly left-sided subcortical structures (thalamus, putamen). Regression analyses revealed that RT slowing over time was selectively associated with decreasing activity in a subnetwork comprising thalamus, striatum, midcingulum, and pontomesencephalic tegmentum. This time-dependent decrease was interpreted as reflecting a decline in arousal level during monotonous, highly repetitive tasks. At the same time, activity in several areas involved in processing visual information increased over time. The authors argued, however, that these increases only constituted a return of activity to baseline levels, reflecting a decrement in the cross-modal suppression of processing input in a task-irrelevant (i.e., visual) modality.

Another PET study (Coull et al., 1998) examined time-related changes in brain activity during a discrimination and a detection task, lasting 18 min each. RT increased significantly over time, and brain activity decreased across both tasks in right dorso- and ventrolateral PFC, right bilateral inferior parietal cortex, left anterior middle frontal gyrus, and left thalamus. Time-related increases in activity were observed in the right caudate nucleus and posterior cingulate cortex. Interestingly, the decrease in right prefrontal and inferior parietal areas was exclusively driven by the detection task. This specificity argues against a general role of these areas in regulating arousal (see also Paus et al., 1997). Rather, since a discrimination task poses stronger selectivity demands, it indicates an interaction of maintenance and selectivity aspects of attention in right frontal and parietal cortices, consistent with the abovementioned findings on right-hemisphere lesions. The authors suggested that increased selection demands during the discrimination task counteracted the typical time-related right frontoparietal deactivation.

Using arterial spin labeling, Lim et al. (2010) measured timerelated changes in brain perfusion during a 20-min detection task.

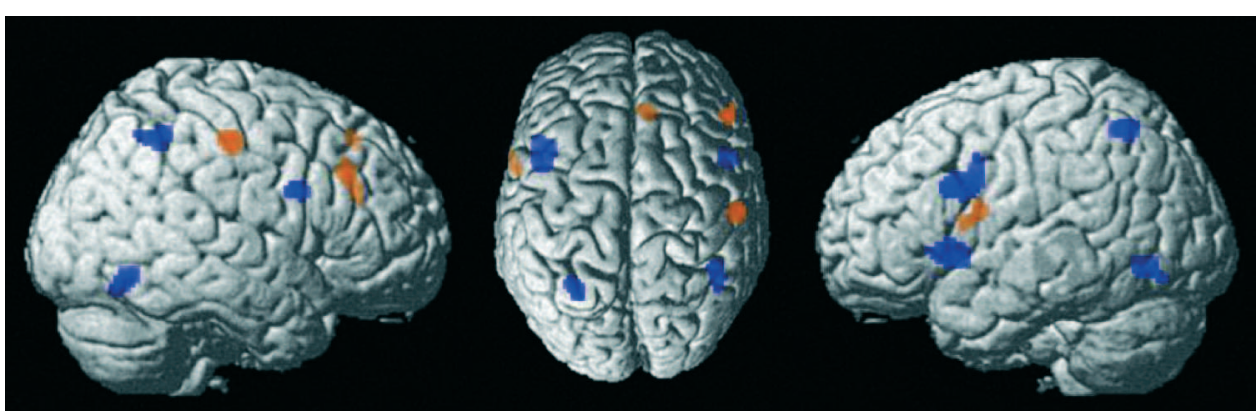

Figure 4. Foci of brain activity with significantly stronger convergence in experiments involving detection (yellow) or discrimination (blue) tasks. 


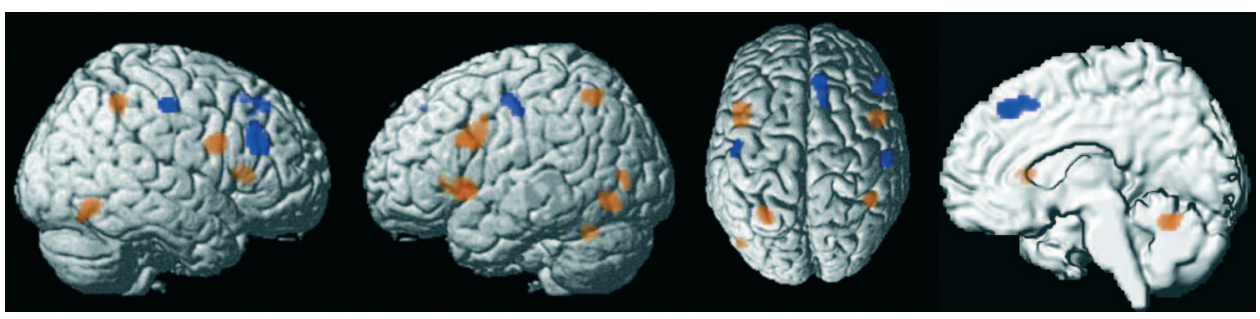

Figure 5. Foci of brain activity with significantly stronger convergence in experiments with temporally predictable (yellow) or unpredictable (blue) stimulus occurrence.

Response speed decreased significantly with time on task, and significant brain activity decreases were observed in right midlateral PFC and bilateral posterior cingulum; no time-related activity increases were reported. Further, no significant associations between neural and performance changes over time were found. These results are more circumscribed than those of previous PET studies, which may be related to methodological differences, but they again demonstrate an involvement of the right midlateral PFC in sustained speeded detection. This is in line with our results, which revealed significantly stronger convergence of activity in this area for detection compared with discrimination tasks. Finally, a recent fMRI study (Breckel, Giessing, \& Thiel, 2011) investigated time-on-task effects during a 32-min simple detection task with lateralized motion distractors using standard fMRI. Over time, RT significantly increased, and hemodynamic activity decreased in a large detection-related network including bilateral ventrolateral PFC, IFJ, TPJ, anterior insula, and somatosensory cortices. No significant time-related increases were found; performance-related neural changes were not reported.

\section{Toward a Brain Network Model for Vigilant Attention}

Our study delineated the neural network involved in VA (i.e., sustaining attention to repetitive, cognitively unchallenging tasks) by means of an ALE meta-analysis of 67 neuroimaging experiments. We found that VA engages an extended cortico-subcortical network with predominant right-lateralization. This lateralization confirms previous qualitative reviews of neuroimaging findings (e.g., Cabeza \& Nyberg, 2000; Husain \& Rorden, 2003) and agrees with studies using functional transcranial Doppler sonography or near-infrared spectroscopy (Helton et al., 2007, 2010; Hitchcock et al., 2003; Shaw et al., 2012, 2009). The right-hemisphere dominance for controlling VA is also corroborated by studies using VA tasks with lateralized stimuli (Heilman \& Van Den Abell, 1979; Warm, Richter, Sprague, Porter, \& Schumsky, 1980; Whitehead, 1991) and by studies in patients with focal right-lateralized brain damage, who showed stronger VA impairments (i.e., worse average performance) than left-hemisphere patients (Coslett, Bowers, \& Heilman, 1987; Howes \& Boller, 1975; Ladavas, 1987; Posner, Inhoff, Friedrich, \& Cohen, 1987). Finally, segregating brain networks on the basis of their functional connectivity patterns during both unconstrained and task-related cognition (i.e., extracting independent components from resting-state fMRI activity and across-study coactivation patterns, respectively) yielded, among others, a right-dominant frontoparietal brain network similar to ours (S. M. Smith et al., 2009; cf. network $9_{20}$ ). This overlap contributes further evidence for the functional distinctiveness of the right-lateralized brain network observed in our analysis.

Helton et al. (2010) suggested that this VA-related rightlateralization may be related to the attentional simplicity of typical VA tasks: When the salience of targets was reduced to increase discrimination difficulty, the right-hemisphere dominance observed with easy-to-discriminate targets vanished and turned into a more symmetrical activity pattern (see also Demeter, HernandezGarcia, Sarter, \& Lustig, 2011; Nebel et al., 2005). Similar effects were observed when comparing phasic alerting (i.e., performance in forewarned simple RT tasks) with intrinsic alerting (i.e., performance in continuous unwarned simple RT tasks), with the former imposing higher discrimination demands than the latter (Sturm \& Willmes, 2001). The current findings support this view: Compared with simple detection tasks, discrimination tasks showed increased activity in a bilateral fronto-parieto-occipital network (cf. Figure 4 and Table S4) as well as in left anterior insula and putamen. These findings accord with cooperative interaction models of hemispheric specialization in which cognitive processes are assumed not to be completely lateralized but to be (asymmetrically) subserved by both hemispheres, with lateralization decreasing with increasing task difficulty (Allen, 1983; Hoptman \& Davidson, 1994). Findings of positive correlations between interhemispheric communication efficiency and sustained attentional performance corroborate the relevance of hemispheric interactions in VA (Rueckert, Baboorian, Stavropoulos, \& Yasutake, 1999; Rueckert, Sorensen, \& Levy, 1994). We conclude that the right hemisphere plays the dominant role in endogenously maintaining the attentional focus, whereas the left hemisphere is additionally recruited by cognitive challenges such as increased selection demand.

\section{Time-Related Effects of VA Maintenance}

Evidence from patients with focal brain damage. The available evidence for relationships between lesion site and time-related performance decline in VA tasks indicates that intact right frontal, bilateral dorsomedial frontal, and posterior temporal and parietal areas are critical for VA maintenance. This is consistent with our findings of the (predominantly right-lateralized) convergence of VA-related activity in midlateral and dorsomedial PFC, IPS, and TPJ with an increasing duration of uninterrupted VA maintenance. The fact that lesion effects tended to be stronger in discrimination than detection tasks suggests that maintenance and selectivity aspects of attention share some neural substrates localized in the damaged frontal and temporoparietal areas. This view is supported 
by studies demonstrating that phasic alerting can transiently compensate not only for impairments in sustaining VA, but also for deficits in spatial attention observed in right-hemisphere patients (Robertson, Mattingley, Rorden, \& Driver, 1998; Robertson, Tegnér, Tham, Lo, \& Nimmo-Smith, 1995; see also Posner, 1993). The right-hemisphere preponderance of this interaction also provides further evidence that the additional left frontal activity in response to increased selectivity demands (see above) reflects higher attentional processes on top of maintaining a stable attentional focus, which cannot compensate for right-hemisphere lesions.

Functional neuroimaging data: Positive correlations with time on task. To test the notion that VA-related righthemisphere activity is specifically related to the maintenance aspect of VA, rather than, for example, selectivity demands, we examined the positive across-study correlation between the duration VA was sustained for and the probability of brain activity to converge in a particular location. This analysis rested on the assumption that brain regions critical for sustaining VA should show more robust activity with longer durations of uninterrupted maintenance demands requiring enhanced attentional effort (Kahneman, 1973; Sarter, Gehring, \& Kozak, 2006). Our analysis revealed significant associations in the right anterior insula, preSMA and adjacent midcingulate cortex, midlateral PFC, vPMC, posterior ventrolateral PFC (IFJ), IPS and adjacent inferior parietal lobule, TPJ, and thalamus, as well as bilateral cerebellar vermis. This clear right-lateralization corroborates the view of a specific role of the right hemisphere in continuously maintaining the attentional focus.

The few neuroimaging studies that directly examined positive intraindividual associations between VA maintenance duration and brain activity yielded heterogeneous results, potentially due to methodological differences, which range from task parameters to measurement duration and imaging modality. Most likely, these factors also contribute to the small overlap with the outcome of our meta-analysis, while this comparison may be additionally affected by differences in the level of analysis: Individual studies examined the consistency of intraindividual time-related changes in brain activity across participants, whereas our meta-analytic approach examined the time-related consistency of brain activity across experiments. In spite of these discrepancies, we found an overlap between our and Breckel et al.'s (2011) findings, which corroborates the involvement of the overlapping regions (pre-SMA and midcingulum as well as right midlateral PFC, vPMC, and thalamus) in maintaining VA.

Functional neuroimaging data: Inverse correlations with time on task. Not a single brain region became less consistently activated with increasing VA maintenance duration. Moreover, given the sparse reporting of deactivation patterns, we could not perform a quantitative analysis of brain regions that may consistently deactivate with time on task. However, functional neuroimaging studies on intraindividual changes with time on task repeatedly revealed activity decreases in mainly right-hemisphere regions and subcortical structures including dorso- and ventrolateral PFC, inferior parietal cortex, anterior insula, and thalamus. These findings converge with results obtained with transcranial Doppler sonography that demonstrated stronger time-on-task decrease in hemodynamic activity during sustained discrimination tasks in the right than left hemisphere (Hitchcock et al., 2003;
Shaw et al., 2009; Warm, Matthews, \& Parasuraman, 2009). At first surprising, the regions showing an intraindividual activity decrease with increasing time on task correspond well to the foci identified in our analysis of positive associations between acrossstudy convergence probability and VA maintenance duration. Put differently, the brain regions that, over time, become activated with increasing consistency are often those that suffer most from prolonged VA maintenance. On a functional level, this pattern may be interpreted in terms of mental fatigue: Prolonged exertion of attentional effort leads to resource depletion with associated reductions in effort and endogenous attentional control.

Although most studies reported time-related performance decrements, only few examined or observed direct associations between this decline and changes in brain activity (see Paus et al., 1997, for an exception). Therefore, the relevance of specific changes in neural activity for observed behavioral changes (and vice versa) remains an open question. Also, self-report data on subjective-state dimensions such as perceived fatigue, arousal, or motivation have hardly been collected and associated with regional changes in brain activity (see Lim et al., 2010, for an exception). Functional interpretations of neural activity changes in terms of fatigue- or arousal-related decline, therefore, rest more on indirect evidence from related research. This points to open questions regarding the relationships between brain activity, behavior, and cognitive-energetic processes in tasks that tax VA.

Are short- and long-term VA qualitatively different? Posner and colleagues (Posner, 1978; Posner \& Boies, 1971; see also Parasuraman et al., 1998) suggested that short-term VA (in the range of seconds) and long-term VA (in the range of minutes or even hours) are basically equivalent, arguing that the "foreperiod of a reaction time task may be considered as a miniature vigilance situation where alertness must be developed rapidly and maintained over a relatively brief interval" (Posner \& Boies, 1971, p. 391). Indeed, our data show time-related changes in the acrossstudy convergence probability within the network presumably subserving VA. This activation pattern is more consistent with Posner's view, since assuming a qualitative difference between short- and long-term VA would have predicted the involvement of distinct brain regions rather than mere quantitative differences within the same network. It should be noted, though, that our interpretation only applies to maintaining VA for more than $10 \mathrm{~s}$, whereas Posner's original suggestion appears to include even shorter maintenance periods as found in typical foreperiod RT paradigms (cf. Niemi \& Näätänen, 1981).

In contradiction to Posner's hypothesis, Breckel et al. (2011) recently dissociated two brain networks related to short-term (i.e., average intertrial interval: $20 \mathrm{~s}$ ) versus long-term (i.e., time on task: 32 min) VA maintenance and assumed them to reflect two distinct mechanisms. Yet, the parametric modulation approach employed decreases the probability of finding spatial overlap a priori, precluding strong inferences. In particular, hierarchical orthogonalization of the parametric regressors may have resulted in the first modulator (reflecting time on task) explaining variance potentially shared between short- and long-term VA (cf. Wood, Nuerk, Sturm, \& Willmes, 2008). This, in turn, might have biased the analysis of brain activity related to short-term VA duration toward subprocesses that are sensitive to energetic short-term but not long-term modulation (e.g., implicit temporal preparation; $\mathrm{cf}$. Langner, Steinborn, Chatterjee, Sturm, \& Willmes, 2010). From 
this, however, it may not necessarily be inferred that short-term VA maintenance does not involve any subprocesses that are also sensitive to long-term modulation (e.g., by fatigue), and vice versa. We, therefore, suggest that the two distinct association patterns observed by Breckel et al. rather reflect two classes of subprocesses involved in maintaining VA. On the basis of previous evidence, we assume that the first class of processes, being sensitive to energetic short-term modulations (within seconds), is related to the expectancy-driven establishing of a preparatory set, which is modulated by sequential trial-to-trial arousal changes (Näätänen, 1970; Steinborn \& Langner, 2012; Vallesi \& Shallice, 2007). In contrast, the second class of processes, being sensitive to longer-term changes (within minutes to hours), would be related to top-down monitoring and energizing of the task schema (Shallice et al., 2008; Stuss et al., 1995), which are modulated by decreasing task engagement over time (Langner, Willmes, et al., 2010; Lorist et al., 2000; Pattyn et al., 2008; Robertson, Manly, et al., 1997; Warm et al., 2008).

In conclusion, the available data on time-related brain activity changes during VA task performance agree with the notion of a right-sided network of frontal, cingulate, insular, parietal, and subcortical regions involved in maintaining VA. This appears to apply to both short- and long-term maintenance, albeit to different degrees. We, therefore, argue that it is these regions that constitute the core brain network subserving VA.

\section{Functional Significance of Core Network Nodes}

Midlateral PFC. Significant convergence in the right midlateral PFC is corroborated by VA-related effects in this region in early neuroimaging studies not meeting our inclusion criteria $(\mathrm{Bu}-$ chsbaum et al., 1990; Cohen et al., 1988; Cohen, Semple, Gross, King, \& Nordahl, 1992; Lewin et al., 1996; see also Cabeza \& Nyberg, 2000), as well as by lesion data (Godefroy, LhullierLamy, \& Rousseaux, 2002; Rueckert \& Grafman, 1996; Wilkins, Shallice, \& McCarthy, 1987). Our analyses revealed that the right midlateral PFC showed stronger convergence (a) with longer VA maintenance, (b) in tasks with covert versus overt responses, (c) in simple detection versus discrimination tasks, and (d) in tasks with a variable versus fixed temporal structure of event occurrence. At the same time, convergence in this region was independent of stimulus modality. This pattern argues against a specific role of this area in mediating speeded motor responses but is consistent with implementing a continuous monitoring for relevant external events. Within the framework proposed by Stuss and colleagues (Shallice et al., 2008; Stuss et al., 1995), this process is viewed as monitoring the input-induced activation level of the task schema. Monitoring is required independently of stimulus modality and may be even more demanding in the absence of overt motor action that produces sensory feedback potentially acting as an external "reminder" to reactivate the monitoring process; the same may hold for the distinction between detection and discrimination. Further, constant monitoring is especially crucial with longer VA maintenance and in temporally variable event sequences, in which the moments of event occurrence cannot be predicted with certainty.

A role of the midlateral PFC in monitoring agrees with conclusions drawn from patient studies. In patients with right lateral PFC lesions, Shallice et al. (2008) observed a specific impairment in a fast version of a sustained covert target counting task, which imposed more demands on event monitoring than the slow version. Furthermore, in tasks with unpredictable event onset, behavioral advantages arise from monitoring the changing conditional probability of stimulus occurrence with elapsing time since the last stimulus (Nobre, Correa, \& Coull, 2007) for conversion into enhanced expectancy and preparation (Niemi \& Näätänen, 1981). Since conditional probability monitoring per se seems not related to PFC activity (Cui, Stetson, Montague, \& Eagleman, 2009; Janssen \& Shadlen, 2005), the PFC might be more involved in this second process: the conversion of subjective probabilities into expectations or predictions. Supporting an essential role of the right PFC in conditional-probability-based temporal preparation, Stuss et al. (2005) observed a specific deficit for patients with right lateral PFC lesions in gaining a response time advantage from a decrease in the conditional probability of target occurrence with increasing foreperiod length (see also Vallesi, Shallice, \& Walsh, 2007). These findings may constitute instances of the more general filter function ascribed to the midlateral PFC (Corbetta, Patel, \& Shulman, 2008), by which expectations are implemented across time via a selective modulation ("biasing") of sensorimotor processing (cf. Beck \& Kastner, 2009).

Inferior frontal junction. Our analyses yielded stronger convergence in bilateral IFJ-a region in the vicinity of the junction of the inferior frontal sulcus and the inferior precentral sulcus-(a) with longer VA maintenance (here restricted to right IFJ), (b) in tasks with overt versus covert responses, (c) in discrimination versus detection tasks, and (d) in tasks with temporally fixed versus variable event occurrence. This pattern favors a role of the IFJ in mediating the mapping between target stimuli and instructed motor response, since this mapping is (a) exclusively required in VA tasks involving motor output and (b) more demanding in discrimination tasks, which require continuous decisions about the response alternative (i.e., go vs. no-go) that the stimulus is mapped onto.

IFJ involvement in setting up S-R connections is supported by Hartstra, Kühn, Verguts, and Brass (2011) reporting that left IFJ activity was associated with implementing new S-R rules. This left dominance agrees with a selective deficit in patients with left (vs. medial or right) frontal lesions (including IFJ) in acquiring S-R mappings in a choice RT task (Alexander et al., 2005). A recent study (Verbruggen, Aron, Stevens, \& Chambers, 2010) using transcranial magnetic stimulation further delineated the role of the right IFJ by showing a specific involvement in detecting infrequent but action-relevant signals (cf. Chikazoe et al., 2009). Right IFJ may thus link nondominant (i.e., unexpected) responses and stimulus features that trigger them, possibly by sending control signals to inferior parietal cortex implementing a stimulus-driven (re)orienting of attention. Finally, Ruge and Wolfensteller (2010) observed a rapid practice-related decline in bilateral IFJ activity associated with mapping instructed responses to stimuli, which reached an asymptotic level above baseline. This argues for a reduced but continuous IFJ involvement in S-R mapping over time.

Our data suggest that despite overlearning such mappings in simple VA tasks, sustaining efficiency in sensorimotor responding may depend on continuous (right) IFJ engagement. On a cognitive level, this might correspond to holding the representation of the S-R link active for continued top-down facilitation of the over- 
learned mapping (see also Brass, Derrfuss, Forstmann, \& von Cramon, 2005). Of note, sustained hemodynamic activity in the IFJ across a block of trials could also reflect recurrent (vs. genuinely sustained) IFJ engagement associated with repeated reactivation processes rather than continuous maintenance; mixed blocked/event-related fMRI designs might clarify this issue. The stronger involvement of the left IFJ in discrimination versus detection tasks is in line with the difficulty-related hemispheric asymmetry reduction alluded to above; however, it might also reflect (covert or even overt) verbal rehearsal of the more complex S-R mapping in discrimination tasks (cf. Friederici, 2002). Finally, the stronger convergence in tasks with a fixed (vs. unpredictable) temporal event sequence suggests that the representation of the mapping may be stronger when the moment of its application can be prepared.

Dorsomedial PFC, midcingulate cortex, and anterior insula. The main analysis across all experiments yielded significant convergence in a large cluster in medial PFC, which included preSMA and more anterior regions of the dorsomedial PFC as well as anterior midcingulate cortex (aMCC; previously often (mis)labeled dorsal anterior cingulate cortex based on Brodmann's coarser segmentation; cf. Vogt, 2005). Our differential analyses revealed stronger convergence in central parts of this cluster (i.e., pre-SMA and aMCC) with longer VA maintenance. Further, the middorsal part of this cluster (i.e., pre-SMA) showed stronger convergence in tasks with overt motor (vs. nonmotor) responses, whereas the most anterior part of this cluster (i.e., the medial superior frontal gyrus [mSFG]) did so in detection (vs. discrimination) tasks as well as in tasks with a variable (vs. fixed) temporal structure.

Pre-SMA has been associated with the cognitive control of motor output (Cieslik, Zilles, Grefkes, \& Eickhoff, 2011; for review, see Nachev, Kennard, \& Husain, 2008), ranging from motor preparation (Cunnington, Windischberger, \& Moser, 2005; Hülsmann, Erb, \& Grodd, 2003) and facilitation (Mars et al., 2009) to motor inhibition (Chen, Muggleton, Tzeng, Hung, \& Juan, 2009; Picton et al., 2007). As VA tasks with motor output benefit from maintaining a preparatory (motor) set, which includes managing the balance between motor preparation and inhibition (Burle, Tandonnet, \& Hasbroucq, 2010; J. R. Jennings \& van der Molen, 2005), pre-SMA may subserve the sustained representation of relevant motor plans and the sustained prevention of their premature release by putting constraints on activity in nonprimary motor cortical areas.

The most anterior part of the medial cluster (i.e., mSFG) appears to be selectively involved in withholding preplanned responses (Brass \& Haggard, 2007). Such "veto" decisions may play an important role for maintaining efficient responding over time in that they allow the preparation and simulation of action without execution. Indeed, activity in anterior medial PFC has been shown to code action intentions across delays (Haynes et al., 2007), and dorsomedial PFC might subserve a "brake" function that enables postponing execution until target occurrence by down-regulation of motor activity (Danielmeier, Eichele, Forstmann, Tittgemeyer, \& Ullsperger, 2011). In sustained performance, this might become necessary when the distance between fluctuating motor cortex baseline activity and motor action limit becomes too small. Evidence for this assumption comes from a study (Eichele et al., 2008) that revealed a decline in dorsomedial PFC activity before erro- neous responses, which may reflect a gradual "release of the brake," shifting neural baseline motor activity too close to the motor action limit. This interpretation fits with the reported cooccurring decline in precuneus activity, a region associated with task-free cognition and mind-wandering (Christoff, Gordon, Smallwood, Smith, \& Schooler, 2009), suggesting that preerror drifts toward task disengagement mediated the brake release.

Simple detection tasks only involve a single response, which can be fully preplanned and easily simulated, and typically evoke more premature responses than discrimination tasks, whose irregularly interspersed no-go trials discourage continuous motor simulation. Therefore, continuous detection tasks should more often invoke veto decisions in between imperative stimuli, consistent with the observed stronger convergence in $\mathrm{mSFG}$ in these tasks. The view of $\mathrm{mSFG}$ activity as mediating the prevention of acting out taskrelated intentions is also supported by our finding stronger convergence in this region when event onsets were unpredictable. Here, the "urge to act" should arise more irregularly, potentially evoking more veto decisions to prevent premature responses.

The midcingulate cortex has been conceptualized as a region where motor intentions and motivational signals interface (Paus, 2001; see also Shackman et al., 2011). Several studies demonstrated a role of this region in response to cues that announce an impending need for sensorimotor processing (Langner, Kellermann, et al., 2011; Luks, Simpson, Feiwell, \& Miller, 2002; Murtha, Chertkow, Beauregard, Dixon, \& Evans, 1996; Weissman, Gopalakrishnan, Hazlett, \& Woldorff, 2005). Patient studies (Alexander et al., 2005; Shallice et al., 2008; Stuss et al., 2005; Stuss, Binns, Murphy, \& Alexander, 2002) indicated that the aMCC region is required for sustaining the intention and preparation to respond (overtly or covertly) in nonroutine tasks or when responses must occur at a particular moment in time. Apart from such proactive processing, the aMCC has also been implicated in performance monitoring and signaling the need for attentional adjustments after committing an error (for review, see Danielmeier \& Ullsperger, 2011). Furthermore, besides adapting task-specific cognitive control parameters, such attentional adjustments should also entail the top-down regulation of midbrain and brain stem arousal systems (Aston-Jones \& Cohen, 2005; Fischer et al., 2008; Mottaghy et al., 2006; Sarter et al., 2001).

Such an arousal regulation system will likely include the anterior insula, an area that was also revealed by our meta-analysis. The anterior insula is involved in representing emotional and bodily states (Craig, 2002; Critchley, Wiens, Rotshtein, \& Öhman, \& Dolan, 2004; Kurth, Zilles, Fox, Laird, \& Eickhoff, 2010) and has been associated with self-reported arousal (Knutson \& Greer, 2008), interoception (Pollatos, Schandry, Auer, \& Kaufmann, 2007), and sympathetic autonomic activity (Critchley, Corfield, Chandler, Mathias, \& Dolan, 2000). Anatomically and functionally, it is tightly connected with the anterior and middle cingulate cortex (Augustine, 1996; Eckert et al., 2009; Medford \& Critchley, 2010; Taylor, Seminowicz, \& Davis, 2009).

An fMRI study (Sridharan, Levitin, \& Menon, 2008) demonstrated the causal involvement of this insular-midcingulate network in switching between central executive and default mode networks, which presumably mediate states of task engagement versus disengagement, respectively. In fact, it has been argued that recurring intrusions of task-unrelated (default-mode) brain activity associated with mind-wandering challenge the integrity of task- 
related functional networks and lie at the heart of attentional fluctuations during sustained task performance (Sonuga-Barke \& Castellanos, 2007). Thus, such periodic intrusions, which compete with VA-related activity, need be suppressed or, at least, immediately undone to protect the maintenance of VA and prevent attentional drifts away from the task at hand. Initiating this switching back to VA-related processing might be subserved by the anterior insula (cf. Sridharan et al., 2008). In accord with this claim, it was recently shown via source localization of electrocortical activity that the cue-induced switching from default activity during the intertrial interval into a mind-set for speeded responding is led by activity in aMCC and anterior insula/inferior frontal cortex (Fischer, Langner, Diers, Brocke, \& Birbaumer, 2010). Together, these findings suggest that the consistently observed anterior insula/midcingulate cortex activity during VA tasks might not result from genuinely sustained but rather from frequently recurrent activity related to bringing the mind back "on track" (i.e., reactivating the VA task schema) while it is about to (a) reduce the intensity of its task engagement or (b) even "wander off" completely. The positive association between consistency of activity in these regions and duration of VA maintenance supports this view, as drifts toward task disengagement should become more frequent over time (cf. Smallwood, O'Connor, Sudbery, \& Obonsawin, 2007). In summary, the available data suggest that during VA tasks, the right anterior insula may be involved in signaling the need for attentional effort investment to facilitate target detection (i.e., to stay on, or get back to, the job at hand), particularly under "energetically" challenging conditions such as increasing time on task.

Collectively, the processes assumed to be subserved by the medial PFC and anterior insular clusters can be subsumed under what Stuss, Shallice, and colleagues (Shallice et al., 2008; Stuss et al., 2005, 1995) referred to as "energizing" (i.e., the (re)activation of the currently relevant task schema without initiating motor actions) and performance monitoring. Converging evidence for this interpretation was provided by Dosenbach et al. (2006), who observed sustained activity in these frontomedial regions and the anterior insula across different tasks, suggesting that it reflected the initial implementation and stable maintenance (or recurrent reactivation; cf. Sridharan et al., 2008) of task sets (see also Dosenbach et al., 2007). Dorsomedial PFC/aMCC and anterior insula may thus monitor performance and energetic state and, if needed, provide reactive control signals to re-engage in taskrelevant processing with optimal intensity. Target regions for such control signals may include the midlateral PFC and parietal cortex for adjusting input expectations, as well as subcortical arousal systems for adjusting ascending modulatory inputs.

Midbrain tegmentum and thalamus. We observed a small cluster of convergence in the pontomesencephalic tegmentum, which was significantly more active in VA-related tasks that required an overt motor (vs. nonmotor) response. The cluster was in the vicinity of the pedunculopontine tegmental nucleus, which is a major source of cholinergic innervation of the cerebral cortex by way of its projections to the thalamus and the basal cholinergic forebrain (for review, see Jones, 2003; Kobayashi \& Isa, 2002). Although this localization must be considered with caution given the spatial resolution of neuroimaging, there is abundant evidence for VA improvement through cholinergic modulation (for review, see Koelega, 1993; Sarter,
Hasselmo, Bruno, \& Givens, 2005). Furthermore, PET studies reported increased hemodynamic activity in this midbrain region during VA maintenance (Kinomura et al., 1996) and a time-related decline of its activity along with a performance decrement (Paus et al., 1997).

Tonic increases in cholinergic neurotransmission might lead to widespread enhancements of cortical arousal (Hasselmo \& Sarter, 2011; Sarter et al., 2001; Steriade, Datta, Pare, Oakson, \& Curro Dossi, 1990), acting in concert with noradrenergic modulation originating in the locus coeruleus (Briand, Gritton, Howe, Young, $\&$ Sarter, 2007). There is also, however, accumulating evidence for phasic, more specifically localized acetylcholine release, which enhances signal-to-noise ratios in task-relevant cortical modules and thus facilitates cue detection. For sustaining attention, such phasic acetylcholine release may be recurrently evoked, as a neural correlate of investing attentional effort, to stabilize task-relevant attentional circuits and performance over time (Hasselmo \& Sarter, 2011; Kozak, Bruno, \& Sarter, 2006; Sarter et al., 2006, 2005). Importantly, such transient acetylcholine release is most likely under top-down control from PFC, which in turn is partially driven by glutamatergic input from mediodorsal thalamus (Hasselmo \& Sarter, 2011), which likewise showed significant convergence in our data.

Thalamic activity during VA, however, may also be related to mediating cortical arousal via relaying the inputs of noradrenergic and other brain stem arousal systems to the cortex (McCormick, 1992; Paus, 2000; Sarter et al., 2001). Especially the noradrenergic system has been considered essential for maintaining alertness (Posner \& Petersen, 1990; A. Smith \& Nutt, 1996). Later research confirmed that the tonic firing mode of the diffuse noradrenergic projections to thalamus and cortex is more related to regulating general arousal than specific attentional functions (Aston-Jones \& Cohen, 2005; see also Sarter et al., 2001). Concurrent evidence was provided by a genetic study, in which noradrenergic genotype was found to predict lapses in VA, possibly mediated via effects on the physiological efficiency of the VA-related brain network (Greene, Bellgrove, Gill, \& Robertson, 2009). One reason for not observing significant convergence in the vicinity of the noradrenergic locus coeruleus in our analysis (despite some reports in individual studies) might be the difficulty to reliably detect activity in small brain stem structures with standard neuroimaging approaches.

Regarding thalamic activity during VA tasks, neuroimaging studies revealed that it not only decreases over time (Coull et al., 1998; Paus et al., 1997) but also varies as a function of arousal changes induced by sleep deprivation (Thomas et al., 2003, 2000; Wu et al., 1991), falling asleep (Hofle et al., 1997), or pharmacological challenges (Coull, Frith, Dolan, Frackowiak, \& Grasby, 1997; Fiset et al., 1999). However, decreased thalamic activity under low-arousal conditions was also found to bounce back when new demands on attention were imposed by the experimenter (Coull et al., 1997; Portas et al., 1998). This is consistent with the view that maintaining arousal (or compensating its time-related decline) is an integral part of maintaining VA (cf. introduction). Thus, the consistent thalamic activity we observed may be taken to indicate that arousal did not drop substantially in the majority of tasks under study. On the other hand, this activity might in part reflect the exertion 
of compensatory attentional effort. The positive correlation between thalamic activity and duration of VA maintenance supports this reasoning, since increasing maintenance duration poses a growing challenge for the VA system (cf. Sarter et al., 2006).

Temporoparietal junction. Our analyses revealed significant convergence of right TPJ activity across all experiments but in particular for longer VA maintenance. Increased activity in this supramodal association area was previously observed when task-relevant sensory changes in the environment were detected (Downar, Crawley, Mikulis, \& Davis, 2000) or expectations about stimuli were violated (Corbetta \& Shulman, 2002). Recent theorizing (Jakobs et al., 2012) conceptualized the right TPJ as a crucial cortical node for the integration of stimulus input with task context (i.e., instructions and expectations), including the comparison of prepared motor programs with current requirements and/or updating of action-related expectations (cf. Eickhoff, Pomjanski, Jakobs, Zilles, \& Langner, 2011). We would thus suggest that the right TPJ contributes to optimal VA task performance by comparing expectations with incoming sensory information, providing an interface between top-down and bottom-up processing and facilitating the stimulus-driven (re)orienting to those inputs that are task relevant (see also Corbetta et al., 2008; Downar, Crawley, Mikulis, \& Davis, 2001).

This reasoning implies that the right TPJ should also become active when attention has drifted away from the task and needs to be refocused once a new task-relevant event occurs. Indeed, an fMRI study (Weissman, Roberts, Visscher, \& Woldorff, 2006) corroborated this implication by showing that right TPJ activity on the current trial was correlated with RT on the subsequent, but not current, trial, presumably reflecting postlapse reorienting of attention. In this case, reorienting may be triggered by internally generated signals of the performance monitoring system (cf. Smallwood, Riby, Heim, \& Davies, 2006), most likely subserved by the dorsal anterior/middle cingulate cortex (Ridderinkhof, Ullsperger, Crone, \& Nieuwenhuis, 2004). This assumption is supported by increased cingulate activity on trials with slow responses (Weissman et al., 2006). Finding increased TPJ convergence with longer VA maintenance is concordant with assuming that lapse- or errortriggered reorienting occurs increasingly often over time, along with the typical time-related increase in the number of attentional drifts away from the task (as expressed, for example, by the number of very slow responses that are immediately followed by much faster responses; cf. Bertelson \& Joffe, 1963).

Intraparietal sulcus. Beyond the main effect, our analyses yielded stronger convergence in right anterior IPS and adjacent inferior parietal cortex (a) with longer VA maintenance, (b) in discrimination versus simple detection tasks, and (c) in tasks with fixed versus variable temporal structures of event occurrence. An essential role of this region in maintaining VA is also supported by deficits in patients with parietal lesions (Malhotra et al., 2009; Rueckert \& Grafman, 1998).

The IPS is associated with guiding the focus of attention in space (for review, see Corbetta \& Shulman, 2002; Posner \& Petersen, 1990; Raz \& Buhle, 2006) but appears to be also involved in nonspatial attentional orienting (see Husain \& Rorden, 2003), such as directing attention to stimulus modality
(Langner, Kellermann, et al., 2011) or moments in time (Coull \& Nobre, 1998). Synthesizing several lines of research, Ptak (2012) argued for a central role of this region in computing a feature- and modality-independent priority map of the environment. This priority map is thought to integrate multidimensional feature information provided by sensory cortex and representations of behavioral goals and expectations originating in frontal cortex (see also Bisley \& Goldberg, 2010). Since perceptually more demanding tasks should benefit more from attentional facilitation, the increased IPS activity observed in response to discrimination (vs. simple detection) demands supports this reasoning. The greater IPS activity in VA tasks with predictable event onsets also concurs with this notion, since attention will be voluntarily directed to the relevant moments in time under such conditions.

Given a balance between attentional drifts away from the task and reorienting toward it during sustained performance (cf. above; see also Smallwood \& Schooler, 2006), we assume that IPS activity does not reflect a steady "holding" of the attentional focus (and its intensity; cf. Kahneman, 1973; Spitzer, Desimone, \& Moran, 1988) but rather recurrent readjustments thereof. Since attentional readjustments can only occur after the preceding disengagement of attention, the reorienting process should engage both IPS and TPJ (Corbetta et al., 2008). Indeed, both regions are frequently coactivated during target detection and stimulus-driven reorienting (Corbetta \& Shulman, 2002; Giessing, Thiel, Rösler, \& Fink, 2006; Jakobs et al., 2012; Kincade, Abrams, Astafiev, Shulman, \& Corbetta, 2005; Marois, Leung, \& Gore, 2000).

Cerebellar vermis. Our meta-analyses yielded stronger convergence in the cerebellar vermis (a) with longer VA maintenance, (b) in tasks with overt versus covert responses, and (c) in tasks with fixed versus variable temporal structures of event occurrence. This suggests a specific role for the cerebellar vermis in the anticipatory timing of motor output, in line with a study (Diedrichsen, Verstynen, Lehman, \& Ivry, 2005) that found impaired anticipatory timing of postural adjustments in patients with cerebellar lesions (see also Trillenberg, Verleger, Teetzmann, Wascher, \& Wessel, 2004) as well as a functional connectivity analysis (Pollok, Gross, Kamp, \& Schnitzler, 2008) that revealed cerebellar involvement in both anticipatory motor control and mismatch-contingent updating of internal sensorimotor models. Together, these findings suggest that the medial cerebellum supports efficient performance in VA tasks with motor output by synchronizing motor preparation with the predicted temporal structure of target events. This conjecture is further corroborated by a recent study (Michael, Garcia, Bussy, Lion-Francois, \& Guibaud, 2009), which demonstrated that the absence of the cerebellar vermis because of congenital dysplasia is related to an impairment in endogenously maintaining responsiveness to visual signals.

\section{Theoretical Implications}

In this section, we summarize some implications our results have for the question of how top-down and bottom-up processes may interact in the control of VA. Here top-down refers to the goal-directed facilitation of input and response processing by attentional biasing, whereas bottom-up refers to processes driven by stimulus input and this input's ability to attract 


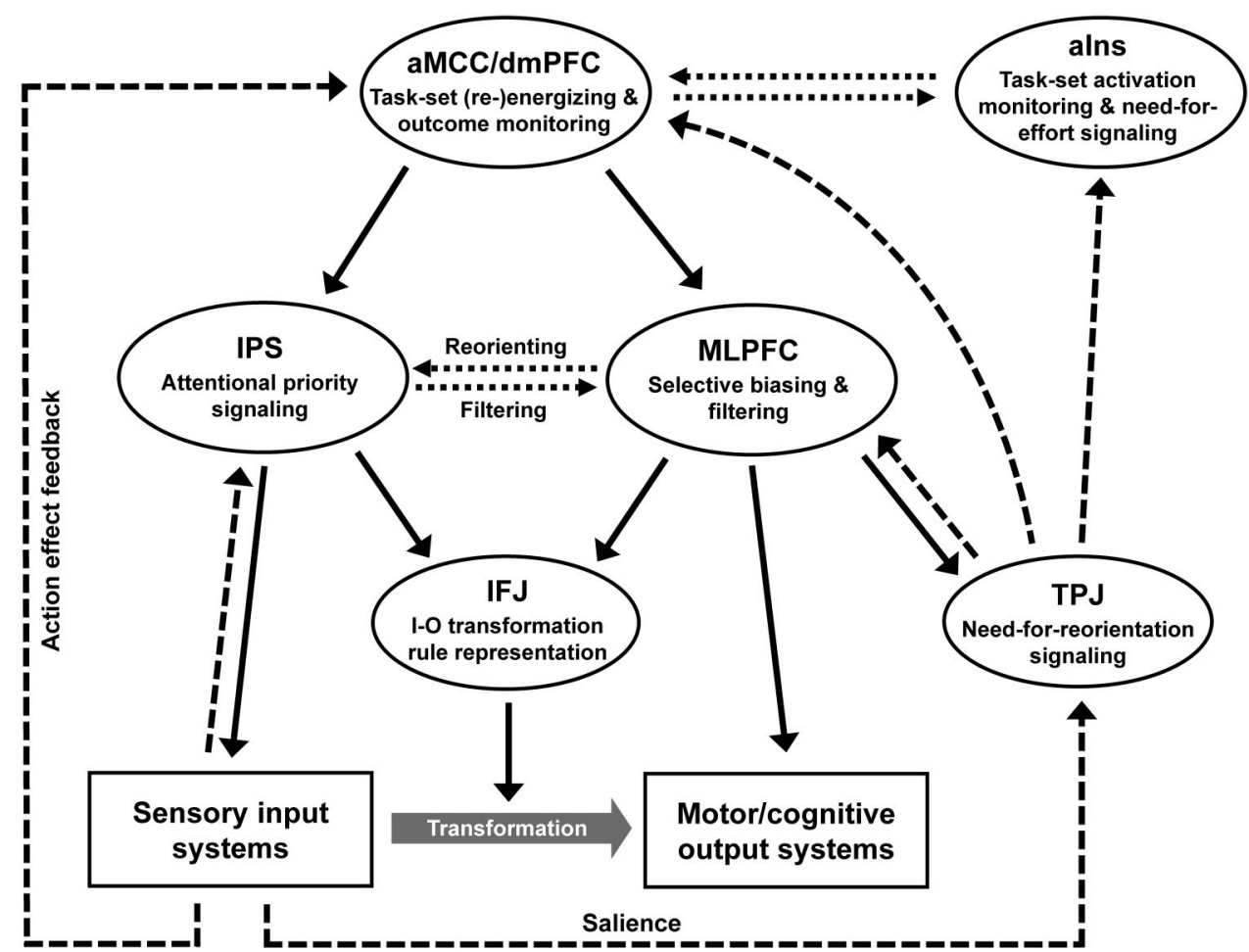

Figure 6. Simplified hierarchical model of the putative functions and interrelations of cortical core nodes of the brain network involved in vigilant attention. Solid lines denote top-down signaling; broken lines denote bottom-up signaling; dotted lines denote within-level signaling. aIns = anterior insula; $\mathrm{aMCC} / \mathrm{dmPFC}=$ anterior midcingulate cortex/dorsomedial prefrontal cortex; IFJ = inferior frontal junction; I-O = input-output; IPS = intraparietal sulcus; MLPFC $=$ midlateral prefrontal cortex; TPJ $=$ temporoparietal junction.

attention and activate appropriate responses. In the aforementioned conceptual framework proposed by Stuss, Shallice, and colleagues (Shallice et al., 2008; Stuss et al., 2005, 1995), bottom-up control of VA corresponds to the automatic, inputdriven activation and selection of the relevant task schema ("contention scheduling"; cf. Norman \& Shallice, 1986; Shallice \& Burgess, 1996). In contrast, top-down control of VA is thought to comprise several supervisory-system processes (i.e., energizing the relevant task schema and suppressing irrelevant schemata, as well as monitoring schema activation level and implementation success) that together mediate the goal-driven facilitation of task-relevant processing.

Our meta-analysis revealed a network that substantially overlaps with the right-lateralized ventral attention network (Corbetta \& Shulman, 2002), which has consistently been associated with the stimulus-driven (bottom-up) reorienting of attention (Corbetta et al., 2008). In an event-related fMRI study (Shulman et al., 2003), the ventral attention network was activated during a continuous visual search task when a target was detected but deactivated between targets, whereas the right IPS and frontal eye fields (i.e., parts of the dorsal "top-down" attention network) showed sustained activity. Similarly, there is extensive overlap between the VA-related network and regions activated by the sudden recognition of a slowly revealed target (Ploran et al., 2007). These and related (e.g., Shulman, Astafiev, McAvoy, d'Avossa, \& Corbetta, 2007; Todd, Fougnie, \&
Marois, 2005) findings suggest that top-down filter signals, possibly from midlateral PFC, convey information on the task relevance of given sensory inputs and enable the selective, stimulus-driven activation of the ventral system for reorienting attention to task-relevant inputs and preventing reorienting to irrelevant events.

Although inferences from brain activity patterns on cognitive processes are necessarily limited (cf. Poldrack, 2006), the substantial overlap between the ventral attention network and the core VA network suggests that sustaining VA may entail maintaining a state in which target stimuli can optimally elicit a reorientation of attention to themselves. Put differently, VA may constitute a task set that enables (recurrent) efficient task-contingent attentional capture (cf. Folk, Remington, \& Johnston, 1992; see also Kiefer \& Martens, 2010; Serences et al., 2005). According to the attentional-control framework proposed by Stuss and colleagues (Shallice et al., 2008; Stuss et al., 2005, 1995), such a state is maintained via monitoring the degree of the task schema's activation and implementation and, if needed, reactivating the relevant schema. In Figure 6, we present a putative and simplified hierarchical model of how these processes might map onto the cortical core network nodes revealed in our meta-analysis.

Our conclusions contradict a view of VA as simply constituting a continuous form of focused, goal-directed attention, being controlled in a purely top-down manner. Rather, they 
agree with viewing sustained attention as a product of top-down and bottom-up modes of control (Sarter et al., 2001; see also Egeth \& Yantis, 1997). Behavioral evidence for an interaction of both processes in VA is, for instance, provided by greater time-on-task performance decrements with less conspicuous targets (Helton \& Warm, 2008; Langner, Willmes, et al., 2010), which typically arise from a stronger decline in top-down attentionally mediated observer sensitivity (Langner, Eickhoff, \& Steinborn, 2011; see See et al., 1995, for review). Within this framework, time-on-task performance decrements would reflect either increasingly less efficient contingent attentional capture (i.e., reductions in top-down modulatory intensity) or gradual shifts from predominantly contingent to more frequent noncontingent capture (i.e., reductions in top-down modulatory selectivity). It remains to be shown which of the presumed stimulusdriven and/or supervisory-system processes are affected by prolonged time on task under what circumstances. So far, most accounts have focused on changes in top-down regulation, resulting from a depletion of some (often underspecified) mental resources (Grier et al., 2003; Langner, Willmes, et al., 2010; Smit et al., 2004; Warm et al., 2008; cf. introduction) or strategic-motivational shifts in attentional effort investment (Boksem \& Tops, 2008; Hockey, 1986, 1997).

At any rate, the existence and predictability of time-related VA decrements provides a powerful example for the pervasive influence of energetic factors on human cognition (Hockey, Coles, \& Gaillard, 1986). Such factors have been considered noise in many psychological models of human information processing, which has often limited these models' predictive or explanatory value in applied settings. Observing VA-related brain activity and its change occurring with increasing time on task is a reminder of the biological grounding of human cognition, which emerges from a "wet" (i.e., physiologically based) mind (Kosslyn \& Koenig, 1992) and is subject to modulations by fatigue, effort, circadian rhythms, etc.

Finally, our analysis of VA-related brain activity corroborates the long-standing view that maintaining VA is no mean task, as it involves the intricate interplay of a substantial number of brain regions. The differential sensitivity of these regions to the duration of VA maintenance suggests, along with other evidence, that maintaining VA is not a unitary process. This provides further support for multiprocess models of VA regulation, as, for example, proposed by Stuss et al. (1995). Recognizing this, one might not consider the seemingly paradoxical dissociation between (low) intellectual demand and (high) subjective effort expenditure all that paradoxical anymore.

\section{Limitations and Future Directions}

\section{Limitations of the Meta-Analysis}

As meta-analyses are based on the available empirical data, their results may be affected by a publication bias in the literature that disfavors null results (R. G. Jennings \& Van Horn, 2012; Rosenthal, 1979). We were able to mitigate this bias by including a set of results from VA tasks that had served as control conditions and, therefore, had not been published as stand-alone findings. Moreover, as detailed elsewhere (Eickhoff \& Bzdok, in press; Rottschy et al., 2012), coordinate-based meta-analyses of neuroimaging data are less susceptible to publication bias than standard meta-analytic approaches that examine effect sizes, as the assessment of spatial convergence across experiments would not be affected by additionally including (observed but unpublished) null results. We, therefore, are confident that the validity of our results was not substantially undermined by such bias.

Second, we were not able to include brain activity correlates of performance parameters or time on task in our quantitative analysis, since such results are yet too sparse. However, we conducted a qualitative review of the few pertinent data from functional neuroimaging and patient studies and integrated the results in our discussion to strengthen our conclusions on the functional significance of the brain areas involved in maintaining VA.

\section{Future Directions}

Knowing that there are so many brain network nodes involved in VA regulation, it should be little surprising that there are many disorders of mind and brain associated with VA impairments. These impairments are by no means restricted to pathological hypofunction - they also include dysfunctional upregulation, as exemplified by the hypervigilance syndrome in posttraumatic stress disorder. The challenge for studies to come is to delineate the neurocomputational operations of each network node during VA maintenance and their contribution to the behavioral outcome. Understanding the functional significance of the different parts of the VA system should also help to understand its failures. This, in turn, has direct relevance for the prediction, diagnosis, and treatment of deficient VA regulation in various neurological and psychiatric patient groups, since understanding the neural basis of specific cognitive subprocesses opens the window to more specifically targeted diagnostic approaches and therapeutic interventions, holding the promise of substantially improved outcomes.

For instance, one avenue for improving the therapy of VA deficits may entail the use of real-time fMRI neurofeedback to support the training of self-alerting strategies, which have proven successful in alleviating attentional deficits after brain damage (Robertson et al., 1995). In fact, it has already been demonstrated that such self-alert training benefits from being combined with an autonomic arousal biofeedback protocol (O'Connell et al., 2008). Another possibility may lie in the treatment of attention-deficit/hyperactivity disorder, where the classic electroencephalography-based neurofeedback methods could be combined with fMRI. This way, learning to selfregulate one's brain activity might be focused not only on relevant electrocortical frequency bands but also on relevant brain structures. Finally, examining the neural correlates of VA dysfunction in different mental disorders may also reveal surprising commonalities across pathophysiological features that in turn suggest the application of established therapeutic approaches for a given condition to other ones. Recently, for example, it has been proposed, in part on physiological grounds, that psychostimulants, being an established treatment for attention-deficit/hyperactivity disorder, could also be useful in the treatment of mania (cf. Hegerl, Himmerich, Engmann, \& Hensch, 2010). 
A deeper understanding of the (neural) mechanisms involved in VA regulation should benefit from simultaneously manipulating several of the key factors that determine performance in VA tasks, such as target salience, task duration, task variability, and incentives. Incorporating these dimensions into the designs of neuroimaging or patient studies has only just begun. On the dependentvariables side, self-report measures have already been developed (e.g., Matthews et al., 2002) to capture multiple dimensions of subjective state, such as perceived fatigue, effort, mind-wandering, and hedonic tone. Future studies may benefit from analyzing both brain-behavior and brain-subjective-state relationships across and within participants. This should also include self-report data collected during neuroimaging sessions, as has been successfully demonstrated for thought probes in studies on mind-wandering (Christoff et al., 2009; Stawarczyk, Majerus, Maquet, \& D'Argembeau, 2011). Integrating multidimensional data on neurobiology, performance, and subjective state should lead to more differentiated and firmer conclusions about the specific functional roles of the brain regions involved in VA (cf. Smallwood, Beach, Schooler, \& Handy, 2008).

Furthermore, apart from interindividual differences, analyzing neural correlates of intraindividual differences in behavior (e.g., the comparison of trials with fast versus slow responses; cf. Drummond et al., 2005) might be revealing. Since increasing time on task is presumably correlated with changes in several variables (e.g., facets of arousal, fatigue, task engagement, or effort investment), the functional interpretation of time-related changes in brain activity might benefit from a moderation analysis approach, which examines how within-subject associations between brain and performance or subjective state are moderated by time on task, including nonlinear relationships (cf. Giambra \& Quilter, 1987).

Another issue concerns the unit of measurement in functional neuroimaging. Assessing both sustained and transient processes simultaneously (e.g., by applying mixed blocked/event-related designs; cf. Donaldson, Petersen, Ollinger, \& Buckner, 2001) may help to differentiate the neural correlates of genuinely tonic versus recurrent phasic processes involved in maintaining VA. To this end, it might also be useful to employ paradigms with event and target rates at intermediate levels: High event rates, as in rapid visual information processing tasks, obviate the separate analysis of brain activity associated with each event and may provide undesirably strong bottom-up stimulation or may produce neural adaptation. Conversely, very low target rates, as in many vigilance tasks, may not yield enough relevant data points for the reliable modeling of target-related brain activity. Furthermore, understanding the neural mechanisms of VA should also profit from moving beyond regional brain activity toward integrating distributed activation patterns by examining functional and effective connectivity between network nodes.

Finally, more studies are needed on time-related performance changes in patients with focal brain damage, since the lesion approach allows inference on regions and their connections that are essential to VA maintenance. These studies, however, need to carefully examine the effects of time since lesion occurrence, since the brain's plasticity might lead to compensatory adaptations that mask the "essentiality" of the damaged area (Rehme, Eickhoff, Wang, Fink, \& Grefkes, 2011). To facilitate connecting results of patient and neuroimaging studies, sophisticated analysis methods such as voxel-based lesion-symptom mapping (Bates et al., 2003) have been developed. Finally, transcranial magnetic stimulation should be used as a complementary approach to study virtual lesion effects in healthy individuals (Chouinard \& Paus, 2010).

\section{Conclusion}

We synthesized current knowledge about the neural mechanisms of human VA, a major attentional function that enables us to stay focused on intellectually simple, monotonous yet attention-demanding tasks. To this end, we combined a coordinate-based meta-analysis of pertinent neuroimaging data with a review of neuroimaging and patient studies of time-ontask effects on VA. The meta-analysis quantitatively tested VA-related regional brain activity for across-study consistency, while the review qualitatively summarized individual studies that tested for time-related changes in regional brain activity or associations between time-related performance decrease and brain lesion site in VA tasks.

Taken together, our analyses and review provided evidence for a mainly right-lateralized cortico-subcortical network subserving VA maintenance. The putative core network comprises dorsomedial, mid- and ventrolateral PFC, anterior insula, and parietal areas (IPS, TPJ), as well as cerebellar vermis, thalamus, basal ganglia (putamen), and midbrain. On the basis of these and previous findings, we conjecture that instead of simply maintaining a steady attentional focus, sustaining VA might rather be conceptualized as a mixture of (a) sustained and/or recurrent top-down processes related to task-set/arousal maintenance and (b) transient bottom-up processes related to the target-driven reorienting of attention. Even though this notion needs further elaboration and empirical testing, the current neurobiological evidence clearly disfavors views that consider VA (or, more generally, sustained attention) a unitary attentional function.

\section{References}

References marked with an asterisk indicate studies included in the meta-analysis.

*Adler, C. M., Sax, K. W., Holland, S. K., Schmithorst, V., Rosenberg, L., \& Strakowski, S. M. (2001). Changes in neuronal activation with increasing attention demand in healthy volunteers: An fMRI study. Synapse, 42, 266-272. doi:10.1002/syn.1112

Alegria, J. (1974). The time course of preparation after a first peak: Some constraints of reacting mechanisms. Quarterly Journal of Experimental Psychology, 26, 622-632. doi:10.1080/14640747408400455

Alexander, M. P., Stuss, D. T., Shallice, T., Picton, T. W., \& Gillingham, S. (2005). Impaired concentration due to frontal lobe damage from two distinct lesion sites. Neurology, 65, 572-579. doi:10.1212/01.wnl .0000172912 .07640 .92

Allen, M. (1983). Models of hemispheric specialization. Psychological Bulletin, 93, 73-104. doi:10.1037/0033-2909.93.1.73

Amunts, K., Malikovic, A., Mohlberg, H., Schormann, T., \& Zilles, K. (2000). Brodmann's areas 17 and 18 brought into stereotaxic spaceWhere and how variable? NeuroImage, 11, 66-84. doi:10.1006/nimg .1999 .0516

Amunts, K., Schleicher, A., Bürgel, U., Mohlberg, H., Uylings, H. B., \& Zilles, K. (1999). Broca's region revisited: Cytoarchitecture and intersubject variability. Journal of Comparative Neurology, 412, 319-341. 
doi:10.1002/(SICI)1096-9861(19990920)412:2<319::AID-CNE10>3.0 . $\mathrm{CO} ; 2-7$

Aston-Jones, G., \& Cohen, J. D. (2005). An integrative theory of locus coeruleus-norepinephrine function: Adaptive gain and optimal performance. Annual Review of Neuroscience, 28, 403-450. doi:10.1146/ annurev.neuro.28.061604.135709

Augustine, J. R. (1996). Circuitry and functional aspects of the insular lobe in primates including humans. Brain Research Reviews, 22, 229-244. doi:10.1016/S0165-0173(96)00011-2

*Ayalon, L., Ancoli-Israel, S., Aka, A. A., McKenna, B. S., \& Drummond, S. P. (2009). Relationship between obstructive sleep apnea severity and brain activation during a sustained attention task. Sleep, 32, 373-381.

Bates, E., Wilson, S. M., Saygin, A. P., Dick, F., Sereno, M. I., Knight, R. T., \& Dronkers, N. F. (2003). Voxel-based lesion-symptom mapping. Nature Neuroscience, 6, 448-450. doi:10.1038/nn1050

Beck, D. M., \& Kastner, S. (2009). Top-down and bottom-up mechanisms in biasing competition in the human brain. Vision Research, 49, 11541165. doi:10.1016/j.visres.2008.07.012

*Belin, P., McAdams, S., Smith, B., Savel, S., Thivard, L., Samson, S., \& Samson, Y. (1998). The functional anatomy of sound intensity discrimination. Journal of Neuroscience, 18, 6388-6394.

*Belin, P., McAdams, S., Thivard, L., Smith, B., Savel, S., Zilbovicius, M., ... Samson, Y. (2002). The neuroanatomical substrate of sound duration discrimination. Neuropsychologia, 40, 1956-1964. doi:10.1016/S00283932(02)00062-3

Bellgrove, M. A., Hawi, Z., Kirley, A., Gill, M., \& Robertson, I. H. (2005). Dissecting the attention deficit hyperactivity disorder (ADHD) phenotype: Sustained attention, response variability and spatial attentional asymmetries in relation to dopamine transporter (DAT1) genotype. Neuropsychologia, 43, 1847-1857. doi:10.1016/j.neuropsychologia .2005.03.011

*Benedict, R. H., Lockwood, A. H., Shucard, J. L., Shucard, D. W., Wack, D., \& Murphy, B. W. (1998). Functional neuroimaging of attention in the auditory modality. NeuroReport, 9, 121-126. doi:10.1097/ 00001756-199801050-00024

*Benedict, R. H., Shucard, D. W., Santa Maria, M. P., Shucard, J. L., Abara, J. P., Coad, M. L., . . . Lockwood, A. (2002). Covert auditory attention generates activation in the rostral/dorsal anterior cingulate cortex. Journal of Cognitive Neuroscience, 14, 637-645. doi:10.1162/ 08989290260045765

Bertelson, P., \& Joffe, R. (1963). Blockings in prolonged serial responding. Ergonomics, 6, 109-116. doi:10.1080/00140136308930682

Bisley, J. W., \& Goldberg, M. E. (2010). Attention, intention, and priority in the parietal lobe. Annual Review of Neuroscience, 33, 1-21. doi: 10.1146/annurev-neuro-060909-152823

Boksem, M. A., \& Tops, M. (2008). Mental fatigue: Costs and benefits. Brain Research Reviews, 59, 125-139. doi:10.1016/j.brainresrev.2008 .07 .001

Brass, M., Derrfuss, J., Forstmann, B., \& von Cramon, D. Y. (2005). The role of the inferior frontal junction area in cognitive control. Trends in Cognitive Sciences, 9, 314-316. doi:10.1016/j.tics.2005.05 .001

Brass, M., \& Haggard, P. (2007). To do or not to do: The neural signature of self-control. Journal of Neuroscience, 27, 9141-9145. doi:10.1523/ JNEUROSCI.0924-07.2007

Breckel, T. P., Giessing, C., \& Thiel, C. M. (2011). Impact of brain networks involved in vigilance on processing irrelevant visual motion. NeuroImage, 55, 1754-1762. doi:10.1016/j.neuroimage.2011.01.025

Briand, L. A., Gritton, H., Howe, W. M., Young, D. A., \& Sarter, M. (2007). Modulators in concert for cognition: Modulator interactions in the prefrontal cortex. Progress in Neurobiology, 83, 69-91. doi: 10.1016/j.pneurobio.2007.06.007
Buchsbaum, M. S., Nuechterlein, K. H., Haier, R. J., Wu, J., Sicotte, N., Hazlett, E., . . . Guich, S. (1990). Glucose metabolic rate in normals and schizophrenics during the Continuous Performance Test assessed by positron emission tomography. British Journal of Psychiatry, 156, $216-$ 227. doi:10.1192/bjp.156.2.216

Burle, B., Tandonnet, C., \& Hasbroucq, T. (2010). Excitatory and inhibitory motor mechanisms of temporal preparation. In A. C. Nobre \& J. T. Coull (Eds.), Attention and time (pp. )243-255. Oxford, England: Oxford University Press. doi:10.1093/acprof:oso/9780199563456.003.0018 *Cabeza, R., Dolcos, F., Prince, S. E., Rice, H. J., Weissman, D. H., \& Nyberg, L. (2003). Attention-related activity during episodic memory retrieval: A cross-function fMRI study. Neuropsychologia, 41, 390-399. doi:10.1016/S0028-3932(02)00170-7

Cabeza, R., \& Nyberg, L. (2000). Imaging cognition II: An empirical review of 275 PET and fMRI studies. Journal of Cognitive Neuroscience, 12, 1-47. doi:10.1162/08989290051137585

Caspers, S., Geyer, S., Schleicher, A., Mohlberg, H., Amunts, K., \& Zilles, K. (2006). The human inferior parietal cortex: Cytoarchitectonic parcellation and interindividual variability. NeuroImage, 33, 430-448. doi: 10.1016/j.neuroimage.2006.06.054

Cavina-Pratesi, C., Valyear, K. F., Culham, J. C., Kohler, S., Obhi, S. S., Marzi, C. A., \& Goodale, M. A. (2006). Dissociating arbitrary stimulus-response mapping from movement planning during preparatory period: Evidence from event-related functional magnetic resonance imaging. Journal of Neuroscience, 26, 2704-2713. doi:10.1523/ JNEUROSCI.3176-05.2006

Chen, C.-Y., Muggleton, N. G., Tzeng, O. J., Hung, D. L., \& Juan, C.-H. (2009). Control of prepotent responses by the superior medial frontal cortex. NeuroImage, 44, 537-545. doi:10.1016/j.neuroimage.2008.09 005

Cheyne, J. A., Solman, G. J., Carriere, J. S., \& Smilek, D. (2009). Anatomy of an error: A bidirectional state model of task engagement/ disengagement and attention-related errors. Cognition, 111, 98-113. doi:10.1016/j.cognition.2008.12.009

Chikazoe, J., Jimura, K., Asari, T., Yamashita, K., Morimoto, H., Hirose, S., . . Konishi, S. (2009). Functional dissociation in right inferior frontal cortex during performance of go/no-go task. Cerebral Cortex, 19, 146 152. doi: $10.1093 /$ cercor/bhn065

Choi, H. J., Zilles, K., Mohlberg, H., Schleicher, A., Fink, G. R. Armstrong, E., \& Amunts, K. (2006). Cytoarchitectonic identification and probabilistic mapping of two distinct areas within the anterior ventral bank of the human intraparietal sulcus. Journal of Comparative Neurology, 495, 53-69. doi:10.1002/cne.20849

Chouinard, P. A., \& Paus, T. (2010). What have we learned from "perturbing" the human cortical motor system with transcranial magnetic stimulation? Frontiers in Human Neuroscience, 4, 173. doi:10.3389/ fnhum.2010.00173

Christoff, K., Gordon, A. M., Smallwood, J., Smith, R., \& Schooler, J. W. (2009). Experience sampling during fMRI reveals default network and executive system contributions to mind wandering. Proceedings of the National Academy of Sciences of the United States of America, 106, 8719-8724. doi:10.1073/pnas.0900234106

Cieslik, E. C., Zilles, K., Grefkes, C., \& Eickhoff, S. B. (2011). Dynamic interactions in the fronto-parietal network during a manual stimulusresponse compatibility task. NeuroImage, 58, 860-869. doi:10.1016/j neuroimage.2011.05.089

Cohen, R. M., Semple, W. E., Gross, M., Holcomb, H. H., Dowling, M. S., \& Nordahl, T. E. (1988). Functional localization of sustained attention: Comparison to sensory stimulation in the absence of instruction. Neuropsychiatry, Neuropsychology, and Behavioral Neurology, 1, 3-20.

Cohen, R. M., Semple, W. E., Gross, M., King, A. C., \& Nordahl, T. E. (1992). Metabolic brain pattern of sustained auditory discrimination. Experimental Brain Research, 92, 165-172. doi:10.1007/BF00230392 
Conners, C. K. (1994). The Conners Continuous Performance Test. Toronto, Canada: Multi-Health Systems.

Corbetta, M., Patel, G., \& Shulman, G. L. (2008). The reorienting system of the human brain: From environment to theory of mind. Neuron, 58, 306-324. doi:10.1016/j.neuron.2008.04.017

Corbetta, M., \& Shulman, G. L. (2002). Control of goal-directed and stimulus-driven attention in the brain. Nature Reviews Neuroscience, 3, 201-215. doi:10.1038/nrn755

Coslett, H. B., Bowers, D., \& Heilman, K. M. (1987). Reduction in cerebral activation after right hemisphere stroke. Neurology, 37, 957-962. doi: 10.1212/WNL.37.6.957

Coull, J. T. (1998). Neural correlates of attention and arousal: Insights from electrophysiology, functional neuroimaging and psychopharmacology. Progress in Neurobiology, 55, 343-361. doi:10.1016/S03010082(98)00011-2

Coull, J. T., Frackowiak, R. S. J., \& Frith, C. D. (1998). Monitoring for target objects: Activation of right frontal and parietal cortices with increasing time on task. Neuropsychologia, 36, 1325-1334. doi:10.1016/ S0028-3932(98)00035-9

*Coull, J. T., \& Frith, C. D. (1998). Differential activation of right superior parietal cortex and intraparietal sulcus by spatial and nonspatial attention. NeuroImage, 8, 176-187. doi:10.1006/nimg.1998 .0354

*Coull, J. T., Frith, C. D., Dolan, R. J., Frackowiak, R. S., \& Grasby, P. M. (1997). The neural correlates of the noradrenergic modulation of human attention, arousal and learning. European Journal of Neuroscience, 9, 589-598. doi:10.1111/j.1460-9568.1997.tb01635.x

*Coull, J. T., Frith, C. D., Frackowiak, R. S., \& Grasby, P. M. (1996). A fronto-parietal network for rapid visual information processing: A PET study of sustained attention and working memory. Neuropsychologia, 34, 1085-1095. doi:10.1016/0028-3932(96)00029-2

Coull, J. T., \& Nobre, A. C. (1998). Where and when to pay attention: The neural systems for directing attention to spatial locations and to time intervals as revealed by both PET and fMRI. Journal of Neuroscience, $18,7426-7435$

Coull, J. T., \& Nobre, A. C. (2008). Dissociating explicit timing from temporal expectation with fMRI. Current Opinion in Neurobiology, 18, 137-144. doi:10.1016/j.conb.2008.07.011

Craig, A. D. (2002). How do you feel? Interoception: The sense of the physiological condition of the body. Nature Reviews Neuroscience, 3, 655-666. doi:10.1038/nrn894

Critchley, H. D., Corfield, D. R., Chandler, M. P., Mathias, C. J., \& Dolan, R. J. (2000). Cerebral correlates of autonomic cardiovascular arousal: A functional neuroimaging investigation in humans. Journal of Physiology, 523, 259-270. doi:10.1111/j.1469-7793.2000.t01-1-00259.x

Critchley, H. D., Wiens, S., Rotshtein, P., Öhman, A., \& Dolan, R. J. (2004). Neural systems supporting interoceptive awareness. Nature Neuroscience, 7, 189-195. doi:10.1038/nn1176

Csikszentmihalyi, M. (1975). Beyond boredom and anxiety: Experiencing flow in work and play. San Francisco, CA: Jossey-Bass.

Cui, X., Stetson, C., Montague, P. R., \& Eagleman, D. M. (2009). Ready ... go: Amplitude of the fMRI signal encodes expectation of cue arrival time. PLoS Biology, 7, e1000167. doi:10.1371/journal.pbio .1000167

Cunnington, R., Windischberger, C., \& Moser, E. (2005). Premovement activity of the pre-supplementary motor area and the readiness for action: Studies of time-resolved event-related functional MRI. $\mathrm{Hu}$ man Movement Science, 24, 644-656. doi:10.1016/j.humov.2005.10 .001

Danielmeier, C., Eichele, T., Forstmann, B. U., Tittgemeyer, M., \& Ullsperger, M. (2011). Posterior medial frontal cortex activity predicts post-error adaptations in task-related visual and motor areas. Journal of Neuroscience, 31, 1780-1789. doi:10.1523/JNEUROSCI .4299-10.2011
Danielmeier, C., \& Ullsperger, M. (2011). Post-error adjustments. Frontiers in Psychology, 2, 233. doi:10.3389/fpsyg.2011.00233

Davies, D. R., \& Parasuraman, R. (1982). The psychology of vigilance. San Diego, CA: Academic Press.

Demeter, E., Hernandez-Garcia, L., Sarter, M., \& Lustig, C. (2011). Challenges to attention: A continuous arterial spin labeling (ASL) study of the effects of distraction on sustained attention. Neurolmage, 54, 1518-1529. doi:10.1016/j.neuroimage.2010.09.026

Diedrichsen, J., Balsters, J. H., Flavell, J., Cussans, E., \& Ramnani, N (2009). A probabilistic MR atlas of the human cerebellum. NeuroImage, 46, 39-46. doi:10.1016/j.neuroimage.2009.01.045

Diedrichsen, J., Verstynen, T., Lehman, S. L., \& Ivry, R. B. (2005) Cerebellar involvement in anticipating the consequences of selfproduced actions during bimanual movements. Journal of Neurophysiology, 93, 801-812. doi:10.1152/jn.00662.2004

Donaldson, D. I., Petersen, S. E., Ollinger, J. M., \& Buckner, R. L. (2001). Dissociating state and item components of recognition memory using fMRI. Neurolmage, 13, 129-142. doi:10.1006/nimg.2000 .0664

Dosenbach, N. U., Fair, D. A., Miezin, F. M., Cohen, A. L., Wenger, K. K., Dosenbach, R. A., . . Petersen, S. E. (2007). Distinct brain networks for adaptive and stable task control in humans. Proceedings of the National Academy of Sciences of the United States of America, 104, 1107311078. doi:10.1073/pnas.0704320104

Dosenbach, N. U., Visscher, K. M., Palmer, E. D., Miezin, F. M., Wenger, K. K., Kang, H. C., . . Petersen, S. E. (2006). A core system for the implementation of task sets. Neuron, 50, 799-812. doi:10.1016/j.neuron .2006 .04 .031

Downar, J., Crawley, A. P., Mikulis, D. J., \& Davis, K. D. (2000). A multimodal cortical network for the detection of changes in the sensory environment. Nature Neuroscience, 3, 277-283. doi:10.1038/72991

Downar, J., Crawley, A. P., Mikulis, D. J., \& Davis, K. D. (2001). The effect of task relevance on the cortical response to changes in visual and auditory stimuli: An event-related fMRI study. NeuroImage, 14, 12561267. doi:10.1006/nimg.2001.0946

Drummond, S. P., Bischoff-Grethe, A., Dinges, D. F., Ayalon, L., Mednick, S. C., \& Meloy, M. J. (2005). The neural basis of the psychomotor vigilance task. Sleep, 28, 1059-1068.

Eckert, M. A., Menon, V., Walczak, A., Ahlstrom, J., Denslow, S., Horwitz, A., \& Dubno, J. R. (2009). At the heart of the ventral attention system: The right anterior insula. Human Brain Mapping, 30, 25302541. doi:10.1002/hbm.20688

Edkins, G., \& Pollock, C. (1997). The influence of sustained attention on railway accidents. Accident Analysis and Prevention, 29, 533-539. doi: 10.1016/S0001-4575(97)00033-X

Egeth, H. E., \& Yantis, S. (1997). Visual attention: Control, representation, and time course. Annual Review of Psychology, 48, 269-297. doi: 10.1146/annurev.psych.48.1.269

Eichele, T., Debener, S., Calhoun, V. D., Specht, K., Engel, A. K., Hugdahl, K., . . . Ullsperger, M. (2008). Prediction of human errors by maladaptive changes in event-related brain networks. Proceedings of the National Academy of Sciences of the United States of America, 105 6173-6178. doi:10.1073/pnas.0708965105

Eickhoff, S. B., \& Bzdok, D. (in press). Meta-analyses in basic and clinical neuroscience: State of the art and perspective. In S. Ulmer \& O. Jansen (Eds.), fMRI: Basics and clinical applications (2nd ed.). Berlin, Germany: Springer.

Eickhoff, S. B., Bzdok, D., Laird, A. R., Kurth, F., \& Fox, P. T. (2012) Activation likelihood estimation meta-analysis revisited. NeuroImage, 59, 2349-2361. doi:10.1016/j.neuroimage.2011.09.017

Eickhoff, S. B., Bzdok, D., Laird, A. R., Roski, C., Caspers, S., Zilles, K., \& Fox, P. T. (2011). Co-activation patterns distinguish cortical modules, their connectivity and functional differentiation. NeuroImage, 57, 938 949. doi:10.1016/j.neuroimage.2011.05.021 
Eickhoff, S. B., Laird, A. R., Grefkes, C., Wang, L. E., Zilles, K., \& Fox, P. T. (2009). Coordinate-based activation likelihood estimation metaanalysis of neuroimaging data: A random-effects approach based on empirical estimates of spatial uncertainty. Human Brain Mapping, 30, 2907-2926. doi:10.1002/hbm.20718

Eickhoff, S. B., Paus, T., Caspers, S., Grosbras, M. H., Evans, A. C., Zilles, K., \& Amunts, K. (2007). Assignment of functional activations to probabilistic cytoarchitectonic areas revisited. NeuroImage, 36, 511521. doi:10.1016/j.neuroimage.2007.03.060

Eickhoff, S. B., Pomjanski, W., Jakobs, O., Zilles, K., \& Langner, R. (2011). Neural correlates of developing and adapting behavioural biases in speeded choice reactions: An fMRI study on predictive motor coding. Cerebral Cortex, 21, 1178-1191. doi:10.1093/cercor/bhq188

Eickhoff, S. B., Stephan, K. E., Mohlberg, H., Grefkes, C., Fink, G. R., Amunts, K., \& Zilles, K. (2005). A new SPM toolbox for combining probabilistic cytoarchitectonic maps and functional imaging data. NeuroImage, 25, 1325-1335. doi:10.1016/j.neuroimage.2004.12.034

*Eyler, L. T., Olsen, R. K., Jeste, D. V., \& Brown, G. G. (2004). Abnormal brain response of chronic schizophrenia patients despite normal performance during a visual vigilance task. Psychiatry Research: Neuroimaging, 130, 245-257. doi:10.1016/j.pscychresns.2004.01.003

*Fassbender, C., Murphy, K., Foxe, J. J., Wylie, G. R., Javitt, D. C., Robertson, I. H., \& Garavan, H. (2004). A topography of executive functions and their interactions revealed by functional magnetic resonance imaging. Cognitive Brain Research, 20, 132-143. doi:10.1016/j .cogbrainres.2004.02.007

Fischer, T., Langner, R., Birbaumer, N., \& Brocke, B. (2008). Arousal and attention: Self-chosen stimulation optimizes cortical excitability and minimizes compensatory effort. Journal of Cognitive Neuroscience, 20, 1443-1453. doi:10.1162/jocn.2008.20101

Fischer, T., Langner, R., Diers, K., Brocke, B., \& Birbaumer, N. (2010). Temporo-spatial dynamics of event-related EEG beta activity during the initial contingent negative variation. PLOS ONE, 5, e12514. doi:10.1371/ journal.pone.0012514

Fiset, P., Paus, T., Daloze, T., Plourde, G., Meuret, P., Bonhomme, V., . . . Evans, A. C. (1999). Brain mechanisms of propofol-induced loss of consciousness in humans: A positron emission tomographic study. Journal of Neuroscience, 19, 5506-5513.

Folk, C. L., Remington, R. W., \& Johnston, J. C. (1992). Involuntary covert orienting is contingent on attentional control settings. Journal of Experimental Psychology: Human Perception and Performance, 18, 1030-1044. doi:10.1037/0096-1523.18.4.1030

Frankenhaeuser, M., \& Gardell, B. (1976). Underload and overload in working life: Outline of a multidisciplinary approach. Journal of Human Stress, 2, 35-46. doi:10.1080/0097840X.1976.9936068

Friederici, A. D. (2002). Towards a neural basis of auditory sentence processing. Trends in Cognitive Sciences, 6, 78-84. doi:10.1016/S13646613(00)01839-8

*Gamma, A., Buck, A., Berthold, T., \& Vollenweider, F. X. (2001). No difference in brain activation during cognitive performance between ecstasy (3,4-methylenedioxymethamphetamine) users and control subjects: A [(H2O)-O-15]-positron emission tomography study. Journal of Clinical Psychopharmacology, 21, 66-71. doi:10.1097/00004714200102000-00012

Geyer, S. (2004). Advances in Anatomy, Embryology and Cell Biology: Vol. 174. The microstructural border between the motor and the cognitive domain in the human cerebral cortex. Berlin, Germany: SpringerVerlag. doi:10.1007/978-3-642-18910-4

Giambra, L. M., \& Quilter, R. E. (1987). A two-term exponential functional description of the time course of sustained attention. Human Factors, 29, 635-643.

Giessing, C., Thiel, C. M., Rösler, F., \& Fink, G. R. (2006). The modulatory effects of nicotine on parietal cortex activity in a cued target detection task depend on cue reliability. Neuroscience, 137, 853-864. doi:10.1016/j.neuroscience.2005.10.005

*Gilbert, S. J., Simons, J. S., Frith, C. D., \& Burgess, P. W. (2006). Performance-related activity in medial rostral prefrontal cortex (area 10) during low-demand tasks. Journal of Experimental Psychology: Human Perception and Performance, 32, 45-58. doi:10.1037/0096-1523.32 .1 .45

*Gitelman, D. R., Alpert, N. M., Kosslyn, S., Daffner, K., Scinto, L., Thompson, W., \& Mesulam, M. M. (1996). Functional imaging of human right hemispheric activation for exploratory movements. Annals of Neurology, 39, 174-179. doi:10.1002/ana.410390206

Godefroy, O., Lhullier-Lamy, C., \& Rousseaux, M. (2002). SRT lengthening: Role of an alertness deficit in frontal damaged patients. Neuropsychologia, 40, 2234-2241. doi:10.1016/S0028-3932(02)00109-4

*Goldstein, R. Z., Tomasi, D., Alia-Klein, N., Zhang, L., Telang, F., \& Volkow, N. D. (2007). The effect of practice on a sustained attention task in cocaine abusers. Neurolmage, 35, 194-206. doi:10.1016/j neuroimage.2006.12.004

Gottsdanker, R. (1975). The attaining and maintaining of preparation. In P. M. A. Rabbitt \& S. Dornic (Eds.), Attention and performance $V$ (pp. 33-42). London, England: Academic Press.

Green, M. F. (1996). What are the functional consequences of neurocognitive deficits in schizophrenia? American Journal of Psychiatry, 153, 321-330.

Greene, C. M., Bellgrove, M. A., Gill, M., \& Robertson, I. H. (2009) Noradrenergic genotype predicts lapses in sustained attention. Neuropsychologia, 47, 591-594. doi:10.1016/j.neuropsychologia.2008.10.003

Grier, R. A., Warm, J. S., Dember, W. N., Matthews, G., Galinsky, T. L., Szalma, J. L., \& Parasuraman, R. (2003). The vigilance decrement reflects limitations in effortful attention, not mindlessness. Human Factors, 45, 349-359. doi:10.1518/hfes.45.3.349.27253

*Habel, U., Koch, K., Pauly, K., Kellermann, T., Reske, M., Backes, V., . . S Schneider, F. (2007). The influence of olfactory-induced negative emotion on verbal working memory: Individual differences in neurobehavioral findings. Brain Research, 1152, 158-170. doi:10.1016/j .brainres.2007.03.048

Hagger, M. S., Wood, C., Stiff, C., \& Chatzisarantis, N. L. (2010). Ego depletion and the strength model of self-control: A meta-analysis. Psychological Bulletin, 136, 495-525. doi:10.1037/a0019486

Hartstra, E., Kühn, S., Verguts, T., \& Brass, M. (2011). The implementation of verbal instructions: An fMRI study. Human Brain Mapping, 32, 1811-1824. doi:10.1002/hbm.21152

Hasselmo, M. E., \& Sarter, M. (2011). Modes and models of forebrain cholinergic neuromodulation of cognition. Neuropsychopharmacology, 36, 52-73. doi:10.1038/npp.2010.104

Haynes, J. D., Sakai, K., Rees, G., Gilbert, S., Frith, C., \& Passingham, R. E. (2007). Reading hidden intentions in the human brain. Current Biology, 17, 323-328. doi:10.1016/j.cub.2006.11.072

Hegerl, U., Himmerich, H., Engmann, B., \& Hensch, T. (2010). Mania and attention-deficit/hyperactivity disorder: Common symptomatology, common pathophysiology and common treatment? Current Opinion in Psychiatry, 23, 1-7. doi:10.1097/YCO.0b013e328331f694

Heilman, K. M., \& Van Den Abell, T. (1979). Right hemispheric dominance for mediating cerebral activation. Neuropsychologia, 17, 315321. doi:10.1016/0028-3932(79)90077-0

Helton, W. S., Hollander, T. D., Warm, J. S., Matthews, G., Dember, W. N., \& Hancock, P. A. (2005). Signal regularity and the mindlessness model of vigilance. British Journal of Psychology, 96, 249-261. doi 10.1348/000712605X38369

Helton, W. S., Hollander, T. D., Warm, J. S., Tripp, L. D., Parsons, K., Matthews, G., . . Hancock, P. A. (2007). The abbreviated vigilance task and cerebral hemodynamics. Journal of Clinical and Experimental Neuropsychology, 29, 545-552. doi:10.1080/13803390600814757 
Helton, W. S., \& Russell, P. N. (2011a). Feature absence-presence and two theories of lapses of sustained attention. Psychological Research, 75, 384-392. doi:10.1007/s00426-010-0316-1

Helton, W. S., \& Russell, P. N. (2011b). Working memory load and the vigilance decrement. Experimental Brain Research, 212, 429-437. doi: 10.1007/s00221-011-2749-1

Helton, W. S., \& Warm, J. S. (2008). Signal salience and the mindlessness theory of vigilance. Acta Psychologica, 129, 18-25. doi:10.1016/j .actpsy.2008.04.002

Helton, W. S., Warm, J. S., Tripp, L. D., Matthews, G., Parasuraman, R., $\&$ Hancock, P. A. (2010). Cerebral lateralization of vigilance: A function of task difficulty. Neuropsychologia, 48, 1683-1688. doi:10.1016/j .neuropsychologia.2010.02.014

Henderson, L., \& Dittrich, W. H. (1998). Preparing to react in the absence of uncertainty: I. New perspectives on simple reaction time. British Journal of Psychology, 89, 531-554. doi:10.1111/j.2044-8295.1998 .tb02702.x

*Herath, P., Klingberg, T., Young, J., Amunts, K., \& Roland, P. (2001). Neural correlates of dual task interference can be dissociated from those of divided attention: An fMRI study. Cerebral Cortex, 11, 796-805. doi:10.1093/cercor/11.9.796

Hitchcock, E. M., Warm, J. S., Matthews, G., Dember, W. N., Shear, P. K., Tripp, L. D., . . Parasuraman, R. (2003). Automation cueing modulates cerebral blood flow and vigilance in a simulated air traffic control task. Theoretical Issues in Ergonomics Science, 4, 89-112. doi:10.1080/ 14639220210159726

Hockey, G. R. J. (1986). A state control theory of adaptation to stress and individual differences in stress management. In G. R. J. Hockey, A. W. K. Gaillard, \& M. G. H. Coles (Eds.), Energetics and human information processing (pp. 285-298). Dordrecht, the Netherlands: Martinus Nijhoff. doi:10.1007/978-94-009-4448-0_19

Hockey, G. R. J. (1997). Compensatory control in the regulation of human performance under stress and high workload: A cognitive-energetical framework. Biological Psychology, 45, 73-93. doi:10.1016/S03010511(96)05223-4

Hockey, G. R. J., Coles, M. G. H., \& Gaillard, A. W. K. (1986). Energetical issues in research on human information processing. In G. R. J. Hockey, A. W. K. Gaillard, \& M. G. H. Coles (Eds.), Energetics and human information processing (pp. 3-21). Dordrecht, the Netherlands: Martinus Nijhoff. doi:10.1007/978-94-009-4448-0_1

Hofle, N., Paus, T., Reutens, D., Fiset, P., Gotman, J., Evans, A. C., \& Jones, B. E. (1997). Regional cerebral blood flow changes as a function of delta and spindle activity during slow wave sleep in humans. Journal of Neuroscience, 17, 4800-4808.

*Holcomb, H. H., Medoff, D. R., Caudill, P. J., Zhao, Z., Lahti, A. C., Dannals, R. F., \& Tamminga, C. A. (1998). Cerebral blood flow relationships associated with a difficult tone recognition task in trained normal volunteers. Cerebral Cortex, 8, 534-542. doi:10.1093/cercor/8 .6 .534

*Honey, G. D., Pomarol-Clotet, E., Corlett, P. R., Honey, R. A., McKenna, P. J., Bullmore, E. T., \& Fletcher, P. C. (2005). Functional dysconnectivity in schizophrenia associated with attentional modulation of motor function. Brain, 128, 2597-2611. doi:10.1093/brain/awh632

*Hong, L. E., Schroeder, M., Ross, T. J., Buchholz, B., Salmeron, B. J., Wonodi, I., . . Stein, E. A. (2011). Nicotine enhances but does not normalize visual sustained attention and the associated brain network in schizophrenia. Schizophrenia Bulletin, 37, 416-425. doi:10.1093/ schbul/sbp089

Hoptman, M. J., \& Davidson, R. J. (1994). How and why do the two cerebral hemispheres interact? Psychological Bulletin, 116, 195-219. doi:10.1037/0033-2909.116.2.195

*Horn, H., Syed, N., Lanfermann, H., Maurer, K., \& Dierks, T. (2003). Cerebral networks linked to the event-related potential P300. European
Archives of Psychiatry and Clinical Neuroscience, 253, 154-159. doi 10.1007/s00406-003-0419-4

Howes, D., \& Boller, F. (1975). Simple reaction time: Evidence for focal impairment from lesions of the right hemisphere. Brain, 98, 317-332. doi:10.1093/brain/98.2.317

Hülsmann, E., Erb, M., \& Grodd, W. (2003). From will to action: Sequential cerebellar contributions to voluntary movement. NeuroImage, 20, 1485-1492. doi:10.1016/S1053-8119(03)00307-0

Humphreys, M. S., \& Revelle, W. (1984). Personality, motivation, and performance: A theory of the relationship between individual differences and information processing. Psychological Review, 91, 153-184. doi: 10.1037/0033-295X.91.2.153

Husain, M., \& Rorden, C. (2003). Non-spatially lateralized mechanisms in hemispatial neglect. Nature Reviews Neuroscience, 4, 26-36. doi: 10.1038/nrn1005

Jakobs, O., Langner, R., Caspers, S., Roski, C., Cieslik, E. C., Zilles, K., . . Eickhoff, S. B. (2012). Across-study and within-subject functional connectivity of a right temporo-parietal junction subregion involved in stimulus-context integration. NeuroImage, 60, 2389-2398. doi: 10.1016/j.neuroimage.2012.02.037

Janssen, P., \& Shadlen, M. N. (2005). A representation of the hazard rate of elapsed time in macaque area LIP. Nature Neuroscience, 8, 234-241. doi: $10.1038 / \mathrm{nn} 1386$

Jennings, J. R., \& van der Molen, M. W. (2005). Preparation for speeded action as a psychophysiological concept. Psychological Bulletin, 131, 434-459. doi:10.1037/0033-2909.131.3.434

Jennings, R. G., \& Van Horn, J. D. (2012). Publication bias in neuroimaging research: Implications for meta-analyses. Neuroinformatics, 10 , 67-80. doi:10.1007/s12021-011-9125-y

*Johannsen, P., Jakobsen, J., Bruhn, P., Hansen, S. B., Gee, A., StodkildeJorgensen, H., \& Gjedde, A. (1997). Cortical sites of sustained and divided attention in normal elderly humans. NeuroImage, 6, 145-155. doi:10.1006/nimg.1997.0292

Johansson, G., Aronsson, G., \& Lindström, B. O. (1978). Social psychological and neuroendocrine stress reactions in highly mechanised work Ergonomics, 21, 583-599. doi:10.1080/00140137808931761

Jones, B. E. (2003). Arousal systems. Frontiers in Bioscience, 8, s438451. doi: $10.2741 / 1074$

Kahneman, D. (1973). Attention and effort. Englewood Cliffs, NJ: Prentice Hall.

*Kansaku, K., Hanakawa, T., Wu, T., \& Hallett, M. (2004). A shared neural network for simple reaction time. NeuroImage, 22, 904-911. doi:10.1016/j.neuroimage.2004.02.006

*Kawashima, R., Satoh, K., Itoh, H., Ono, S., Furumoto, S., Gotoh, R., . . . Fukuda, H. (1996). Functional anatomy of GO/NO-GO discrimination and response selection-A PET study in man. Brain Research, 728, 79-89. doi:10.1016/0006-8993(96)00389-7

Kiefer, M., \& Martens, U. (2010). Attentional sensitization of unconscious cognition: Task sets modulate subsequent masked semantic priming Journal of Experimental Psychology: General, 139, 464-489. doi: 10.1037/a0019561

*Kim, J., Whyte, J., Wang, J., Rao, H., Tang, K. Z., \& Detre, J. A. (2006) Continuous ASL perfusion fMRI investigation of higher cognition Quantification of tonic CBF changes during sustained attention and working memory tasks. NeuroImage, 31, 376-385. doi:10.1016/j neuroimage.2005.11.035

Kincade, J. M., Abrams, R. A., Astafiev, S. V., Shulman, G. L., \& Corbetta, M. (2005). An event-related functional magnetic resonance imaging study of voluntary and stimulus-driven orienting of attention. Journal of Neuroscience, 25, 4593-4604. doi:10.1523/JNEUROSCI .0236-05.2005

Kinomura, S., Larsson, J., Gulyas, B., \& Roland, P. E. (1996). Activation by attention of the human reticular formation and thalamic intralaminar nuclei. Science, 271, 512-515. doi:10.1126/science.271.5248.512 
Knutson, B., \& Greer, S. M. (2008). Anticipatory affect: Neural correlates and consequences for choice. Philosophical Transactions of the Royal Society of London Series B: Biological Sciences, 363, 3771-3786. doi: 10.1098/rstb.2008.0155

Kobayashi, Y., \& Isa, T. (2002). Sensory-motor gating and cognitive control by the brainstem cholinergic system. Neural Networks, 15, 731-741. doi:10.1016/S0893-6080(02)00059-X

*Koch, K., Pauly, K., Kellermann, T., Seiferth, N. Y., Reske, M., Backes, V., . . Habel, U. (2007). Gender differences in the cognitive control of emotion: An fMRI study. Neuropsychologia, 45, 2744-2754. doi: 10.1016/j.neuropsychologia.2007.04.012

Koelega, H. S. (1993). Stimulant drugs and vigilance performance: A review. Psychopharmacology, 111, 1-16. doi:10.1007/BF02257400

Koski, L., \& Petrides, M. (2001). Time-related changes in task performance after lesions restricted to the frontal cortex. Neuropsychologia, 39, 268-281. doi:10.1016/S0028-3932(00)00110-X

Kosslyn, S. M., \& Koenig, O. (1992). Wet mind: The new cognitive neuroscience. New York, NY: Free Press.

Kozak, R., Bruno, J. P., \& Sarter, M. (2006). Augmented prefrontal acetylcholine release during challenged attentional performance. Cerebral Cortex, 16, 9-17. doi:10.1093/cercor/bhi079

*Krug, A., Markov, V., Eggermann, T., Krach, S., Zerres, K., Stocker, T., . . Kircher, T. (2008). Genetic variation in the schizophrenia-risk gene neuregulin1 correlates with differences in frontal brain activation in a working memory task in healthy individuals. Neurolmage, 42, 15691576. doi:10.1016/j.neuroimage.2008.05.058

Kurth, F., Zilles, K., Fox, P. T., Laird, A. R., \& Eickhoff, S. B. (2010). A link between the systems: Functional differentiation and integration within the human insula revealed by meta-analysis. Brain Structure and Function, 214, 519-534. doi:10.1007/s00429-010-0255-z

Ladavas, E. (1987). Is the hemispatial deficit produced by right parietal lobe damage associated with retinal or gravitational coordinates? Brain, 110, 167-180. doi:10.1093/brain/110.1.167

Lancaster, J. L., Tordesillas-Gutierrez, D., Martinez, M., Salinas, F., Evans, A., Zilles, K., . . . Fox, P. T. (2007). Bias between MNI and Talairach coordinates analyzed using the ICBM-152 brain template. Human Brain Mapping, 28, 1194-1205. doi:10.1002/hbm.20345

Langner, R., Eickhoff, S. B., \& Steinborn, M. B. (2011). Mental fatigue modulates dynamic adaptation to perceptual demand in speeded detection. PLoS ONE, 6,, e28399. doi:10.1371/journal.pone.0028399

Langner, R., Kellermann, T., Boers, F., Sturm, W., Willmes, K., \& Eickhoff, S. B. (2011). Modality-specific perceptual expectations selectively modulate baseline activity in auditory, somatosensory, and visual cortices. Cerebral Cortex, 21, 2850-2862. doi:10.1093/cercor/bhr083

*Langner, R., Kellermann, T., Eickhoff, S. B., Boers, F., Chatterjee, A., Willmes, K., \& Sturm, W. (2012). Staying responsive to the world: Modality-specific and -nonspecific contributions to speeded auditory, tactile, and visual stimulus detection. Human Brain Mapping, 33, $398-$ 418. doi:10.1002/hbm. 21220

Langner, R., Steinborn, M. B., Chatterjee, A., Sturm, W., \& Willmes, K. (2010). Mental fatigue and temporal preparation in simple reaction-time performance. Acta Psychologica, 133, 64-72. doi:10.1016/j.actpsy.2009 .10 .001

Langner, R., Willmes, K., Chatterjee, A., Eickhoff, S. B., \& Sturm, W. (2010). Energetic effects of stimulus intensity on prolonged simple reaction-time performance. Psychological Research, 74, 499-512. doi: 10.1007/s00426-010-0275-6

*Lawrence, N. S., Ross, T. J., Hoffmann, R., Garavan, H., \& Stein, E. A. (2003). Multiple neuronal networks mediate sustained attention. Journal of Cognitive Neuroscience, 15, 1028-1038. doi:10.1162/ 089892903770007416

*Lawrence, N. S., Ross, T. J., \& Stein, E. A. (2002). Cognitive mechanisms of nicotine on visual attention. Neuron, 36, 539-548. doi:10.1016/ S0896-6273(02)01004-8
Lewin, J. S., Friedman, L., Wu, D., Miller, D. A., Thompson, L. A., Klein, S. K., . . Duerk, J. L. (1996). Cortical localization of human sustained attention: Detection with functional MR using a visual vigilance paradigm. Journal of Computer Assisted Tomography, 20, 695-701. doi: 10.1097/00004728-199609000-00002

Lim, J., \& Dinges, D. F. (2008). Sleep deprivation and vigilant attention Annals of the New York Academy of Sciences, 1129, 305-322. doi 10.1196/annals. 1417.002

Lim, J., \& Dinges, D. F. (2010). A meta-analysis of the impact of shortterm sleep deprivation on cognitive variables. Psychological Bulletin 136, 375-389. doi:10.1037/a0018883

*Lim, J., Wu, W. C., Wang, J., Detre, J. A., Dinges, D. F., \& Rao, H. (2010). Imaging brain fatigue from sustained mental workload: An ASL perfusion study of the time-on-task effect. NeuroImage, 49, 3426-3435. doi:10.1016/j.neuroimage.2009.11.020

*Lockwood, A. H., Wack, D. S., Benedict, R. H., Coad, M. L., Sussman, J. E., \& Burkard, R. F. (2008). Multi-site phasic neural activity mediates the execution of an auditory continuous performance task: A PET and electrophysiological study. Journal of Neuroimaging, 18, 364-374. doi: 10.1111/j.1552-6569.2007.00196_1.x

Lorist, M. M., Klein, M., Nieuwenhuis, S., De Jong, R., Mulder, G., \& Meijman, T. F. (2000). Mental fatigue and task control: Planning and preparation. Psychophysiology, 37, 614-625. doi:10.1111/1469-8986 .3750614

Luks, T. L., Simpson, G. V., Feiwell, R. J., \& Miller, W. L. (2002). Evidence for anterior cingulate cortex involvement in monitoring preparatory attentional set. NeuroImage, 17, 792-802. doi:10.1006/nimg .2002 .1210

Mackworth, N. H. (1948). The breakdown of vigilance during prolonged visual search. Quarterly Journal of Experimental Psychology, 1, 6-21. doi:10.1080/17470214808416738

Malhotra, P., Coulthard, E. J., \& Husain, M. (2009). Role of right posterior parietal cortex in maintaining attention to spatial locations over time. Brain, 132, 645-660. doi:10.1093/brain/awn350

Malikovic, A., Amunts, K., Schleicher, A., Mohlberg, H., Eickhoff, S. B., Wilms, M., . . . Zilles, K. (2007). Cytoarchitectonic analysis of the human extrastriate cortex in the region of $\mathrm{V} 5 / \mathrm{MT}+$ : A probabilistic, stereotaxic map of area hOc5. Cerebral Cortex, 17, 562-574. doi: 10.1093/cercor/bhj181

Manly, T., Owen, A. M., McAvinue, L., Datta, A., Lewis, G. H., Scott, S. K., . . . Robertson, I. H. (2003). Enhancing the sensitivity of a sustained attention task to frontal damage: Convergent clinical and functional imaging evidence. Neurocase, 9, 340-349. doi:10.1076/neur 9.4.340.15553

Manly, T., Robertson, I. H., Galloway, M., \& Hawkins, K. (1999). The absent mind: Further investigations of sustained attention to response Neuropsychologia, 37, 661-670. doi:10.1016/S0028-3932(98)00127-4

*Marklund, P., Fransson, P., Cabeza, R., Petersson, K. M., Ingvar, M., \& Nyberg, L. (2007). Sustained and transient neural modulations in prefrontal cortex related to declarative long-term memory, working memory, and attention. Cortex, 43, 22-37. doi:10.1016/S00109452(08)70443-X

Marois, R., Leung, H. C., \& Gore, J. C. (2000). A stimulus-driven approach to object identity and location processing in the human brain. Neuron, 25, 717-728. doi:10.1016/S0896-6273(00)81073-9

Mars, R. B., Klein, M. C., Neubert, F. X., Olivier, E., Buch, E. R., Boorman, E. D., \& Rushworth, M. F. (2009). Short-latency influence of medial frontal cortex on primary motor cortex during action selection under conflict. Journal of Neuroscience, 29, 6926-6931. doi:10.1523/ JNEUROSCI.1396-09.2009

Matthews, G., Campbell, S. E., Falconer, S., Joyner, L. A., Huggins, J., Gilliland, K., . . . Warm, J. S. (2002). Fundamental dimensions of subjective state in performance settings: Task engagement, distress, and worry. Emotion, 2, 315-340. doi:10.1037/1528-3542.2.4.315 
Matthews, G., \& Westerman, S. J. (1994). Energy and tension as predictors of controlled visual and memory search. Personality and Individual Differences, 17, 617-626. doi:10.1016/0191-8869(94)90134-1

McCormick, D. A. (1992). Neurotransmitter actions in the thalamus and cerebral cortex and their role in neuromodulation of thalamocortical activity. Progress in Neurobiology, 39, 337-388. doi:10.1016/03010082(92)90012-4

Medford, N., \& Critchley, H. D. (2010). Conjoint activity of anterior insular and anterior cingulate cortex: Awareness and response. Brain Structure and Function, 214, 535-549. doi:10.1007/s00429-010-0265-x

Michael, G. A., Garcia, S., Bussy, G., Lion-Francois, L., \& Guibaud, L. (2009). Reactivity to visual signals and the cerebellar vermis: Evidence from a rare case with rhombencephalosynapsis. Behavioral Neuroscience, 123, 86-96. doi:10.1037/a0013726

Mirsky, A. F., Anthony, B. J., Duncan, C. C., Ahearn, M. B., \& Kellam, S. G. (1991). Analysis of the elements of attention: A neuropsychological approach. Neuropsychology Review, 2, 109-145. doi:10.1007/ BF01109051

Mottaghy, F. M., Willmes, K., Horwitz, B., Müller, H. W., Krause, B. J., \& Sturm, W. (2006). Systems level modeling of a neuronal network subserving intrinsic alertness. Neurolmage, 29, 225-233. doi:10.1016/j .neuroimage.2005.07.034

Muraven, M., \& Baumeister, R. F. (2000). Self-regulation and depletion of limited resources: Does self-control resemble a muscle? Psychological Bulletin, 126, 247-259. doi:10.1037/0033-2909.126.2.247

Murtha, S., Chertkow, H., Beauregard, M., Dixon, R., \& Evans, A. (1996). Anticipation causes increased blood flow to the anterior cingulate cortex. Human Brain Mapping, 4, 103-112. doi:10.1002/(SICI)10970193(1996)4:2<103::AID-HBM2>3.0.CO;2-7

Näätänen, R. (1970). The diminishing time-uncertainty with the lapse of time after the warning signal in reaction-time experiments with varying fore-periods. Acta Psychologica, 34, 399-419. doi:10.1016/00016918(70)90035-1

Nachev, P., Kennard, C., \& Husain, M. (2008). Functional role of the supplementary and pre-supplementary motor areas. Nature Reviews Neuroscience, 9, 856-869. doi:10.1038/nrn2478

*Naito, E., Kinomura, S., Geyer, S., Kawashima, R., Roland, P. E., \& Zilles, K. (2000). Fast reaction to different sensory modalities activates common fields in the motor areas, but the anterior cingulate cortex is involved in the speed of reaction. Journal of Neurophysiology, 83, 1701-1709.

Nebel, K., Wiese, H., Stude, P., de Greiff, A., Diener, H. C., \& Keidel, M. (2005). On the neural basis of focused and divided attention. Cognitive Brain Research, 25, 760-776. doi:10.1016/j.cogbrainres.2005.09.011

Niemi, P., \& Näätänen, R. (1981). Foreperiod and simple reaction time. Psychological Bulletin, 89, 133-162. doi:10.1037/0033-2909.89.1.133

Nobre, A. C., Correa, A., \& Coull, J. T. (2007). The hazards of time. Current Opinion in Neurobiology, 17, 465-470. doi:10.1016/j.conb .2007.07.006

Norman, D., \& Shallice, T. (1986). Attention to action: Willed and automatic control of behavior. In R. J. Davidson, G. E. Schwartz, \& D. Shapiro (Eds.), Consciousness and self-regulation (Vol. 4, pp. 1-18). New York, NY: Plenum Press.

O'Connell, R. G., Bellgrove, M. A., Dockree, P. M., Lau, A., Fitzgerald, M., \& Robertson, I. H. (2008). Self-alert training: Volitional modulation of autonomic arousal improves sustained attention. Neuropsychologia, 46, 1379-1390. doi:10.1016/j.neuropsychologia.2007.12.018

*Ogg, R. J., Zou, P., Allen, D. N., Hutchins, S. B., Dutkiewicz, R. M., \& Mulhern, R. K. (2008). Neural correlates of a clinical continuous performance test. Magnetic Resonance Imaging, 26, 504-512. doi:10.1016/ j.mri.2007.09.004

O'Hanlon, J. F. (1981). Boredom: Practical consequences and a theory. Acta Psychologica, 49, 53-82. doi:10.1016/0001-6918(81)90033-0
*Okamura, N., Yanai, K., Higuchi, M., Sakai, J., Iwata, R., Ido, T., . . . Itoh, M. (2000). Functional neuroimaging of cognition impaired by a classical antihistamine, d-chlorpheniramine. British Journal of Pharmacology, 129, 115-123. doi:10.1038/sj.bjp.0702994

O'Keeffe, F. M., Murray, B., Coen, R. F., Dockree, P. M., Bellgrove, M. A., Garavan, H., . . . Robertson, I. H. (2007). Loss of insight in frontotemporal dementia, corticobasal degeneration and progressive supranuclear palsy. Brain, 130, 753-764. doi:10.1093/brain/awl367

*Ortuño, F., Ojeda, N., Arbizu, J., López, P., Martí-Climent, J. M., Peñuelas, I., \& Cervera, S. (2002). Sustained attention in a counting task: Normal performance and functional neuroanatomy. Neurolmage, 17, 411-420. doi:10.1006/nimg.2002.1168

Parasuraman, R. (1984). Sustained attention in detection and discrimination. In R. Parasuraman \& D. R. Davies (Eds.), Varieties of attention (pp. 243-271). Orlando, FL: Academic Press.

Parasuraman, R., Warm, J. S., \& See, J. E. (1998). Brain systems of vigilance. In R. Parasuraman (Ed.), The attentive brain (pp. 221-256). Cambridge, MA: MIT Press.

*Pardo, J. V., Fox, P. T., \& Raichle, M. E. (1991). Localization of a human system for sustained attention by positron emission tomography. Nature, 349, 61-64. doi:10.1038/349061a0

Pattyn, N., Neyt, X., Henderickx, D., \& Soetens, E. (2008). Psychophysiological investigation of vigilance decrement: Boredom or cognitive fatigue? Physiology and Behavior, 93, 369-378. doi:10.1016/j.physbeh 2007.09.016

Paus, T. (2000). Functional anatomy of arousal and attention systems in the human brain. Progress in Brain Research, 126, 65-77. doi:10.1016/ S0079-6123(00)26007-X

Paus, T. (2001). Primate anterior cingulate cortex: Where motor control, drive and cognition interface. Nature Reviews Neuroscience, 2, 417 424. doi:10.1038/35077500

*Paus, T., Zatorre, R. J., Hofle, N., Caramanos, Z., Gotman, J., Petrides, M., \& Evans, A. C. (1997). Time-related changes in neural systems underlying attention and arousal during the performance of an auditory vigilance task. Journal of Cognitive Neuroscience, 9, 392-408. doi: 10.1162/jocn.1997.9.3.392

*Périn, B., Godefroy, O., Fall, S., \& de Marco, G. (2010). Alertness in young healthy subjects: An fMRI study of brain region interactivity enhanced by a warning signal. Brain and Cognition, 72, 271-281. doi:10.1016/j.bandc.2009.09.010

Pfaff, D. W. (2006). Brain arousal and information theory: Neural and genetic mechanisms. Cambridge, MA: Harvard University Press.

Pfaff, D., Ribeiro, A., Matthews, J., \& Kow, L. M. (2008). Concepts and mechanisms of generalized central nervous system arousal. Annals of the New York Academy of Sciences, 1129, 11-25. doi:10.1196/annals.1417 .019

*Pfefferbaum, A., Desmond, J. E., Galloway, C., Menon, V., Glover, G. H., \& Sullivan, E. V. (2001). Reorganization of frontal systems used by alcoholics for spatial working memory: An fMRI study. NeuroImage, 14, 7-20. doi:10.1006/nimg.2001.0785

Picton, T. W., Stuss, D. T., Alexander, M. P., Shallice, T., Binns, M. A., \& Gillingham, S. (2007). Effects of focal frontal lesions on response inhibition. Cerebral Cortex, 17, 826-838. doi:10.1093/cercor/bhk031

Ploran, E. J., Nelson, S. M., Velanova, K., Donaldson, D. I., Petersen, S. E., \& Wheeler, M. E. (2007). Evidence accumulation and the moment of recognition: Dissociating perceptual recognition processes using fMRI Journal of Neuroscience, 27, 11912-11924. doi:10.1523/JNEUROSCI .3522-07.2007

Poffenberger, A. T. (1927). The effects of continuous mental work. American Journal of Psychology, 39, 283-296. doi:10.2307/1415418

Poldrack, R. A. (2006). Can cognitive processes be inferred from neuroimaging data? Trends in Cognitive Sciences, 10, 59-63. doi:10.1016/j tics.2005.12.004 
Pollatos, O., Schandry, R., Auer, D. P., \& Kaufmann, C. (2007). Brain structures mediating cardiovascular arousal and interoceptive awareness. Brain Research, 1141, 178-187. doi:10.1016/j.brainres.2007.01.026

Pollok, B., Gross, J., Kamp, D., \& Schnitzler, A. (2008). Evidence for anticipatory motor control within a cerebello-diencephalic-parietal network. Journal of Cognitive Neuroscience, 20, 828-840. doi:10.1162/ jocn.2008.20506

Portas, C. M., Rees, G., Howseman, A. M., Josephs, O., Turner, R., \& Frith, C. D. (1998). A specific role for the thalamus in mediating the interaction of attention and arousal in humans. Journal of Neuroscience, $18,8979-8989$.

Posner, M. I. (1978). Chronometric explorations of mind. Hillsdale, NJ: Erlbaum.

Posner, M. I. (1993). Interaction of arousal and selection in the posterior attention network. In A. D. Baddeley \& L. Weiskrantz (Eds.), Attention: Selection, awareness, and control. A tribute to Donald Broadbent (pp. 390-405). New York, NY: Clarendon Press.

Posner, M. I., \& Boies, S. J. (1971). Components of attention. Psychological Review, 78, 391-408. doi:10.1037/h0031333

Posner, M. I., Inhoff, A. W., Friedrich, F. J., \& Cohen, A. (1987). Isolating attentional systems: A cognitive-anatomical analysis. Psychobiology, $15,107-121$

Posner, M. I., \& Petersen, S. E. (1990). The attention system of the human brain. Annual Review of Neuroscience, 13, 25-42. doi:10.1146/annurev .ne.13.030190.000325

Ptak, R. (2012). The frontoparietal attention network of the human brain: Action, saliency, and a priority map of the environment. Neuroscientist, 18, 502-515. doi:10.1177/1073858411409051

Raz, A., \& Buhle, J. (2006). Typologies of attentional networks. Nature Reviews Neuroscience, 7, 367-379. doi:10.1038/nrn1903

Rehme, A. K., Eickhoff, S. B., Wang, L. E., Fink, G. R., \& Grefkes, C. (2011). Dynamic causal modeling of cortical activity from the acute to the chronic stage after stroke. NeuroImage, 55, 1147-1158. doi:10.1016/ j.neuroimage.2011.01.014

Requin, J., Brener, J., \& Ring, C. (1991). Preparation for action. In J. R. Jennings \& M. G. H. Coles (Eds.), Handbook of cognitive psychophysiology: Central and autonomic nervous system approaches (pp. 357448). Oxford, England: Wiley.

Richter, D. O., Senter, R. J., \& Warm, J. S. (1981). Effects of the rate and regularity of background events on sustained attention. Bulletin of the Psychonomic Society, 18, 207-210.

Ridderinkhof, K. R., Ullsperger, M., Crone, E. A., \& Nieuwenhuis, S. (2004). The role of the medial frontal cortex in cognitive control. Science, 306, 443-447. doi:10.1126/science.1100301

Robertson, I. H. (2003). The absent mind: Attention and error. The Psychologist, 16, 476-479.

Robertson, I. H., \& Garavan, H. (2004). Vigilant attention. In M. S. Gazzaniga (Ed.), The cognitive neurosciences (3rd ed., pp. 631-640). Cambridge, MA: MIT Press.

Robertson, I. H., Manly, T., Andrade, J., Baddeley, B. T., \& Yiend, J. (1997). "Oops!": performance correlates of everyday attentional failures in traumatic brain injured and normal subjects. Neuropsychologia, 35, 747-758. doi:10.1016/S0028-3932(97)00015-8

Robertson, I. H., Mattingley, J. B., Rorden, C., \& Driver, J. (1998). Phasic alerting of neglect patients overcomes their spatial deficit in visual awareness. Nature, 395, 169-172. doi:10.1038/25993

Robertson, I. H., \& O'Connell, R. G. (2010). Vigilant attention. In A. C. Nobre \& J. T. Coull (Eds.), Attention and time (pp. 79-88). Oxford, England: Oxford University Press. doi:10.1093/acprof:oso/ 9780199563456.003.0006

Robertson, I. H., Ridgeway, V., Greenfield, E., \& Parr, A. (1997). Motor recovery after stroke depends on intact sustained attention: A 2-year follow-up study. Neuropsychology, 11, 290-295. doi:10.1037/08944105.11.2.290
Robertson, I. H., Tegnér, R., Tham, K., Lo, A., \& Nimmo-Smith, I. (1995) Sustained attention training for unilateral neglect: Theoretical and rehabilitation implications. Journal of Clinical and Experimental Neuropsychology, 17, 416-430. doi:10.1080/01688639508405133

Robertson, I. H., Ward, T., Ridgeway, V., \& Nimmo-Smith, I. (1996). The structure of normal human attention: The Test of Everyday Attention. Journal of the International Neuropsychological Society, 2, 525-534. doi:10.1017/S1355617700001697

Robinson, E. S., \& Bills, A. G. (1926). Two factors in the work decrement. Journal of Experimental Psychology, 9, 415-443. doi:10.1037/ h0072598

Rosenthal, R. (1979). The "file drawer problem" and tolerance for null results. Psychological Bulletin, 86, 638-641. doi:10.1037/0033-2909.86 .3 .638

Rosvold, H. E., Mirsky, A. F., Sarason, I., Bransome, E. D., Jr., \& Beck, L. H. (1956). A continuous performance test of brain damage. Journal of Consulting Psychology, 20, 343-350. doi:10.1037/h0043220

Rottschy, C., Eickhoff, S. B., Schleicher, A., Mohlberg, H., Kujovic, M., Zilles, K., \& Amunts, K. (2007). Ventral visual cortex in humans: Cytoarchitectonic mapping of two extrastriate areas. Human Brain Mapping, 28, 1045-1059. doi:10.1002/hbm.20348

Rottschy, C., Langner, R., Dogan, I., Reetz, K., Laird, A. R., Schulz, J. B., . . E Eickhoff, S. B. (2012). Modelling neural correlates of working memory: A coordinate-based meta-analysis. Neurolmage, 60, 830-846. doi:10.1016/j.neuroimage.2011.11.050

Rueckert, L., Baboorian, D., Stavropoulos, K., \& Yasutake, C. (1999) Individual differences in callosal efficiency: Correlation with attention Brain and Cognition, 41, 390-410. doi:10.1006/brcg.1999.1142

Rueckert, L., \& Grafman, J. (1996). Sustained attention deficits in patients with right frontal lesions. Neuropsychologia, 34, 953-963. doi:10.1016/ 0028-3932(96)00016-4

Rueckert, L., \& Grafman, J. (1998). Sustained attention deficits in patients with lesions of posterior cortex. Neuropsychologia, 36, 653-660. doi 10.1016/S0028-3932(97)00150-4

Rueckert, L., Sorensen, L., \& Levy, J. (1994). Callosal efficiency is related to sustained attention. Neuropsychologia, 32, 159-173. doi:10.1016/ 0028-3932(94)90003-5

Rueda, M. R., Posner, M. I., \& Rothbart, M. K. (2011). Attentional control and self-regulation. In K. D. Vohs \& R. F. Baumeister (Eds.), Handbook of self-regulation: Research, theory, and applications (2nd ed., pp. 284-299). New York, NY: Guilford Press.

Ruge, H., \& Wolfensteller, U. (2010). Rapid formation of pragmatic rule representations in the human brain during instruction-based learning. Cerebral Cortex, 20, 1656-1667. doi:10.1093/cercor/bhp228

*Salgado-Pineda, P., Junqué, C., Vendrell, P., Baeza, I., Bargalló, N., Falcón, C., \& Bernardo, M. (2004). Decreased cerebral activation during CPT performance: Structural and functional deficits in schizophrenic patients. NeuroImage, 21, 840-847. doi:10.1016/j.neuroimage.2003.10 .027

Sarter, M., Gehring, W. J., \& Kozak, R. (2006). More attention must be paid: The neurobiology of attentional effort. Brain Research Reviews, 51, 145-160. doi:10.1016/j.brainresrev.2005.11.002

Sarter, M., Givens, B., \& Bruno, J. P. (2001). The cognitive neuroscience of sustained attention: Where top-down meets bottom-up. Brain Research Reviews, 35, 146-160. doi:10.1016/S0165-0173(01)00044-3

Sarter, M., Hasselmo, M. E., Bruno, J. P., \& Givens, B. (2005). Unraveling the attentional functions of cortical cholinergic inputs: Interactions between signal-driven and cognitive modulation of signal detection. Brain Research Reviews, 48, 98-111. doi:10.1016/j.brainresrev.2004.08.006

Scerbo, M. W. (1998). What's so boring about vigilance? In R. B. Hoffman, M. F. Sherrick, \& J. S. Warm (Eds.), Viewing psychology as a whole: The integrative science of William N Dember. (pp. 145-166). Washington, DC: American Psychological Association. doi:10.1037/ 10290-006 
Scerbo, M. W., Warm, J. S., \& Fisk, A. D. (1986-1987). Event asynchrony and signal regularity in sustained attention. Current Psychological Research \& Reviews, 5, 335-343. doi:10.1007/BF02686601

Scheperjans, F., Hermann, K., Eickhoff, S. B., Amunts, K., Schleicher, A., $\&$ Zilles, K. (2008). Observer-independent cytoarchitectonic mapping of the human superior parietal cortex. Cerebral Cortex, 18, 846-867. doi: $10.1093 /$ cercor/bhm116

*Schlagenhauf, F., Wustenberg, T., Schmack, K., Dinges, M., Wrase, J., Koslowski, M., .. . Heinz, A. (2008). Switching schizophrenia patients from typical neuroleptics to olanzapine: Effects on BOLD response during attention and working memory. European Neuropsychopharmacology, 18, 589-599. doi:10.1016/j.euroneuro.2008.04.013

*Schmidt, C., Collette, F., Leclercq, Y., Sterpenich, V., Vandewalle, G., Berthomier, P., . . Peigneux, P. (2009). Homeostatic sleep pressure and responses to sustained attention in the suprachiasmatic area. Science, 324, 516-519. doi:10.1126/science.1167337

*Schneider, F., Habel, U., Reske, M., Kellermann, T., Stocker, T., Shah, N. J., . . Gaebel, W. (2007). Neural correlates of working memory dysfunction in first-episode schizophrenia patients: An fMRI multicenter study. Schizophrenia Research, 89, 198-210. doi:10.1016/j .schres.2006.07.021

*Schnell, K., Heekeren, K., Schnitker, R., Daumann, J., Weber, J., Hesselmann, V., . . . Gouzoulis-Mayfrank, E. (2007). An fMRI approach to particularize the frontoparietal network for visuomotor action monitoring: Detection of incongruence between test subjects' actions and resulting perceptions. NeuroImage, 34, 332-341. doi:10.1016/j .neuroimage.2006.08.027

See, J. E., Howe, S. R., Warm, J. S., \& Dember, W. N. (1995). Metaanalysis of the sensitivity decrement in vigilance. Psychological Bulletin, 117, 230-249. doi:10.1037/0033-2909.117.2.230

Serences, J. T., Shomstein, S., Leber, A. B., Golay, X., Egeth, H. E., \& Yantis, S. (2005). Coordination of voluntary and stimulus-driven attentional control in human cortex. Psychological Science, 16, 114-122. doi:10.1111/j.0956-7976.2005.00791.x

Shackman, A. J., Salomons, T. V., Slagter, H. A., Fox, A. S., Winter, J. J., \& Davidson, R. J. (2011). The integration of negative affect, pain and cognitive control in the cingulate cortex. Nature Reviews Neuroscience, 12, 154-167. doi:10.1038/nrn2994

Shallice, T., \& Burgess, P. (1996). The domain of supervisory processes and temporal organization of behaviour. Philosophical Transactions of the Royal Society of London Series B: Biological Sciences, 351, 14051411. doi:10.1098/rstb.1996.0124

Shallice, T., Stuss, D. T., Alexander, M. P., Picton, T. W., \& Derkzen, D. (2008). The multiple dimensions of sustained attention. Cortex, 44, 794-805. doi:10.1016/j.cortex.2007.04.002

Shaw, T. H., Finomore, V., Warm, J., \& Matthews, G. (2012). Effects of regular or irregular event schedules on cerebral hemovelocity during a sustained attention task. Journal of Clinical and Experimental Neuropsychology, 34, 57-66. doi:10.1080/13803395.2011.621890

Shaw, T. H., Warm, J. S., Finomore, V., Tripp, L., Matthews, G., Weiler, E., \& Parasuraman, R. (2009). Effects of sensory modality on cerebral blood flow velocity during vigilance. Neuroscience Letters, 461, 207211. doi:10.1016/j.neulet.2009.06.008

Shulman, G. L., Astafiev, S. V., McAvoy, M. P., d'Avossa, G., \& Corbetta, M. (2007). Right TPJ deactivation during visual search: Functional significance and support for a filter hypothesis. Cerebral Cortex, 17, 2625-2633. doi:10.1093/cercor/bhl170

Shulman, G. L., McAvoy, M. P., Cowan, M. C., Astafiev, S. V., Tansy, A. P., d'Avossa, G., \& Corbetta, M. (2003). Quantitative analysis of attention and detection signals during visual search. Journal of Neurophysiology, 90, 3384-3397. doi:10.1152/jn.00343.2003

Smallwood, J., Beach, E., Schooler, J. W., \& Handy, T. C. (2008). Going AWOL in the brain: Mind wandering reduces cortical analysis of exter- nal events. Journal of Cognitive Neuroscience, 20, 458-469. doi: 10.1162/jocn.2008.20037

Smallwood, J., Davies, J. B., Heim, D., Finnigan, F., Sudberry, M., O'Connor, R., \& Obonsawin, M. (2004). Subjective experience and the attentional lapse: Task engagement and disengagement during sustained attention. Consciousness and Cognition, 13, 657-690. doi:10.1016/j .concog.2004.06.003

Smallwood, J., O'Connor, R. C., Sudbery, M. V., \& Obonsawin, M. (2007). Mind-wandering and dysphoria. Cognition and Emotion, 21, 816-842. doi:10.1080/02699930600911531

Smallwood, J., Riby, L., Heim, D., \& Davies, J. B. (2006). Encoding during the attentional lapse: Accuracy of encoding during the semantic sustained attention to response task. Consciousness and Cognition, 15, 218-231. doi:10.1016/j.concog.2005.03.003

Smallwood, J., \& Schooler, J. W. (2006). The restless mind. Psychological Bulletin, 132, 946-958. doi:10.1037/0033-2909.132.6.946

Smit, A. S., Eling, P. A. T. M., \& Coenen, A. M. L. (2004). Mental effort causes vigilance decrease due to resource depletion. Acta Psychologica, 115, 35-42. doi:10.1016/j.actpsy.2003.11.001

Smith, A., \& Nutt, D. (1996). Noradrenaline and attention lapses. Nature, 380, 291. doi: $10.1038 / 380291 \mathrm{a} 0$

Smith, S. M., Fox, P. T., Miller, K. L., Glahn, D. C., Fox, P. M., Mackay, C. E., . . B Beckmann, C. F. (2009). Correspondence of the brain's functional architecture during activation and rest. Proceedings of the National Academy of Sciences of the United States of America, 106, 13040-13045. doi:10.1073/pnas.0905267106

*Smits, M., Dippel, D. W., Houston, G. C., Wielopolski, P. A., Koudstaal, P. J., Hunink, M. G., \& van der Lugt, A. (2009). Postconcussion syndrome after minor head injury: Brain activation of working memory and attention. Human Brain Mapping, 30, 2789-2803. doi:10.1002/hbm .20709

Sonuga-Barke, E. J., \& Castellanos, F. X. (2007). Spontaneous attentional fluctuations in impaired states and pathological conditions: A neurobiological hypothesis. Neuroscience and Biobehavioral Reviews, 31, $977-$ 986. doi:10.1016/j.neubiorev.2007.02.005

Spitzer, H., Desimone, R., \& Moran, J. (1988). Increased attention enhances both behavioral and neuronal performance. Science, 240, 338 340. doi:10.1126/science. 3353728

Sridharan, D., Levitin, D. J., \& Menon, V. (2008). A critical role for the right fronto-insular cortex in switching between central-executive and default-mode networks. Proceedings of the National Academy of Sciences of the United States of America, 105, 12569-12574. doi:10.1073/ pnas.0800005105

Stawarczyk, D., Majerus, S., Maquet, P., \& D'Argembeau, A. (2011). Neural correlates of ongoing conscious experience: Both taskunrelatedness and stimulus-independence are related to default network activity. PLOS ONE, 6, e16997. doi:10.1371/journal.pone.0016997

Steinborn, M. B., Flehmig, H. C., Westhoff, K., \& Langner, R. (2009). Differential effects of prolonged work on performance measures in self-paced speed tests. Advances in Cognitive Psychology, 5, 105-113. doi:10.2478/v10053-008-0070-8

Steinborn, M. B., \& Langner, R. (2011). Distraction by irrelevant sound during foreperiods selectively impairs temporal preparation. Acta Psychologica, 136, 405-418. doi:10.1016/j.actpsy.2011.01.008

Steinborn, M. B., \& Langner, R. (2012). Arousal modulates temporal preparation under increased time uncertainty: Evidence from higherorder sequential foreperiod effects. Acta Psychologica, 139, 65-76. doi:10.1016/j.actpsy.2011.10.010

Steriade, M., Datta, S., Pare, D., Oakson, G., \& Curro Dossi, R. C. (1990). Neuronal activities in brain-stem cholinergic nuclei related to tonic activation processes in thalamocortical systems. Journal of Neuroscience, 10, 2541-2559.

*Sturm, W., de Simone, A., Krause, B. J., Specht, K., Hesselmann, V., Radermacher, I., . . Willmes, K. (1999). Functional anatomy of intrinsic 
alertness: Evidence for a fronto-parietal-thalamic-brainstem network in the right hemisphere. Neuropsychologia, 37, 797-805. doi:10.1016/ S0028-3932(98)00141-9

*Sturm, W., Longoni, F., Fimm, B., Dietrich, T., Weis, S., Kemna, S., . . Willmes, K. (2004). Network for auditory intrinsic alertness: A PET study. Neuropsychologia, 42, 563-568. doi:10.1016/j.neuropsychologia .2003.11.004

*Sturm, W., Schmenk, B., Fimm, B., Specht, K., Weis, S., Thron, A., \& Willmes, K. (2006). Spatial attention: More than intrinsic alerting? Experimental Brain Research, 171, 16-25. doi:10.1007/s00221-0050253-1

Sturm, W., \& Willmes, K. (2001). On the functional neuroanatomy of intrinsic and phasic alertness. Neurolmage, 14, S76-S84. doi:10.1006/ nimg.2001.0839

Stuss, D. T., Alexander, M. P., Shallice, T., Picton, T. W., Binns, M. A., Macdonald, R., . . Katz, D. I. (2005). Multiple frontal systems controlling response speed. Neuropsychologia, 43, 396-417. doi:10.1016/ j.neuropsychologia.2004.06.010

Stuss, D. T., Binns, M. A., Murphy, K. J., \& Alexander, M. P. (2002). Dissociations within the anterior attentional system: Effects of task complexity and irrelevant information on reaction time speed and accuracy. Neuropsychology, 16, 500-513. doi:10.1037/0894-4105.16.4.500

Stuss, D. T., Shallice, T., Alexander, M. P., \& Picton, T. W. (1995). A multidisciplinary approach to anterior attentional functions. Annals of the New York Academy of Sciences, 769, 191-211. doi:10.1111/j.17496632.1995.tb38140.x

Szalma, J. L., Warm, J. S., Matthews, G., Dember, W. N., Weiler, E. M., Meier, A., \& Eggemeier, F. T. (2004). Effects of sensory modality and task duration on performance, workload, and stress in sustained attention. Human Factors, 46, 219-233. doi:10.1518/hfes.46.2.219.37334

*Tana, M. G., Montin, E., Cerutti, S., \& Bianchi, A. M. (2010). Exploring cortical attentional system by using fMRI during a Continuous Perfomance Test. Computational Intelligence and Neuroscience, 10, 329213. doi: $10.1155 / 2010 / 329213$

Taylor, K. S., Seminowicz, D. A., \& Davis, K. D. (2009). Two systems of resting state connectivity between the insula and cingulate cortex. Human Brain Mapping, 30, 2731-2745. doi:10.1002/hbm.20705

Temple, J. G., Warm, J. S., Dember, W. N., Jones, K. T. S., LaGrange, C. M., \& Matthews, G. (2000). The effects of signal salience and caffeine on performance, workload, and stress in an abbreviated vigilance task. Human Factors, 42, 183-194. doi:10.1518/ 001872000779656480

Thackray, R. I. (1981). The stress of boredom and monotony: A consideration of the evidence. Psychosomatic Medicine, 43, 165-176.

*Thakral, P. P., \& Slotnick, S. D. (2009). The role of parietal cortex during sustained visual spatial attention. Brain Research, 1302, 157-166. doi: 10.1016/j.brainres.2009.09.031

Thayer, R. E. (1978). Toward a psychological theory of multidimensional activation (arousal). Motivation and Emotion, 2, 1-34. doi:10.1007/ BF00992729

Thomas, M. L., Sing, H. C., Belenky, G., Holcomb, H. H., Mayberg, H. S., Dannals, R. F., . . . Redmond, D. P. (2003). Neural basis of alertness and cognitive performance impairments during sleepiness: II. Effects of 48 and $72 \mathrm{~h}$ of sleep deprivation on waking human regional brain activity. Thalamus \& Related Systems, 2, 199-229. doi:10.1017/S1472928803000207

Thomas, M., Sing, H., Belenky, G., Holcomb, H., Mayberg, H., Dannals, R., . . . Redmond, D. (2000). Neural basis of alertness and cognitive performance impairments during sleepiness. I. Effects of 24 $\mathrm{h}$ of sleep deprivation on waking human regional brain activity. Journal of Sleep Research, 9, 335-352. doi:10.1046/j.1365-2869.2000 .00225.x

Todd, J. J., Fougnie, D., \& Marois, R. (2005). Visual short-term memory load suppresses temporo-parietal junction activity and induces inatten- tional blindness. Psychological Science, 16, 965-972. doi:10.1111/j 1467-9280.2005.01645.x

Trillenberg, P., Verleger, R., Teetzmann, A., Wascher, E., \& Wessel, K. (2004). On the role of the cerebellum in exploiting temporal contingencies: Evidence from response times and preparatory EEG potentials in patients with cerebellar atrophy. Neuropsychologia, 42, 754763. doi:10.1016/j.neuropsychologia.2003.11.005

Turkeltaub, P. E., Eden, G. F., Jones, K. M., \& Zeffiro, T. A. (2002). Meta-analysis of the functional neuroanatomy of single-word reading: Method and validation. NeuroImage, 16, 765-780. doi:10.1006/nimg .2002 .1131

Turkeltaub, P. E., Eickhoff, S. B., Laird, A. R., Fox, M., Wiener, M., \& Fox, P. T. (2012). Minimizing within-experiment and within-group effects in activation likelihood estimation meta-analyses. Human Brain Mapping, 33, 1-13. doi:10.1002/hbm.21186

Ulich, E. (1960). Unterforderung als arbeitspsychologisches Problem. [Underload as a problem of work psychology]. Psychologie und Praxis, 4 $156-161$.

Vallesi, A., \& Shallice, T. (2007). Developmental dissociations of preparation over time: Deconstructing the variable foreperiod phenomena Journal of Experimental Psychology: Human Perception and Performance, 33, 1377-1388. doi:10.1037/0096-1523.33.6.1377

Vallesi, A., Shallice, T., \& Walsh, V. (2007). Role of the prefrontal cortex in the foreperiod effect: TMS evidence for dual mechanisms in tempora preparation. Cerebral Cortex, 17, 466-474. doi:10.1093/cercor/bhj163 van Breukelen, G. J., Roskam, E. E., Eling, P. A., Jansen, R. W., Souren, D. A., \& Ickenroth, J. G. (1995). A model and diagnostic measures for response time series on tests of concentration: Historical background, conceptual framework, and some applications. Brain and Cognition, 27, 147-179. doi:10.1006/brcg.1995.1015

Vandenberghe, R., Gitelman, D. R., Parrish, T. B., \& Mesulam, M. M (2001). Functional specificity of superior parietal mediation of spatial shifting. NeuroImage, 14, 661-673. doi:10.1006/nimg.2001.0860

van Zomeren, A. H., \& Brouwer, W. H. (1994). Clinical neurospychology of attention. New York, NY: Oxford Press.

Verbruggen, F., Aron, A. R., Stevens, M. A., \& Chambers, C. D. (2010). Theta burst stimulation dissociates attention and action updating in human inferior frontal cortex. Proceedings of the National Academy of Sciences of the United States of America, 107, 1396613971. doi:10.1073/pnas.1001957107

Vogt, B. A. (2005). Pain and emotion interactions in subregions of the cingulate gyrus. Nature Reviews Neuroscience, 6, 533-544. doi $10.1038 / \mathrm{nrn} 1704$

Warm, J. S., Matthews, G., \& Parasuraman, R. (2009). Cerebral hemodynamics and vigilance performance. Military Psychology, 21, S75-S100 doi:10.1080/08995600802554706

Warm, J. S., Parasuraman, R., \& Matthews, G. (2008). Vigilance requires hard mental work and is stressful. Human Factors, 50, 433-441. doi: $10.1518 / 001872008 X 312152$

Warm, J. S., Richter, D. O., Sprague, R. L., Porter, P. K., \& Schumsky, D. A. (1980). Listening with a dual brain: Hemispheric asymmetry in sustained attention. Bulletin of the Psychonomic Society, 15, 229-232.

Weissman, D. H., Gopalakrishnan, A., Hazlett, C. J., \& Woldorff, M. G. (2005). Dorsal anterior cingulate cortex resolves conflict from distracting stimuli by boosting attention toward relevant events. Cerebral Cortex, 15, 229-237. doi:10.1093/cercor/bhh125

Weissman, D. H., Roberts, K. C., Visscher, K. M., \& Woldorff, M. G. (2006). The neural bases of momentary lapses in attention. Nature Neuroscience, 9, 971-978. doi:10.1038/nn1727

*Welander-Vatn, A. S., Jensen, J., Lycke, C., Agartz, I., Server, A., Gadmar, O. B., . . . Andreassen, O. A. (2009). No altered dorsal anterior cingulate activation in bipolar II disorder patients during a Go/No-go task: An fMRI study. Bipolar Disorders, 11, 270-279. doi:10.1111/j 1399-5618.2009.00680.x 
Wesnes, K., \& Warburton, D. M. (1983). Effects of smoking on rapid information processing performance. Neuropsychobiology, 9, 223-229. doi:10.1159/000117969

Whitehead, R. (1991). Right hemisphere processing superiority during sustained visual attention. Journal of Cognitive Neuroscience, 3, 329334. doi:10.1162/jocn.1991.3.4.329

Wickens, C. D., Gordon, S. E., \& Liu, Y. (1998). An introduction to human factors engineering. New York, NY: Addison Wesley Longman.

Wilkins, A. J., Shallice, T., \& McCarthy, R. (1987). Frontal lesions and sustained attention. Neuropsychologia, 25, 359-365. doi:10.1016/00283932(87)90024-8

Wilkinson, R. T. (1964). Effects of up to 60 hours' sleep deprivation on different types of work. Ergonomics, 7, 175-186. doi:10.1080/ 00140136408930736
*Wingen, M., Kuypers, K. P., van de Ven, V., Formisano, E., \& Ramaekers, J. G. (2008). Sustained attention and serotonin: A pharmaco-fMRI study. Human Psychopharmacology, 23, 221-230. doi:10.1002/hup.923

Wood, G., Nuerk, H. C., Sturm, D., \& Willmes, K. (2008). Using parametric regressors to disentangle properties of multi-feature processes. Behavioral and Brain Functions, 4, 38. doi:10.1186/1744-9081-4-38

Wu, J. C., Gillin, J. C., Buchsbaum, M. S., Hershey, T., Hazlett, E., Sicotte, N., \& Bunney, W. E., Jr. (1991). The effect of sleep deprivation on cerebral glucose metabolic rate in normal humans assessed with positron emission tomography. Sleep, 14, 155-162.

*Zatorre, R. J., Mondor, T. A., \& Evans, A. C. (1999). Auditory attention to space and frequency activates similar cerebral systems. NeuroImage, 10, 544-554. doi:10.1006/nimg.1999.0491

(Appendix follows) 
Appendix

Description of All Contrasts Included in the Meta-Analysis

\begin{tabular}{|c|c|c|c|c|c|c|c|c|c|}
\hline Study & $n$ & Contrast & Task & Modality & Motor response & Time (s) & Event rate & WM & $\mathrm{TP}$ \\
\hline Adler et al. (2001) & 9 & task $>$ sensory control & Discrim & Visual & Yes & 30 & High & Yes & Yes \\
\hline Adler et al. (2001) & 9 & task $>$ sensory control & Discrim & Visual & Yes & 30 & High & No & Yes \\
\hline *Ayalon et al. $(2009)^{\mathrm{a}}$ & 14 & task $>$ rest & Discrim & Visual & Yes & 21 & High & No & Yes \\
\hline Belin et al. (1998) & 7 & task $>$ sensory control & Discrim & Auditory & No & 120 & High & No & Yes \\
\hline Belin et al. (2002) & 7 & task $>$ sensory control & Discrim & Auditory & No & 120 & High & No & Yes \\
\hline Benedict et al. (1998) & 7 & task $>$ rest & Discrim & Auditory & Yes & 60 & High & No & Yes \\
\hline Benedict et al. (2002) & 12 & task $>$ sensory control & Discrim & Auditory & No & 60 & High & No & Yes \\
\hline *Cabeza et al. (2003) & 20 & task $>$ rest & Detect & Visual & No & 15 & Low & No & No \\
\hline Coull \& Frith (1998) & 6 & task $>$ rest & Discrim & Visual & Yes & 90 & High & No & Yes \\
\hline Coull \& Frith (1998) & 4 & task $>$ rest & Discrim & Visual & Yes & 90 & High & No & Yes \\
\hline Coull et al. (1997) & 13 & task $>$ rest & Discrim & Visual & Yes & 90 & High & Yes & Yes \\
\hline Coull et al. (1996) & 8 & task $>$ rest & Discrim & Visual & Yes & 150 & High & Yes & Yes \\
\hline Eyler et al. (2004) & 10 & task $>$ rest & Discrim & Visual & Yes & 21 & High & No & Yes \\
\hline Fassbender et al. (2004) & 21 & task $>$ rest & Discrim & Visual & Yes & 90 & High & No & Yes \\
\hline Gamma et al. (2001) & 11 & task $>$ sensory control & Discrim & Visual & Yes & 60 & High & Yes & Yes \\
\hline *Gilbert et al. (2006) & 14 & task $>$ motor control & Detect & Visual & Yes & 24 & High & No & No \\
\hline Gitelman et al. (1996) & 8 & task $>$ sensorimotor control & Detect & Auditory & Yes & 60 & Low & No & No \\
\hline Goldstein et al. (2007) & 12 & task $>$ rest & Discrim & Visual & Yes & 63 & High & No & Yes \\
\hline *Habel et al. $(2007)^{\mathrm{b}}$ & 47 & task $>$ rest & Discrim & Visual & Yes & 30 & High & No & Yes \\
\hline Herath et al. (2001) & 10 & task $>$ sensory control & Detect & Tactile & Yes & 30 & High & No & No \\
\hline Herath et al. (2001) & 10 & task $>$ sensory control & Detect & Visual & Yes & 30 & High & No & No \\
\hline Holcomb et al. (1998) & 12 & task $>$ rest & Detect & Auditory & Yes & 60 & High & No & Yes \\
\hline *Honey et al. (2005) & 12 & task $>$ sensory control & Discrim & Visual & Yes & 30 & High & No & Yes \\
\hline *Hong et al. (2011) & 24 & task $>$ sensory control & Discrim & Visual & Yes & 90 & High & Yes & Yes \\
\hline *Hong et al. (2011) & 24 & task $>$ rest & Discrim & Visual & Yes & 90 & High & No & Yes \\
\hline Horn et al. (2003) & 12 & task $>$ sensory control & Discrim & Auditory & No & 32 & High & No & Yes \\
\hline Johannsen et al. (1997) & 16 & task $>$ sensory control & Discrim & Visual & No & 40 & High & No & No \\
\hline Johannsen et al. (1997) & 16 & task $>$ sensory control & Discrim & Tactile & No & 40 & High & No & No \\
\hline Kansaku et al. (2004) & 10 & task $>$ rest & Detect & Mixed & No & 27 & High & No & No \\
\hline Kansaku et al. (2004) & 10 & task $>$ rest & Detect & Mixed & Yes & 27 & High & No & No \\
\hline Kawashima et al. (1996) & 9 & task $>$ sensory control & Discrim & Visual & Yes & 60 & High & No & No \\
\hline Kim et al. (2006) & 12 & task $>$ rest & Discrim & Visual & Yes & 360 & Low & No & No \\
\hline *Krug et al. (2008) & 85 & task $>$ sensory control & Discrim & Visual & Yes & 30 & High & No & Yes \\
\hline Langner et al. (2012) & 20 & task $>$ sensorimotor control & Detect & Mixed & Yes & 20 & High & No & No \\
\hline Langner et al. (2012) & 20 & task $>$ sensorimotor control & Detect & Mixed $^{\mathrm{c}}$ & Yes & 20 & High & No & No \\
\hline *Lawrence et al. (2003) & 25 & task $>$ rest & Discrim & Visual & Yes & 90 & High & No & Yes \\
\hline Lawrence et al. (2003) & 25 & task $>$ sensorimotor control & Discrim & Visual & Yes & 90 & High & Yes & Yes \\
\hline${ }^{*}$ Lawrence et al. $(2002)^{\mathrm{d}}$ & 15 & task $>$ rest & Discrim & Visual & Yes & 90 & High & No & Yes \\
\hline *Lawrence et al. $(2002)^{\mathrm{d}}$ & 15 & task $>$ sensorimotor control & Discrim & Visual & Yes & 90 & High & Yes & Yes \\
\hline Lim et al. (2010) & 14 & task $>$ rest & Detect & Visual & Yes & 1200 & Low & No & No \\
\hline Lockwood et al. (2008) & 12 & task $>$ rest & Discrim & Auditory & Yes & 60 & High & No & No \\
\hline Marklund et al. (2007) & 13 & task $>$ rest & Detect & Visual & Yes & 90 & Low & No & No \\
\hline Naito et al. (2000) & 9 & task $>$ rest & Detect & Mixed & Yes & 200 & High & No & No \\
\hline Ogg et al. (2008) & 30 & task $>$ rest & Discrim & Visual & Yes & 21 & High & No & Yes \\
\hline *Okamura et al. (2000) & 12 & task $>$ rest & Discrim & Visual & Yes & 135 & High & No & Yes \\
\hline Ortuño et al. (2002) & 10 & task $>$ sensory control & Detect & Auditory & No & 60 & High & Yes & Yes \\
\hline Pardo et al. (1991) & 10 & task $>$ rest & Detect & Tactile & No & 40 & Low & No & No \\
\hline Pardo et al. (1991) & 9 & task $>$ rest & Detect & Tactile & No & 40 & Low & No & No \\
\hline Pardo et al. (1991) & 19 & task $>$ rest & Detect & Visual & No & 40 & Low & No & No \\
\hline Paus et al. (1997) & 8 & task $>$ sensory control & Discrim & Auditory & Yes & 60 & High & No & Yes \\
\hline Périn et al. (2010) & 16 & task $>$ sensorimotor control & Detect & Visual & Yes & 60 & High & No & No \\
\hline Pfefferbaum et al. (2001) & 10 & task $>$ rest & Discrim & Visual & Yes & 36 & High & No & Yes \\
\hline *Salgado-Pineda et al. (2004) & 14 & task $>$ sensorimotor control & Discrim & Visual & Yes & 220 & High & Yes & Yes \\
\hline *Schlagenhauf et al. (2008) & 10 & task $>$ rest & Discrim & Visual & Yes & 31 & High & No & Yes \\
\hline Schmidt et al. (2009) ${ }^{\mathrm{e}}$ & 31 & task $>$ rest & Detect & Visual & Yes & 690 & Low & No & No \\
\hline *Schneider et al. (2007) & 81 & task $>$ sensory control & Discrim & Visual & Yes & 30 & High & No & Yes \\
\hline
\end{tabular}


Appendix (continued)

\begin{tabular}{|c|c|c|c|c|c|c|c|c|c|}
\hline Study & $n$ & Contrast & Task & Modality & Motor response & Time (s) & Event rate & WM & $\mathrm{TP}$ \\
\hline Schnell et al. (2007) & 15 & task $>$ sensorimotor control & Detect & Visual & Yes & 30 & Low & No & No \\
\hline *Smits et al. (2009) & 11 & task $>$ rest & Discrim & Auditory & Yes & 30 & High & No & Yes \\
\hline Sturm et al. (1999) & 15 & task $>$ sensorimotor control & Detect & Visual & Yes & 40 & High & No & No \\
\hline Sturm et al. (2004) & 10 & task $>$ sensorimotor control & Detect & Auditory & Yes & 40 & High & No & No \\
\hline Sturm et al. (2006) & 10 & task $>$ rest & Detect & Visual & Yes & 60 & High & No & No \\
\hline Tana et al. (2010) & 8 & task $>$ sensory control & Discrim & Visual & Yes & 120 & High & No & No \\
\hline Thakral \& Slotnick (2009) & 8 & task $>$ sensory control & Detect & Visual & Yes & 14 & Low & No & No \\
\hline Vandenberghe et al. (2001) & 6 & task $>$ rest & Detect & Visual & Yes & 27 & Low & No & No \\
\hline Welander-Vatn et al. (2009) & 28 & task $>$ rest & Discrim & Visual & Yes & 20 & High & No & \\
\hline Wingen et al. (2008) & 10 & task $>$ rest & Discrim & Visual & Yes & 1800 & High & No & \\
\hline Zatorre et al. (1999) & 8 & task $>$ rest & Discrim & Auditory & Yes & 60 & High & No & No \\
\hline
\end{tabular}

Note. An asterisk indicates that the data included here had not been explicitly reported in the publication but were provided by the authors upon request. $n=$ number of participants; modality = sensory modality of response signals ("mixed" refers to activity averaged across different modalities); time = duration of continuous maintenance of vigilant attention (with concurrent measurement of brain activity); WM = working memory: Task put (modest) demands on WM; TP = temporal predictability: Fixed timing of task events enabled prediction of the moment of stimulus occurrence; discrim $=$ stimulus discrimination task; detect $=$ stimulus detection task

${ }^{a}$ Task data reflect activity averaged across all trials (go and no-go trials) in healthy controls only. ${ }^{\mathrm{b}}$ Data are based on a joint reanalysis of the data used by Habel et al. (2007) and Koch et al. (2007), which both employed the same paradigm in two partially overlapping samples; the reanalysis joined the data from the nonoverlapping subgroups of each sample. ${ }^{\mathrm{c}}$ Data are based on a condition in which stimulus modality (visual, auditory, or tactile) randomly varied between trials (as opposed to a between-block variation that all other "mixed modality" contrasts are based on). "Data are only based on the smoke subsample (under placebo conditions); all nonsmoking controls were part of the sample used in Lawrence et al. (2003). ${ }^{\mathrm{e}}$ Data reflect global alertness effect (based on trials with intermediate reaction time during the evening session) across the entire sample.

Received January 29, 2012

Revision received July 13, 2012

Accepted September 17, 2012

\section{Correction to Taylor, Rastle, and Davis (2012)}

In the article "Can Cognitive Models Explain Brain Activation During Word and Pseudoword Reading? A Meta-Analysis of 36 Neuroimaging Studies" by J. S. H. Taylor, Kathleen Rastle, and Matthew H. Davis (Psychological Bulletin, Advance online publication. October 8, 2012. doi: 10.1037/a0030266), there is an error in Table 1.

Under Statistical threshold (column 6), should read:

" $p<.01$ uncorrected, $p<.05$ cluster corrected" for Binder et al. (2003)

" $p<.001$ uncorrected, $p<.05$ cluster corrected" for Binder et al. (2005)

DOI: $10.1037 / \mathrm{a} 0030891$ 